Review

\title{
Iranian Medicinal Plants: From Ethnomedicine to Actual Studies
}

\author{
Piergiacomo Buso ${ }^{1}$, Stefano Manfredini ${ }^{1}{ }^{\mathbb{D}}$, Hamid Reza Ahmadi-Ashtiani ${ }^{2,3}$, \\ Sabrina Sciabica ${ }^{1}$, Raissa Buzzi ${ }^{1,4}$, Silvia Vertuani ${ }^{1, *}$ and Anna Baldisserotto ${ }^{1}$ (D) \\ 1 Department of Life Sciences and Biotechnology, Master Course in Cosmetic Sciences, University of Ferrara, \\ Via Luigi Borsari 43, 44121 Ferrara, Italy; piergiacomo.buso@student.unife.it (P.B.); smanfred@unife.it (S.M.); \\ sabrina.sciabica@student.unife.it (S.S.); raissa.buzzi@unife.it (R.B.); anna.baldisserotto@unife.it (A.B.) \\ 2 Department of Basic Sciences, Faculty of Pharmacy, Tehran Medical Sciences, Islamic Azad University, \\ Tehran 194193311, Iran; ahmadi@iaups.ac.ir \\ 3 Cosmetic, Hygienic and Detergent Sciences and Technology Research Center, Tehran Medical Sciences, \\ Islamic Azad University, Tehran 194193311, Iran \\ 4 Ambrosialab S.r.l. University of Ferrara Spinof Company, Via Mortara 171, 44121 Ferrara, Italy \\ * Correspondence: silvia.vertuani@unife.it
}

Received: 9 January 2020; Accepted: 21 February 2020; Published: 26 February 2020

\begin{abstract}
Iran has a rich and diverse cultural heritage, consisting of a complex traditional medicine deeply rooted in the history of the territory that goes back to the Assyrian and Babylonian civilizations. The ethnomedical practices that can be identifiable nowadays derive from the experience of local people who have developed remedies against a wide range of diseases handing down the knowledge from generation to generation over the millennia. Traditional medicine practices represent an important source of inspiration in the process of the development of new drugs and therapeutic strategies. In this context, it is useful to determine the state of the art of ethnomedical studies, concerning the Iranian territory, and of scientific studies on plants used in traditional Iranian medicine. Data regarding 245 plants used in Iranian ethnomedical practices and scientific studies conducted on 89 plants collected in the Iranian territory have been reported. All of the scientific studies here reported draw inspiration from traditional medicine. The World Health Organization (WHO) has repeatedly called for an intensification of the scientific validation processes of traditional medicines intended as an important contribution to public health in various parts of the world. The process of study and validation of Iranian ethnomedical practices appears to be at an early stage.
\end{abstract}

Keywords: Iranian traditional medicine; biological activities; pharmaceutical; cosmeceutical; nutriceutical

\section{Introduction}

Traditional medicine practices represent an important and often underestimated part of healthcare around the world. Moreover, traditional knowledge is a source of inspiration for researches on biological activities of vegetal extracts and pure compounds that can be obtained from them. A great number of lifesaving therapeutic assets belonging to modern medicine and new active compounds are derived from traditional knowledge and traditional uses of plants.

The awareness of this fact led to the drawing up of the World Health Assembly (WHA) resolution on Traditional Medicine (WHA62.13) and the WHO Traditional Medicine Strategy 2002-2005 and 2014-2023. These documents aim to integrate at the international level national healthcare systems with traditional knowledge and practices through an assessment of safety, efficacy, and quality of the treatments. In order to achieve these objectives, it is necessary to properly carry out scientific researches; the biological activities of the plants used must be tested, and the effectiveness of the treatments both "in vitro" and "in vivo" must be assessed considering the risk/benefit profile. Thus, one of the main 
raised issues-related to the use of traditional practices in national policies and regulations-is the lack of research data [1].

WHO defines traditional medicine as follows: “Traditional medicine has a long history. It is the sum total of the knowledge, skill, and practices based on the theories, beliefs, and experiences indigenous to different cultures, whether explicable or not, used in the maintenance of health as well as in the prevention, diagnosis, improvement or treatment of physical and mental illness" [2].

In light of a literature search, the traditional Iranian medicine (also known as Persian medicine) results, particularly rich in information, which can justify new studies regarding the therapeutic use of plants and vegetal extracts; it consists of the totality of the knowledge passed down through the generations and of the practices based entirely on observations and practical experience used, from ancient times to nowadays, in diagnosis, prevention, and elimination of diseases in the Iranian territory [3].

In this context, it was of great interest for us to collect scientific reports/studies, deriving from traditional practices, regarding health properties: biological activities of native Iranian plants proper to the medicinal, dermo-cosmetic, and nutriceutical use, in order to provide a complete overview of the scientific knowledge and establish a starting point for further research. Particular attention was paid to works that open up research possibilities on new therapeutic assets that deserve a follow-up to determine the efficacy of the reported biological activities in vivo.

\section{Materials and Methods}

\section{The Present Review Was Performed Adopting The Following Databases: Scifinder, Pubmed, Google Scholar}

Selection criteria were defined, including articles regarding ethnobotanical studies on medicinal plants traditionally used in the Iranian territory and articles reporting scientific studies on plants grown and collected in Iran, including biological activities that can be spent in the pharmaceutical, cosmetic/cosmeceutical, nutraceutical fields. Particular attention was paid to works that may open up research paths to new therapeutic assets. All the studies reported in this review draw inspiration from Iranian traditional medicine practices.

The following keywords were selected: "Iran plants", "Iranian medicinal plants", "Iranian plants biological activities". Only articles in the English language were selected, and data from patents, symposiums, and congress abstracts were excluded because not enough complete to warrant an effective comparison with full papers. Papers that did not show a clear botanical identification were rejected. The database www.theplantlist.org was used to check the correctness of the nomenclature of the reported plant species.

\section{Results and Discussion}

\subsection{Medicinal Plants Traditionally Used in Iran}

Iran has a history of great importance in the field of traditional medicine practices; this knowledge heritage goes back to the time of Babylonian-Assyrian civilization; every generation added his experience and new elements to this "cultural database". Nowadays, medicinal plants are still used in Iran as curatives for various types of health problems [4]. A great part of this traditional knowledge has not been considered by the scientific point of view yet, and it would be advisable to check the effectiveness of the traditional treatments, especially when there are no supporting data in the scientific literature.

A bibliographic search was performed, selecting ethnobotanical studies conducted through questionnaires and personal interviews with traditional healers and local people in the Iranian territory that include clear botanical identification of the plants, traditional uses, and type of administration.

Table 1 collects reports of plants used for medicinal purposes in the Iranian territory, their local name, the part of the plant used, type of extraction/preparation, the territory where the plant use is reported. 
Table 1. Plants traditionally used as medicinal remedies in the Iranian territory. Local name, part of the plant used, type of extraction/preparation, the area where the use of the plant is reported. (N.r. = not reported)

\begin{tabular}{|c|c|c|c|c|c|c|c|c|}
\hline & $\begin{array}{l}\text { Scientific } \\
\text { Name }\end{array}$ & Family & $\begin{array}{l}\text { Local } \\
\text { Name }\end{array}$ & $\begin{array}{l}\text { Part } \\
\text { Used }\end{array}$ & $\begin{array}{l}\text { Type of } \\
\text { Extract }\end{array}$ & $\begin{array}{l}\text { Medicinal } \\
\text { Uses }\end{array}$ & Area & Author (s) \\
\hline 1. & $\begin{array}{l}\text { Abelmoschus } \\
\text { esculentus (L.) } \\
\text { Moench }\end{array}$ & Malvaceae & Bamieh & Seed & n.r. & $\begin{array}{l}\text { Anti-inflammatory, Diuretic, } \\
\text { Laxative }\end{array}$ & $\begin{array}{l}\text { Mashhad city, } \\
\text { Northeastern Iran }\end{array}$ & $\begin{array}{l}\text { [5] Amiri and } \\
\text { Joharchi } 2013\end{array}$ \\
\hline 2. & $\begin{array}{l}\text { Acanthophyllum } \\
\text { sordidum Bunge } \\
\text { ex Boiss. }\end{array}$ & Caryophylaceae & Choobak & Root & n.r. & Warts, Washing & $\begin{array}{l}\text { Mashhad city, } \\
\text { Northeastern Iran }\end{array}$ & $\begin{array}{l}\text { [5] Amiri and } \\
\text { Joharchi } 2013\end{array}$ \\
\hline 3. & $\begin{array}{c}\text { Acanthophyllum } \\
\text { spp. }\end{array}$ & Caryophyllaceae & Chobak & Aerial parts & $\begin{array}{c}\text { Herbal } \\
\text { tea/decoction }\end{array}$ & Antiparasitic & $\begin{array}{l}\text { Shiraz, Fars } \\
\text { province }\end{array}$ & $\begin{array}{l}\text { [6] Bahmani et } \\
\text { al. } 2016\end{array}$ \\
\hline 4. & $\begin{array}{l}\text { Achillea } \\
\text { millefolium } \mathrm{L} . \\
\text { Achillea } \\
\text { millefolium } \mathrm{L} \text {. }\end{array}$ & $\begin{array}{l}\text { Asteraceae } \\
\text { Asteraceae }\end{array}$ & $\begin{array}{c}\text { n.r. } \\
\text { Boomadaran }\end{array}$ & $\begin{array}{l}\text { Inflorescence } \\
\text { Aerial parts }\end{array}$ & $\begin{array}{c}\text { Boiled, steamed } \\
\text { Herbal } \\
\text { tea/decoction }\end{array}$ & $\begin{array}{l}\text { Antidiabetic } \\
\text { Antiparasitic }\end{array}$ & $\begin{array}{l}\text { Urmia county, } \\
\text { Northwest Iran } \\
\text { Shiraz, Fars } \\
\text { province }\end{array}$ & $\begin{array}{l}\text { [7] } \\
\text { Bahmani et al. } \\
2014 \\
\text { [6] Bahmani et } \\
\text { al. } 2016\end{array}$ \\
\hline 5. & $\begin{array}{c}\text { Achillea } \\
\text { santolinoides } \\
\text { subsp. wilhelmsii } \\
\text { (K. Koch) Gruter }\end{array}$ & Asteraceae & Bumadaran & Aerial parts & n.r. & $\begin{array}{c}\text { Anti-hemorrhoids, } \\
\text { Antidiarrhea, Hypoglycemic, } \\
\text { Anthelmintic, Mastitis, } \\
\text { Antacid, Dyspepsia, Nerve } \\
\text { Tonic, Treatment of } \\
\text { Osteoarthritis, Treatment of } \\
\text { Blood Flooding, Appetizer }\end{array}$ & $\begin{array}{l}\text { Mashhad city, } \\
\text { Northeastern Iran }\end{array}$ & $\begin{array}{l}\text { [5] Amiri and } \\
\text { Joharchi } 2013\end{array}$ \\
\hline 6. & $\begin{array}{c}\text { Adiantum } \\
\text { capillus-veneris } \\
\text { L. }\end{array}$ & Pteridaceae & Parsiavashan & Aerial parts & n.r. & $\begin{array}{c}\text { Antitussive, Anti-hemorrhoid, } \\
\text { Treatment of Sore Throat, } \\
\text { Febrifuge, Jaundice, Laxative, } \\
\text { Anti-thirst, Treatment of } \\
\text { Orchitis }\end{array}$ & $\begin{array}{l}\text { Mashhad city, } \\
\text { Northeastern Iran }\end{array}$ & $\begin{array}{l}\text { [5] Amiri and } \\
\text { Joharchi } 2013\end{array}$ \\
\hline 7. & Alcea spp. & Malvaceae & Gole Khatmi & Flower & n.r. & $\begin{array}{c}\text { Antitussive, Febrifuge, } \\
\text { Treatment of Pimples, Laxative, } \\
\text { Depurative, Treatment of Gum } \\
\text { Swelling }\end{array}$ & $\begin{array}{l}\text { Mashhad city, } \\
\text { Northeastern Iran }\end{array}$ & $\begin{array}{l}\text { [5] Amiri and } \\
\text { Joharchi } 2013\end{array}$ \\
\hline 8. & $\begin{array}{l}\text { Alhagi graecorum } \\
\text { Boiss. }\end{array}$ & Fabaceae & Taranjabin & Manna & n.r. & $\begin{array}{l}\text { Jaundice, Laxative, Febrifuge, } \\
\text { Thirst, Aphthous Ulcers }\end{array}$ & $\begin{array}{c}\text { Mashhad city, } \\
\text { Northeastern Iran }\end{array}$ & $\begin{array}{l}\text { [5] Amiri and } \\
\text { Joharchi } 2013\end{array}$ \\
\hline 9. & $\begin{array}{l}\text { Alhagi maurorum } \\
\text { Medik. }\end{array}$ & Fabaceae & $\begin{array}{l}\text { Khar Shotor- } \\
\text { Taranjabin }\end{array}$ & $\begin{array}{l}\text { Aerial parts - } \\
\text { Manna }\end{array}$ & n.r. & $\begin{array}{l}\text { Appetite Suppressant, Diuretic, } \\
\text { Jaundice, Febrifuge }\end{array}$ & $\begin{array}{l}\text { Mashhad city, } \\
\text { Northeastern Iran }\end{array}$ & $\begin{array}{l}\text { [5] Amiri and } \\
\text { Joharchi } 2013\end{array}$ \\
\hline
\end{tabular}


Table 1. Cont

\begin{tabular}{|c|c|c|c|c|c|c|c|c|}
\hline & $\begin{array}{l}\text { Scientific } \\
\text { Name }\end{array}$ & Family & $\begin{array}{l}\text { Local } \\
\text { Name }\end{array}$ & $\begin{array}{l}\text { Part } \\
\text { Used }\end{array}$ & $\begin{array}{l}\text { Type of } \\
\text { Extract }\end{array}$ & $\begin{array}{l}\text { Medicinal } \\
\text { Uses }\end{array}$ & Area & Author (s) \\
\hline 10. & $\begin{array}{c}\text { Allium } \\
\text { altissimum Regel }\end{array}$ & Amaryllidaceae & Musir & Bulb & n.r. & $\begin{array}{l}\text { Antiseptic, Appetizer, } \\
\text { Digestive }\end{array}$ & $\begin{array}{c}\text { Mashhad city, } \\
\text { Northeastern Iran }\end{array}$ & $\begin{array}{l}\text { [5] Amiri and } \\
\text { Joharchi } 2013\end{array}$ \\
\hline 11. & $\begin{array}{c}\text { Allium сера } \\
\text { Allium сера L. }\end{array}$ & $\begin{array}{l}\text { Amaryllidaceae } \\
\text { Amaryllidaceae }\end{array}$ & $\begin{array}{l}\text { Piaz } \\
\text { Piaz }\end{array}$ & $\begin{array}{l}\text { Bulb } \\
\text { Seed }\end{array}$ & $\begin{array}{c}\text { Herbal } \\
\text { tea/decoction } \\
\text { n.r. }\end{array}$ & $\begin{array}{c}\text { Antiparasitic } \\
\text { Treatment of Trichoptlosis }\end{array}$ & $\begin{array}{c}\text { Shiraz, Fars } \\
\text { province } \\
\text { Mashhad city, } \\
\text { Northeastern Iran }\end{array}$ & $\begin{array}{l}\text { [6] Bahmani et al. } \\
2016 \\
\text { [5] Amiri and } \\
\text { Joharchi } 2013\end{array}$ \\
\hline 12. & $\begin{array}{c}\text { Allium } \\
\text { haementhoides } \\
\text { Bioss. \& Ruet. } \\
\text { Ex Regel }\end{array}$ & Liliaceae & Sorpa & $\begin{array}{l}\text { Leaf, flower } \\
\text { stem }\end{array}$ & Brew & Peptic Ulcer & Lorestan province & [8] Delfan et al. 2015 \\
\hline 13. & $\begin{array}{l}\text { Allium sativum } \\
\text { L. }\end{array}$ & Amaryllidaceae & Sir & Bulb & n.r. & $\begin{array}{c}\text { Hypoglycemic, Cardiac } \\
\text { Diseases, Antiseptic, } \\
\text { Toothache, } \\
\text { Antihyperlipidemia, } \\
\text { Anthelmintic, } \\
\text { Antihypertensive }\end{array}$ & $\begin{array}{l}\text { Mashhad city, } \\
\text { Northeastern Iran }\end{array}$ & $\begin{array}{l}\text { [5] Amiri and } \\
\text { Joharchi } 2013\end{array}$ \\
\hline 14. & $\begin{array}{c}\text { Althaea officinalis } \\
\text { L. }\end{array}$ & Malvaceae & Charme giah & Root & n.r. & $\begin{array}{l}\text { Mouth Wounds, Bone Fracture, } \\
\text { Treatment of Bruises, } \\
\text { Treatment of Dysuria }\end{array}$ & $\begin{array}{l}\text { Mashhad city, } \\
\text { Northeastern Iran }\end{array}$ & $\begin{array}{l}\text { [5] Amiri and } \\
\text { Joharchi } 2013\end{array}$ \\
\hline 15. & $\begin{array}{c}\text { Alyssum } \\
\text { alyssoides (L.) L. }\end{array}$ & Brassicaceae & Ghodumeh & Seed & n.r. & $\begin{array}{c}\text { Pharyngitis, Antitussive, } \\
\text { Febrifuge, Laxative, Treatment } \\
\text { of Hoarseness }\end{array}$ & $\begin{array}{l}\text { Mashhad city, } \\
\text { Northeastern Iran }\end{array}$ & $\begin{array}{l}\text { [5] Amiri and } \\
\text { Joharchi } 2013\end{array}$ \\
\hline 16. & $\begin{array}{c}\text { Alyssum } \\
\text { desertorum Stapf. }\end{array}$ & Brassicaceae & n.r. & Seed & $\begin{array}{l}\text { Boiled, herbal } \\
\text { fumigation }\end{array}$ & Antidiabetic & $\begin{array}{l}\text { Urmia county, } \\
\text { Northwest Iran }\end{array}$ & $\begin{array}{c}\text { [7] } \\
\text { Bahmani et al. } 2014\end{array}$ \\
\hline 17. & $\begin{array}{l}\text { Amaranthus } \\
\text { caudatus L. }\end{array}$ & Amaranthaceae & Taj Khorus & Aerial parts & n.r. & $\begin{array}{l}\text { Disinfectant Treatment of } \\
\text { Enteritis, Febrifuge, } \\
\text { Antitussive, Antidiarrhea, } \\
\text { Laxative }\end{array}$ & $\begin{array}{l}\text { Mashhad city, } \\
\text { Northeastern Iran }\end{array}$ & $\begin{array}{l}\text { [5] Amiri and } \\
\text { Joharchi } 2013\end{array}$ \\
\hline 18. & $\begin{array}{l}\text { Amygdalus } \\
\text { commonis } \\
\text { Amygdalus } \\
\text { communis }\end{array}$ & $\begin{array}{l}\text { Rosaceae } \\
\text { Rosaseae }\end{array}$ & $\begin{array}{l}\text { Badam-e shirin } \\
\text { Baadam }\end{array}$ & $\begin{array}{l}\text { Green fruit and } \\
\text { seed } \\
\text { Fruit }\end{array}$ & $\begin{array}{l}\text { Boiled, brewed, } \\
\text { raw } \\
\text { Herbal } \\
\text { tea/decoction }\end{array}$ & $\begin{array}{l}\text { Anti-hair Loss } \\
\text { Antiparasitic }\end{array}$ & $\begin{array}{c}\text { Khiregah-e Jangali, } \\
\text { Ghasemloo } \\
\text { Shiraz, Fars } \\
\text { province }\end{array}$ & $\begin{array}{c}{[9]} \\
\text { Baharvand-Ahmadi } \\
\text { et al. } 2015 \\
\text { [6] Bahmani et al. } \\
2016\end{array}$ \\
\hline
\end{tabular}


Table 1. Cont

\begin{tabular}{|c|c|c|c|c|c|c|c|c|}
\hline & $\begin{array}{l}\text { Scientific } \\
\text { Name }\end{array}$ & Family & $\begin{array}{l}\text { Local } \\
\text { Name }\end{array}$ & $\begin{array}{l}\text { Part } \\
\text { Used }\end{array}$ & $\begin{array}{l}\text { Type of } \\
\text { Extract }\end{array}$ & $\begin{array}{l}\text { Medicinal } \\
\text { Uses }\end{array}$ & Area & Author (s) \\
\hline 19. & $\begin{array}{l}\text { Anacamptis } \\
\text { morio (L.) R. M. } \\
\text { Bateman }\end{array}$ & Orchidaceae & Saalab gholveh & Root & n.r. & Tonic & $\begin{array}{l}\text { Mashhad city, } \\
\text { Northeastern Iran }\end{array}$ & $\begin{array}{l}\text { [5] Amiri and } \\
\text { Joharchi } 2013\end{array}$ \\
\hline 20. & $\begin{array}{c}\text { Anastatica } \\
\text { hierochuntica } \mathrm{L} \text {. }\end{array}$ & Brassicaceae & Change mayam & Aerial parts & n.r. & $\begin{array}{l}\text { Bring Luck to Pregnant } \\
\text { Women, Menstrual Regulator }\end{array}$ & $\begin{array}{l}\text { Mashhad city, } \\
\text { Northeastern Iran }\end{array}$ & $\begin{array}{l}\text { [5] Amiri and } \\
\text { Joharchi } 2013\end{array}$ \\
\hline 21. & Anchusa italica & Boraginaceae & Gole-gazou & Leaf, flower & Decoction & Stomach Ache & Lorestan province & [8] Delfan et al. 2015 \\
\hline 22. & $\begin{array}{l}\text { Anethum } \\
\text { graveolens } \mathrm{L}\end{array}$ & Apiaceae & Shevid & Fruit & n.r. & $\begin{array}{c}\text { Abortion, Anti-dysmenorrhea, } \\
\text { Galactogogue, } \\
\text { Antihyperlipidemia, } \\
\text { Carminative }\end{array}$ & $\begin{array}{l}\text { Mashhad city, } \\
\text { Northeastern Iran }\end{array}$ & $\begin{array}{l}\text { [5] Amiri and } \\
\text { Joharchi } 2013\end{array}$ \\
\hline 23. & $\begin{array}{l}\text { Anthemis } \\
\text { tinctoria } \mathrm{L} \text {. }\end{array}$ & Asteraceae & $\begin{array}{l}\text { Baboone-ye } \\
\text { zard }\end{array}$ & Flowering shoot & $\begin{array}{l}\text { Boiled, brewed, } \\
\text { paste }\end{array}$ & $\begin{array}{l}\text { Beauty and Clarity of the Skin, } \\
\text { Strengthening of Hair Roots }\end{array}$ & $\begin{array}{l}\text { Khiregah-e Jangali, } \\
\text { Ghasemloo valley }\end{array}$ & $\begin{array}{c}{[9]} \\
\text { Baharvand-Ahmadi } \\
\text { et al. } 2015\end{array}$ \\
\hline 24. & $\begin{array}{l}\text { Apium graveolens } \\
\text { L. }\end{array}$ & Apiaceae & Karafs & Fruit & n.r. & $\begin{array}{c}\text { Emmenagogue, Diuretic, } \\
\text { Carminative }\end{array}$ & $\begin{array}{c}\text { Mashhad city, } \\
\text { Northeastern Iran }\end{array}$ & $\begin{array}{l}\text { [5] Amiri and } \\
\text { Joharchi } 2013\end{array}$ \\
\hline 25. & $\begin{array}{l}\text { Arctium lappa } \mathrm{L} \text {. } \\
\text { Arctium lappa } \mathrm{L} \text {. }\end{array}$ & $\begin{array}{l}\text { Asteraceae } \\
\text { Asteraceae }\end{array}$ & $\begin{array}{l}\text { Baba Adam } \\
\text { n.r. }\end{array}$ & $\begin{array}{l}\text { Leaves - Root } \\
\text { Root, leaf }\end{array}$ & $\begin{array}{c}\text { n.r. } \\
\text { Boiled, steamed }\end{array}$ & $\begin{array}{c}\text { Diuretic Cholagogue, } \\
\text { Depurative, Hypoglycemic } \\
\text { Antidiabetic }\end{array}$ & $\begin{array}{l}\text { Mashhad city, } \\
\text { Northeastern Iran } \\
\text { Urmia county, } \\
\text { Northwest Iran }\end{array}$ & $\begin{array}{c}\text { [5] Amiri and } \\
\text { Joharchi } 2013 \\
\text { [7] } \\
\text { Bahmani et al. } 2014\end{array}$ \\
\hline 26. & $\begin{array}{c}\text { Arnebia } \\
\text { euchroma (Royle) } \\
\text { I.M.Johnst. }\end{array}$ & Boraginaceae & Havachoobeh & Root & n.r. & $\begin{array}{c}\text { Treatment of Dermal Disorders, } \\
\text { Hair Tonic }\end{array}$ & $\begin{array}{l}\text { Mashhad city, } \\
\text { Northeastern Iran }\end{array}$ & $\begin{array}{l}\text { [5] Amiri and } \\
\text { Joharchi } 2013\end{array}$ \\
\hline 27. & $\begin{array}{l}\text { Artemisia } \\
\text { absinthium } \\
\text { Artemisia } \\
\text { absinthium L. }\end{array}$ & $\begin{array}{l}\text { Asteraceae } \\
\text { Asteraceae }\end{array}$ & $\begin{array}{l}\text { Ofsantin } \\
\text { Afsantin }\end{array}$ & $\begin{array}{l}\text { Leaf } \\
\text { Aerial parts }\end{array}$ & $\begin{array}{c}\text { Herbal } \\
\text { tea/decoction } \\
\text { n.r. }\end{array}$ & $\begin{array}{c}\text { Antiparasitic } \\
\text { Anthelmintic, Appetizer, } \\
\text { Indigestion }\end{array}$ & $\begin{array}{c}\text { Shiraz, Fars } \\
\text { province } \\
\text { Mashhad city, } \\
\text { Northeastern Iran }\end{array}$ & $\begin{array}{l}\text { [6] Bahmani et al. } \\
2016 \\
\text { [5] Amiri and } \\
\text { Joharchi } 2013\end{array}$ \\
\hline 28. & $\begin{array}{c}\text { Artemisia } \\
\text { dracunculus } \mathrm{L} .\end{array}$ & Asteraceae & Tarkhun & Leaves & n.r. & $\begin{array}{l}\text { Appetizer, Dyspepsia, } \\
\text { Anthelmintic, Antacid, } \\
\text { Carminative }\end{array}$ & $\begin{array}{l}\text { Mashhad city, } \\
\text { Northeastern Iran }\end{array}$ & $\begin{array}{l}\text { [5] Amiri and } \\
\text { Joharchi } 2013\end{array}$ \\
\hline 29. & $\begin{array}{l}\text { Artemisia sieberi } \\
\text { Besser }\end{array}$ & Asteraceae & Dermaneh & Flowering shoot & $\begin{array}{l}\text { Boiled, brewed, } \\
\text { paste }\end{array}$ & Baldness & $\begin{array}{l}\text { Khiregah-e Jangali, } \\
\text { Ghasemloo valley }\end{array}$ & $\begin{array}{c}{[9]} \\
\text { Baharvand-Ahmadi } \\
\text { et al. } 2015\end{array}$ \\
\hline 30. & $\begin{array}{l}\text { Artemisia } \\
\text { vulgaris L. }\end{array}$ & Asteraceae & Baranjasef & Flower & n.r. & $\begin{array}{l}\text { Nerve Tonic, Sexual Impotency, } \\
\text { Menstrual Regulator }\end{array}$ & $\begin{array}{l}\text { Mashhad city, } \\
\text { Northeastern Iran }\end{array}$ & $\begin{array}{l}\text { [5] Amiri and } \\
\text { Joharchi } 2013\end{array}$ \\
\hline
\end{tabular}


Table 1. Cont

\begin{tabular}{|c|c|c|c|c|c|c|c|c|}
\hline & $\begin{array}{l}\text { Scientific } \\
\text { Name }\end{array}$ & Family & $\begin{array}{l}\text { Local } \\
\text { Name }\end{array}$ & $\begin{array}{l}\text { Part } \\
\text { Used }\end{array}$ & $\begin{array}{l}\text { Type of } \\
\text { Extract }\end{array}$ & $\begin{array}{l}\text { Medicinal } \\
\text { Uses }\end{array}$ & Area & Author (s) \\
\hline 31. & Arundo donax $\mathrm{L}$. & Poaceae & $\begin{array}{l}\text { Tabashir } \\
\text { ghalam }\end{array}$ & Latex & n.r. & $\begin{array}{l}\text { Aphthous Ulcer, Anti Thirst, } \\
\text { Depurative, Treatment of } \\
\text { Pimples, Febrifuge }\end{array}$ & $\begin{array}{l}\text { Mashhad city, } \\
\text { Northeastern Iran }\end{array}$ & $\begin{array}{l}\text { [5] Amiri and Joharchi } \\
2013\end{array}$ \\
\hline 32. & $\begin{array}{c}\text { Astragalus } \\
\text { adscendens Boiss. } \\
\text { \& Hausskn. ex } \\
\text { Boiss. }\end{array}$ & Fabaceae & Gazangabin & Manna & n.r. & Laxative, Febrifuge Digestive & $\begin{array}{l}\text { Mashhad city, } \\
\text { Northeastern Iran }\end{array}$ & $\begin{array}{l}\text { [5] Amiri and Joharchi } \\
2013\end{array}$ \\
\hline 33. & $\begin{array}{l}\text { Astragalus } \\
\text { fasciculifolius } \\
\text { subsp. } \\
\text { arbusculinus } \\
\text { (Bornm. \& } \\
\text { Gauba) Tietz }\end{array}$ & Fabaceae & Anzerut & Gum & n.r. & $\begin{array}{c}\text { Antitussive, Jaundice, Laxative, } \\
\text { Anthelmintic }\end{array}$ & $\begin{array}{l}\text { Mashhad city, } \\
\text { Northeastern Iran }\end{array}$ & $\begin{array}{c}{[5]} \\
\text { Amiri and Joharchi } 2013\end{array}$ \\
\hline 34. & $\begin{array}{l}\text { Astragalus } \\
\text { hamosus L. }\end{array}$ & Fabaceae & Nakhonak & Fruit & n.r. & $\begin{array}{l}\text { Anodyne, Repel of Kidney } \\
\text { Stone, Diuretic, Arthrodynia, } \\
\text { Carminative }\end{array}$ & $\begin{array}{l}\text { Mashhad city, } \\
\text { Northeastern Iran }\end{array}$ & $\begin{array}{c}{[5]} \\
\text { Amiri and Joharchi } 2013\end{array}$ \\
\hline 35. & $\begin{array}{l}\text { Astragalus } \\
\text { sieversianus } \\
\text { Pall. }\end{array}$ & Fabaceae & Gol Sefid & Fruit & n.r. & Menstrual Disorders & $\begin{array}{l}\text { Mashhad city, } \\
\text { Northeastern Iran }\end{array}$ & $\begin{array}{c}{[5]} \\
\text { Amiri and Joharchi } 2013\end{array}$ \\
\hline 36. & Astragalus spp. & Fabaceae & Katira & Gum & n.r. & $\begin{array}{l}\text { Mouth Wounds, Aphrodisiac, } \\
\text { Cystitis, Hair Tonic }\end{array}$ & $\begin{array}{l}\text { Mashhad city, } \\
\text { Northeastern Iran }\end{array}$ & $\begin{array}{c}\text { [5] } \\
\text { Amiri and Joharchi } 2013\end{array}$ \\
\hline 37. & $\begin{array}{c}\text { Atropa } \\
\text { belladonna } \mathrm{L} \text {. }\end{array}$ & Solanaceae & Beladon & Leaves & n.r. & Antispasmodic, Sedative & $\begin{array}{c}\text { Mashhad city, } \\
\text { Northeastern Iran }\end{array}$ & $\begin{array}{c}{[5]} \\
\text { Amiri and Joharchi } 2013 \\
\end{array}$ \\
\hline 38. & $\begin{array}{l}\text { Avena sativa } \mathrm{L} . \\
\text { Avena sativa } \mathrm{L} \text {. }\end{array}$ & $\begin{array}{l}\text { Poaceae } \\
\text { Poaceae }\end{array}$ & $\begin{array}{l}\text { Jo dosar } \\
\text { n.r. }\end{array}$ & $\begin{array}{l}\text { Seed } \\
\text { Seed, } \\
\text { glumelle }\end{array}$ & $\begin{array}{l}\text { n.r. } \\
\text { Boiled }\end{array}$ & $\begin{array}{l}\text { Treatment of Acne } \\
\text { Blood Refining }\end{array}$ & $\begin{array}{l}\text { Mashhad city, } \\
\text { Northeastern Iran } \\
\text { Urmia county, } \\
\text { Northwest Iran }\end{array}$ & $\begin{array}{c}{[5]} \\
\text { Amiri and Joharchi } 2013 \\
{[7]} \\
\text { Bahmani et al. } 2014\end{array}$ \\
\hline 39. & $\begin{array}{l}\text { Berberis } \\
\text { integerima } \\
\text { Bunge. } \\
\text { Berberis } \\
\text { integerima } \\
\text { Bunge }\end{array}$ & $\begin{array}{l}\text { Berberidaceae } \\
\text { Berberidaceae }\end{array}$ & $\begin{array}{l}\text { n.r. } \\
\text { Zereshk } \\
\text { Kuhi }\end{array}$ & $\begin{array}{l}\text { Fruit, leaf, } \\
\text { skin } \\
\text { Fruit }\end{array}$ & $\begin{array}{l}\text { Boiled, steamed } \\
\text { n.r. }\end{array}$ & $\begin{array}{c}\text { Antidiabetic } \\
\text { Hypoglycemic, } \\
\text { Antihypertensive, Blood and } \\
\text { Liver Cleanser, Jaundice, } \\
\text { Febrifuge, Antigout }\end{array}$ & $\begin{array}{l}\text { Urmia county, } \\
\text { Northwest Iran } \\
\text { Mashhad city, } \\
\text { Northeastern Iran }\end{array}$ & $\begin{array}{c}\text { [7] } \\
\text { Bahmani et al. } 2014 \\
{[5]} \\
\text { Amiri and Joharchi } 2013\end{array}$ \\
\hline
\end{tabular}


Table 1. Cont

\begin{tabular}{|c|c|c|c|c|c|c|c|c|}
\hline & $\begin{array}{l}\text { Scientific } \\
\text { Name }\end{array}$ & Family & $\begin{array}{l}\text { Local } \\
\text { Name }\end{array}$ & $\begin{array}{c}\text { Part } \\
\text { Used }\end{array}$ & $\begin{array}{l}\text { Type of } \\
\text { Extract }\end{array}$ & $\begin{array}{l}\text { Medicinal } \\
\text { Uses }\end{array}$ & Area & Author (s) \\
\hline 40. & Berberis sp. & Berberidaceae & Zereshk & Fruit & n.r. & $\begin{array}{c}\text { Antigout, Blood and Liver } \\
\text { Cleanser, Febrifuge, } \\
\text { Anthelmintic, Treatment of } \\
\text { Dysentery }\end{array}$ & $\begin{array}{l}\text { Mashhad city, } \\
\text { Northeastern Iran }\end{array}$ & $\begin{array}{c}{[5]} \\
\text { Amiri and Joharchi } 2013\end{array}$ \\
\hline 41. & Borago officinalis & Boraginaceae & Gholegavza & an Flower & $\begin{array}{c}\text { Herbal } \\
\text { tea/decoction }\end{array}$ & Antiparasitic & $\begin{array}{c}\text { Shiraz, Fars } \\
\text { province }\end{array}$ & [6] Bahmani et al. 2016 \\
\hline 42. & $\begin{array}{l}\text { Brassica napus } \\
\text { Brassica napus L. }\end{array}$ & $\begin{array}{l}\text { Brassicaceae } \\
\text { Brassicaceae }\end{array}$ & $\begin{array}{l}\text { Kolza } \\
\text { Shalgham }\end{array}$ & $\begin{array}{l}\text { Leaf } \\
\text { Seed }\end{array}$ & $\begin{array}{l}\text { Decoction } \\
\text { n.r. }\end{array}$ & $\begin{array}{c}\text { Stomach Ache } \\
\text { Antiseptic, Treatment of Cold, } \\
\text { Tonic }\end{array}$ & $\begin{array}{l}\text { Lorestan province } \\
\text { Mashhad city, } \\
\text { Northeastern Iran }\end{array}$ & $\begin{array}{c}\text { [8] Delfan et al. } 2015 \\
\text { [5] } \\
\text { Amiri and Joharchi } 2013\end{array}$ \\
\hline 43. & $\begin{array}{l}\text { Brassica nigra } \\
\text { (L.) K.Koch }\end{array}$ & Brassicaceae & Khardal & Seed & n.r. & Laxative & $\begin{array}{l}\text { Mashhad city, } \\
\text { Northeastern Iran }\end{array}$ & $\begin{array}{c}{[5]} \\
\text { Amiri and Joharchi } 2013\end{array}$ \\
\hline 44. & $\begin{array}{l}\text { Bunium } \\
\text { cylindricum } \\
\text { (Boiss. \& } \\
\text { Hohen.) Drude }\end{array}$ & Apiaceae & Zireh Siah & Fruit & n.r. & Carminative & $\begin{array}{l}\text { Mashhad city, } \\
\text { Northeastern Iran }\end{array}$ & $\begin{array}{c}{[5]} \\
\text { Amiri and Joharchi } 2013\end{array}$ \\
\hline 45. & $\begin{array}{l}\text { Bunium persicum } \\
\text { (Boiss.) } \\
\text { B. Fedtsch. }\end{array}$ & Apiaceae & Zireh Siah & Fruit & n.r. & $\begin{array}{c}\text { Obesity, Galactogogue, } \\
\text { Flavoring, Carminative, } \\
\text { Calmative, Appetizer, } \\
\text { Indigestion }\end{array}$ & $\begin{array}{l}\text { Mashhad city, } \\
\text { Northeastern Iran }\end{array}$ & $\begin{array}{c}{[5]} \\
\text { Amiri and Joharchi } 2013\end{array}$ \\
\hline 46. & $\begin{array}{c}\text { Caccinia } \\
\text { macranthera } \\
\text { (Banks \& Sol.) } \\
\text { Brand }\end{array}$ & Boraginaceae & $\begin{array}{l}\text { Gavzaban } \\
\text { sabz }\end{array}$ & $\begin{array}{l}\text { Aerial } \\
\text { parts }\end{array}$ & n.r. & $\begin{array}{c}\text { Sedative, Treatment of Cough, } \\
\text { Expectorant }\end{array}$ & $\begin{array}{l}\text { Mashhad city, } \\
\text { Northeastern Iran }\end{array}$ & $\begin{array}{c}{[5]} \\
\text { Amiri and Joharchi } 2013\end{array}$ \\
\hline 47. & $\begin{array}{l}\text { Camellia sinensis } \\
\text { (L.) Kuntze }\end{array}$ & Theaceae & Chai Sabz & Leaves & n.r. & $\begin{array}{c}\text { Obesity, Anticancer, } \\
\text { Antihypertensive, Hepatitis, } \\
\text { Antihyperlipidemia }\end{array}$ & $\begin{array}{l}\text { Mashhad city, } \\
\text { Northeastern Iran }\end{array}$ & $\begin{array}{c}{[5]} \\
\text { Amiri and Joharchi } 2013\end{array}$ \\
\hline 48. & $\begin{array}{l}\text { Cannabis sativa } \\
\text { L. }\end{array}$ & Cannabinaceae & Shahdaneh & Seed & n.r. & $\begin{array}{c}\text { Sedative, Tonic Treatment of } \\
\text { Osteoarthritis, Treatment of Ear } \\
\text { Pain }\end{array}$ & $\begin{array}{l}\text { Mashhad city, } \\
\text { Northeastern Iran }\end{array}$ & $\begin{array}{c}{[5]} \\
\text { Amiri and Joharchi } 2013\end{array}$ \\
\hline 49. & $\begin{array}{l}\text { Capparis spinosa } \\
\text { L. }\end{array}$ & Capparaceae & Kavar & Fruit-Root & n.r. & $\begin{array}{c}\text { Liver Tonic, Hepatitis, } \\
\text { Appetizer, Anthelmintic, } \\
\text { Stomach Tonic, Emmenagogue, } \\
\text { Antigout }\end{array}$ & $\begin{array}{l}\text { Mashhad city, } \\
\text { Northeastern Iran }\end{array}$ & $\begin{array}{c}{[5]} \\
\text { Amiri and Joharchi } 2013\end{array}$ \\
\hline
\end{tabular}


Table 1. Cont.

\begin{tabular}{|c|c|c|c|c|c|c|c|c|}
\hline & $\begin{array}{l}\text { Scientific } \\
\text { Name }\end{array}$ & Family & $\begin{array}{l}\text { Local } \\
\text { Name }\end{array}$ & $\begin{array}{l}\text { Part } \\
\text { Used }\end{array}$ & $\begin{array}{l}\text { Type of } \\
\text { Extract }\end{array}$ & $\begin{array}{l}\text { Medicinal } \\
\text { Uses }\end{array}$ & Area & Author (s) \\
\hline 50. & $\begin{array}{c}\text { Capsella } \\
\text { bursa-pastoris } \\
\text { (L.) Medik. }\end{array}$ & Brassicaceae & $\begin{array}{l}\text { Kiseh } \\
\text { Keshish }\end{array}$ & Seed & n.r. & $\begin{array}{c}\text { Period Regulator, } \\
\text { Anti-hemorrhage, Antidiarrhea }\end{array}$ & $\begin{array}{l}\text { Mashhad city, } \\
\text { Northeastern Iran }\end{array}$ & $\begin{array}{c}{[5]} \\
\text { Amiri and Joharchi } 2013\end{array}$ \\
\hline 51. & $\begin{array}{l}\text { Capsicum } \\
\text { annuum L. }\end{array}$ & Solanaceae & $\begin{array}{c}\text { Felfel } \\
\text { Ghermez }\end{array}$ & Fruit & n.r. & $\begin{array}{l}\text { Appetizer, Spice, Treatment of } \\
\text { Osteoarthritis, Tonic, } \\
\text { Stimulant, Aphrodisiac }\end{array}$ & $\begin{array}{c}\text { Mashhad city, } \\
\text { Northeastern Iran }\end{array}$ & $\begin{array}{l}{[5]} \\
\text { Amiri and Joharchi } 2013\end{array}$ \\
\hline 52. & $\begin{array}{l}\text { Carthamus } \\
\text { tinctorius L. }\end{array}$ & Asteraceae & $\begin{array}{l}\text { Golrang } \\
\text { (Kajireh) }\end{array}$ & $\begin{array}{l}\text { Flower - } \\
\text { Seed }\end{array}$ & n.r. & $\begin{array}{l}\text { Emmenagogue, Flavoring } \\
\text { Luxative, Treatment of } \\
\text { Rheumatism }\end{array}$ & $\begin{array}{l}\text { Mashhad city, } \\
\text { Northeastern Iran }\end{array}$ & $\begin{array}{c}{[5]} \\
\text { Amiri and Joharchi } 2013\end{array}$ \\
\hline 53. & $\begin{array}{l}\text { Centaurea behen } \\
\text { L. }\end{array}$ & Asteraceae & $\begin{array}{l}\text { Bahman } \\
\text { Sefid }\end{array}$ & Root & n.r. & Aphrodisiac, Anti-lithiasis & $\begin{array}{c}\text { Mashhad city, } \\
\text { Northeastern Iran }\end{array}$ & $\begin{array}{c}{[5]} \\
\text { Amiri and Joharchi } 2013\end{array}$ \\
\hline 54. & $\begin{array}{c}\text { Centaurea } \\
\text { depressa } \mathrm{M} \text {. Bieb. }\end{array}$ & Asteraceae & $\begin{array}{l}\text { Gole } \\
\text { Gandom }\end{array}$ & $\begin{array}{l}\text { Aerial } \\
\text { parts }\end{array}$ & n.r. & $\begin{array}{c}\text { Digestive, Febrifuge, } \\
\text { Cholagogue, Blood Cleanser, } \\
\text { Antigout }\end{array}$ & $\begin{array}{l}\text { Mashhad city, } \\
\text { Northeastern Iran }\end{array}$ & $\begin{array}{c}{[5]} \\
\text { Amiri and Joharchi } 2013\end{array}$ \\
\hline 55. & $\begin{array}{l}\text { Cerasus avium } \\
\text { (L.) Moench }\end{array}$ & Rosaceae & $\begin{array}{l}\text { Dome } \\
\text { Gilas }\end{array}$ & Pedicel & n.r. & $\begin{array}{l}\text { Anti-lithiasis, Prostate } \\
\text { Disorders Kidney Stone, } \\
\text { Anti-inflammatory }\end{array}$ & $\begin{array}{l}\text { Mashhad city, } \\
\text { Northeastern Iran }\end{array}$ & $\begin{array}{c}{[5]} \\
\text { Amiri and Joharchi } 2013\end{array}$ \\
\hline 56. & $\begin{array}{l}\text { Cerasus } \\
\text { microcarpa }\end{array}$ & Rosaceae & n.r. & Fruit & Boiled, raw use & Blood Refining & $\begin{array}{l}\text { Urmia county, } \\
\text { Northwest Iran }\end{array}$ & $\begin{array}{c}\text { [7] } \\
\text { Bahmani et al. } 2014\end{array}$ \\
\hline 57. & $\begin{array}{l}\text { Ceterach } \\
\text { officinalis }\end{array}$ & Phillicineae & Sarakhs & $\begin{array}{l}\text { Aerial } \\
\text { parts }\end{array}$ & Paste & Head Itching & $\begin{array}{l}\text { Khiregah-e Jangali, } \\
\text { Ghasemloo valley }\end{array}$ & $\begin{array}{c}{[9]} \\
\text { Baharvand-Ahmadi et } \\
\text { al. } 2015\end{array}$ \\
\hline 58. & $\begin{array}{l}\text { Cichorium } \\
\text { intybus L. } \\
\text { Cichorium } \\
\text { intybus L. }\end{array}$ & $\begin{array}{l}\text { Asteraceae } \\
\text { Asteraceae }\end{array}$ & $\begin{array}{l}\text { Kasni } \\
\text { Kasni }\end{array}$ & $\begin{array}{l}\text { Aerial } \\
\text { parts } \\
\text { Root, } \\
\text { leaves, } \\
\text { flower, } \\
\text { and seeds }\end{array}$ & $\begin{array}{c}\text { n.r. } \\
\text { Boiled }\end{array}$ & $\begin{array}{c}\text { Treatment of Palpitation, } \\
\text { Appetizer, Depurative, } \\
\text { Treatment of Furuncles, } \\
\text { Jaundice, Febrifuge, } \\
\text { Anti-allergic } \\
\text { Head Itching }\end{array}$ & $\begin{array}{l}\text { Mashhad city, } \\
\text { Northeastern Iran } \\
\text { Khiregah-e Jangali, } \\
\text { Ghasemloo valley }\end{array}$ & $\begin{array}{c}{[5]} \\
\text { Amiri and Joharchi } 2013 \\
{[9]} \\
\text { Baharvand-Ahmadi et } \\
\text { al. } 2015\end{array}$ \\
\hline 59. & $\begin{array}{l}\text { Cinnamomum } \\
\text { verum } \\
\text { Cinnamomum } \\
\text { verum }\end{array}$ & $\begin{array}{l}\text { Lauraceae } \\
\text { Lauraceae }\end{array}$ & $\begin{array}{c}\text { n.r. } \\
\text { Darchin }\end{array}$ & $\begin{array}{l}\text { Skin } \\
\text { Fruit shells }\end{array}$ & $\begin{array}{c}\text { Boiled } \\
\text { Herbal } \\
\text { tea/decoction }\end{array}$ & $\begin{array}{l}\text { Antidiabetic } \\
\text { Antiparasitic }\end{array}$ & $\begin{array}{l}\text { Urmia county, } \\
\text { Northwest Iran } \\
\text { Shiraz, Fars } \\
\text { province }\end{array}$ & $\begin{array}{c}\text { [7] } \\
\text { Bahmani et al. } 2014 \\
\text { [6] Bahmani et al. } 2016\end{array}$ \\
\hline
\end{tabular}


Table 1. Cont.

\begin{tabular}{|c|c|c|c|c|c|c|c|c|}
\hline & $\begin{array}{l}\text { Scientific } \\
\text { Name }\end{array}$ & Family & $\begin{array}{l}\text { Local } \\
\text { Name }\end{array}$ & $\begin{array}{c}\text { Part } \\
\text { Used }\end{array}$ & $\begin{array}{l}\text { Type of } \\
\text { Extract }\end{array}$ & $\begin{array}{l}\text { Medicinal } \\
\text { Uses }\end{array}$ & Area & Author (s) \\
\hline 60. & $\begin{array}{c}\text { Citrullus } \\
\text { colocynthis (L.) } \\
\text { Schrad. } \\
\text { Citrullus } \\
\text { colocynthis (L.) } \\
\text { Schrad. }\end{array}$ & $\begin{array}{l}\text { Cucurbitaceae } \\
\text { Cucurbitaceae }\end{array}$ & $\begin{array}{c}\text { n.r. } \\
\text { Hanzal }\end{array}$ & $\begin{array}{c}\text { Fruit } \\
\text { Fruit-Seed }\end{array}$ & $\begin{array}{l}\text { Boiled } \\
\text { n.r. }\end{array}$ & $\begin{array}{c}\text { Antidiabetic } \\
\text { Purgative, Anodyne, } \\
\text { Hypoglycemic }\end{array}$ & $\begin{array}{l}\text { Urmia county, } \\
\text { Northwest Iran } \\
\text { Mashhad city, } \\
\text { Northeastern Iran }\end{array}$ & $\begin{array}{c}\text { [7] } \\
\text { Bahmani et al. } 2014 \\
\text { [5] } \\
\text { Amiri and Joharchi } 2013\end{array}$ \\
\hline 61. & $\begin{array}{l}\text { Citrus } \\
\text { aurantiifolia } \\
\text { (Christm.) } \\
\text { Swingle }\end{array}$ & Rutaceae & $\begin{array}{l}\text { Limu } \\
\text { Amani }\end{array}$ & Fruit & n.r. & Antihypertensive, Calmative & $\begin{array}{l}\text { Mashhad city, } \\
\text { Northeastern Iran }\end{array}$ & $\begin{array}{c}{[5]} \\
\text { Amiri and Joharchi } 2013\end{array}$ \\
\hline 62. & $\begin{array}{c}\text { Citrus aurantium } \\
\text { L. }\end{array}$ & Rutaceae & $\begin{array}{l}\text { Bahar } \\
\text { Naranj }\end{array}$ & Flower & n.r. & $\begin{array}{c}\text { Anti-stress, Cardiac Tonic, } \\
\text { Food Digestion, } \\
\text { Antihypertensive }\end{array}$ & $\begin{array}{l}\text { Mashhad city, } \\
\text { Northeastern Iran }\end{array}$ & $\begin{array}{c}{[5]} \\
\text { Amiri and Joharchi } 2013\end{array}$ \\
\hline 63. & $\begin{array}{l}\text { Clinopodium } \\
\text { graveolens (M. } \\
\text { Bieb.) Kuntze }\end{array}$ & Lamiaceae & Faranjmeshk & Seed & n.r. & $\begin{array}{c}\text { Pharyngitis, Gastric Ulcer, } \\
\text { Nerve Tonic }\end{array}$ & $\begin{array}{l}\text { Mashhad city, } \\
\text { Northeastern Iran }\end{array}$ & $\begin{array}{c}{[5]} \\
\text { Amiri and Joharchi } 2013\end{array}$ \\
\hline 64. & $\begin{array}{l}\text { Colchicum } \\
\text { autumnale L. }\end{array}$ & Colchicaceae & Suranjan & Root & n.r. & $\begin{array}{l}\text { Antigout, Calmative, } \\
\text { Arthrodynia }\end{array}$ & $\begin{array}{l}\text { Mashhad city, } \\
\text { Northeastern Iran }\end{array}$ & $\begin{array}{c}{[5]} \\
\text { Amiri and Joharchi } 2013\end{array}$ \\
\hline 65. & $\begin{array}{c}\text { Colchicum } \\
\text { kotschyi Boiss. }\end{array}$ & Liliaceae & $\begin{array}{l}\text { Gol-e } \\
\text { hasrat }\end{array}$ & Flower & Paste & Lice & $\begin{array}{l}\text { Khiregah-e Jangali, } \\
\text { Ghasemloo valley }\end{array}$ & $\begin{array}{c}{[9]} \\
\text { Baharvand-Ahmadi et } \\
\text { al. } 2015\end{array}$ \\
\hline 66. & $\begin{array}{l}\text { Conium } \\
\text { maculatum } \mathrm{L} .\end{array}$ & Apiaceae & Shokaran & Root & n.r. & $\begin{array}{c}\text { Cholagogue, Depilator, } \\
\text { Treatment of Dermal Allergies }\end{array}$ & $\begin{array}{l}\text { Mashhad city, } \\
\text { Northeastern Iran }\end{array}$ & $\begin{array}{c}{[5]} \\
\text { Amiri and Joharchi } 2013\end{array}$ \\
\hline 67. & $\begin{array}{l}\text { Convolvulus } \\
\text { arvensis L. }\end{array}$ & Convolvulaceae & $\begin{array}{l}\text { Pichak-e } \\
\text { sahraee }\end{array}$ & $\begin{array}{l}\text { Aerial } \\
\text { parts }\end{array}$ & Paste & Skin Spots & $\begin{array}{l}\text { Khiregah-e Jangali, } \\
\text { Ghasemloo valley }\end{array}$ & $\begin{array}{c}{[9]} \\
\text { Baharvand-Ahmadi et } \\
\text { al. } 2015\end{array}$ \\
\hline 68. & Cordia myxa L. & Boraginaceae & Sepestan & Fruit & n.r. & $\begin{array}{l}\text { Pharyngitis, Antitussive, } \\
\text { Febrifuge, Laxative }\end{array}$ & $\begin{array}{l}\text { Mashhad city, } \\
\text { Northeastern Iran }\end{array}$ & $\begin{array}{c}{[5]} \\
\text { Amiri and Joharchi } 2013\end{array}$ \\
\hline 69. & $\begin{array}{l}\text { Coriandrum } \\
\text { sativum L. }\end{array}$ & Apiaceae & Geshniz & Fruit & n.r. & $\begin{array}{c}\text { Acne, Treatment of Flatulence, } \\
\text { Appetizer, Aphrodisiac, } \\
\text { Calmative, Jaundice, } \\
\text { Antiseptic, Aromatic }\end{array}$ & $\begin{array}{l}\text { Mashhad city, } \\
\text { Northeastern Iran }\end{array}$ & $\begin{array}{c}{[5]} \\
\text { Amiri and Joharchi } 2013\end{array}$ \\
\hline 70 & Cornus mas L. & Cornaceae & $\begin{array}{l}\text { Zoghal } \\
\text { Akhteh }\end{array}$ & Fruit & n.r. & $\begin{array}{l}\text { Prostatic Hypertrophy, } \\
\text { Anti-hemorrhage, } \\
\text { Antidiarrhea, Febrifuge }\end{array}$ & $\begin{array}{l}\text { Mashhad city, } \\
\text { Northeastern Iran }\end{array}$ & $\begin{array}{c}{[5]} \\
\text { Amiri and Joharchi } 2013\end{array}$ \\
\hline
\end{tabular}


Table 1. Cont

\begin{tabular}{|c|c|c|c|c|c|c|c|c|}
\hline & $\begin{array}{l}\text { Scientific } \\
\text { Name }\end{array}$ & Family & $\begin{array}{l}\text { Local } \\
\text { Name }\end{array}$ & $\begin{array}{l}\text { Part } \\
\text { Used }\end{array}$ & $\begin{array}{l}\text { Type of } \\
\text { Extract }\end{array}$ & $\begin{array}{l}\text { Medicinal } \\
\text { Uses }\end{array}$ & Area & Author (s) \\
\hline 71. & Coronilla varia $\mathrm{L}$. & Fabaceae & n.r. & Leaf & Raw use, boiled & Antidiabetic & $\begin{array}{l}\text { Urmia county, } \\
\text { Northwest Iran }\end{array}$ & $\begin{array}{c}\text { [7] } \\
\text { Bahmani et al. } 2014\end{array}$ \\
\hline 72. & $\begin{array}{l}\text { Corylus avellana } \\
\text { L. }\end{array}$ & Betulaceae & Fandogh & Fruit & n.r. & $\begin{array}{l}\text { Treatment of Anemia, } \\
\text { Depurative, Appetizer }\end{array}$ & $\begin{array}{c}\text { Mashhad city, } \\
\text { Northeastern Iran }\end{array}$ & $\begin{array}{c}{[5]} \\
\text { Amiri and Joharchi } 2013\end{array}$ \\
\hline 73. & $\begin{array}{l}\text { Crataegus aronia } \\
\text { (L.) Bosc ex Dc. }\end{array}$ & Rosaceae & n.r. & $\begin{array}{l}\text { Fruit and } \\
\text { skin }\end{array}$ & Raw use, boiled & Antidiabetic & $\begin{array}{l}\text { Urmia county, } \\
\text { Northwest Iran }\end{array}$ & $\begin{array}{c}\text { [7] } \\
\text { Bahmani et al. } 2014\end{array}$ \\
\hline 74. & $\begin{array}{l}\text { Crataegus } \\
\text { oxycantha L. }\end{array}$ & Rosaceae & n.r. & $\begin{array}{c}\text { Fruit, } \\
\text { flower } \\
\text { root, skin }\end{array}$ & Raw use, boiled & Antidiabetic & $\begin{array}{l}\text { Urmia county, } \\
\text { Northwest Iran }\end{array}$ & $\begin{array}{c}{[7]} \\
\text { Bahmani et al. } 2014\end{array}$ \\
\hline 75. & Crataegus sp. & Rosaceae & $\begin{array}{l}\text { Sorkhe } \\
\text { Valik }\end{array}$ & Fruit-Leaves & n.r. & $\begin{array}{c}\text { Depurative, Repairs Blood } \\
\text { Vessel }\end{array}$ & $\begin{array}{l}\text { Mashhad city, } \\
\text { Northeastern Iran }\end{array}$ & $\begin{array}{c}{[5]} \\
\text { Amiri and Joharchi } 2013\end{array}$ \\
\hline 76. & Crocus satious L. & Iridaceae & Zaffaron & Style & n.r. & $\begin{array}{c}\text { Tonic, Dysmenorrheal, } \\
\text { Emmenagogue, Nerve Tonic, } \\
\text { Premature Ejaculation, Gastric } \\
\text { Ulcer, Aphrodisiac }\end{array}$ & $\begin{array}{l}\text { Mashhad city, } \\
\text { Northeastern Iran }\end{array}$ & $\begin{array}{c}{[5]} \\
\text { Amiri and Joharchi } 2013\end{array}$ \\
\hline 77. & $\begin{array}{l}\text { Cucumis satious } \\
\text { L. }\end{array}$ & Cucurbitaceae & Khiar & Seed & n.r. & $\begin{array}{l}\text { Diuretic, Anti-lithiasis, Blood } \\
\text { Cleansing, Febrifuge }\end{array}$ & $\begin{array}{l}\text { Mashhad city, } \\
\text { Northeastern Iran }\end{array}$ & $\begin{array}{c}{[5]} \\
\text { Amiri and Joharchi } 2013\end{array}$ \\
\hline 78. & $\begin{array}{l}\text { Cuminum } \\
\text { cyminum L. }\end{array}$ & Apiaceae & $\begin{array}{l}\text { Zireh Sabz } \\
\text { (Keravieh) }\end{array}$ & Fruit & n.r. & $\begin{array}{c}\text { Treatment of Colic, } \\
\text { Galactogogue, Obesity, } \\
\text { Digestive, Flavoring, } \\
\text { Antiseptic }\end{array}$ & $\begin{array}{l}\text { Mashhad city, } \\
\text { Northeastern Iran }\end{array}$ & $\begin{array}{c}{[5]} \\
\text { Amiri and Joharchi } 2013\end{array}$ \\
\hline 79. & $\begin{array}{l}\text { Cuscuta } \\
\text { epithymum } \\
\text { Murray }\end{array}$ & Convolvolaceae & Aftimun & $\begin{array}{l}\text { Aerial } \\
\text { parts }\end{array}$ & n.r. & Laxative, Anti-hemorrhoids & $\begin{array}{l}\text { Mashhad city, } \\
\text { Northeastern Iran }\end{array}$ & $\begin{array}{c}{[5]} \\
\text { Amiri and Joharchi } 2013\end{array}$ \\
\hline 80. & $\begin{array}{l}\text { Cydonia oblonga } \\
\text { Mill. }\end{array}$ & Rosaceae & Beh Daneh & Seed-Leaves & n.r. & $\begin{array}{c}\text { Cardiac Diseases, Antitussive, } \\
\text { Sore Throat, Laxative, } \\
\text { Febrifuge }\end{array}$ & $\begin{array}{l}\text { Mashhad city, } \\
\text { Northeastern Iran }\end{array}$ & $\begin{array}{c}{[5]} \\
\text { Amiri and Joharchi } 2013\end{array}$ \\
\hline 81. & $\begin{array}{l}\text { Cyperus rotundus } \\
\text { L. }\end{array}$ & Cyperaceae & Soade Kufi & Root & n.r. & Strengthening of Memory & $\begin{array}{l}\text { Mashhad city, } \\
\text { Northeastern Iran }\end{array}$ & $\begin{array}{c}{[5]} \\
\text { Amiri and Joharchi } 2013\end{array}$ \\
\hline 82. & $\begin{array}{l}\text { Dactylorhiza } \\
\text { umbrosa (Kar. \& } \\
\text { Kir.) Nevski }\end{array}$ & Orchidaceae & $\begin{array}{l}\text { Saalab } \\
\text { panjeh }\end{array}$ & Root & n.r. & $\begin{array}{c}\text { Treatment of Sexual Impotency, } \\
\text { Tonic }\end{array}$ & $\begin{array}{l}\text { Mashhad city, } \\
\text { Northeastern Iran }\end{array}$ & $\begin{array}{c}{[5]} \\
\text { Amiri and Joharchi } 2013\end{array}$ \\
\hline
\end{tabular}


Table 1. Cont

\begin{tabular}{|c|c|c|c|c|c|c|c|c|}
\hline & $\begin{array}{l}\text { Scientific } \\
\text { Name }\end{array}$ & Family & $\begin{array}{l}\text { Local } \\
\text { Name }\end{array}$ & $\begin{array}{c}\text { Part } \\
\text { Used }\end{array}$ & $\begin{array}{l}\text { Type of } \\
\text { Extract }\end{array}$ & $\begin{array}{l}\text { Medicinal } \\
\text { Uses }\end{array}$ & Area & Author (s) \\
\hline 83. & $\begin{array}{l}\text { Datura } \\
\text { stramonium } \mathrm{L} . \\
\quad \text { Datura } \\
\text { stramonium L. }\end{array}$ & $\begin{array}{l}\text { Solanaceae } \\
\text { Solanaceae }\end{array}$ & $\begin{array}{l}\text { Tatureh } \\
\text { Tatureh }\end{array}$ & $\begin{array}{l}\text { Seed } \\
\text { Seed }\end{array}$ & $\begin{array}{c}\text { n.r. } \\
\text { Boiled and Paste }\end{array}$ & $\begin{array}{c}\text { Sedative, Treatment of } \\
\text { Addiction, Treatment of Colic } \\
\text { Wound Healing, Wound } \\
\text { Disinfection }\end{array}$ & $\begin{array}{l}\text { Mashhad city, } \\
\text { Northeastern Iran } \\
\text { Khiregah-e Jangali, } \\
\text { Ghasemloo valley }\end{array}$ & $\begin{array}{c}{[5]} \\
\text { Amiri and Joharchi } 2013 \\
\text { [9] } \\
\text { Baharvand-Ahmadi et } \\
\text { al. } 2015\end{array}$ \\
\hline 84. & Daucus carota $\mathrm{L}$. & Apiaceae & Havij & Fruit & n.r. & Diuretic, Emmenagogue & $\begin{array}{l}\text { Mashhad city, } \\
\text { Northeastern Iran }\end{array}$ & $\begin{array}{c}{[5]} \\
\text { Amiri and Joharchi } 2013 \\
\end{array}$ \\
\hline 85. & $\begin{array}{c}\text { Delphinium } \\
\text { semibarbatum } \\
\text { Bien. ex Boiss }\end{array}$ & Ranunculaceae & Zarir & Flower & n.r. & $\begin{array}{l}\text { Treatment of Dermal Allergies, } \\
\text { Coloring }\end{array}$ & $\begin{array}{l}\text { Mashhad city, } \\
\text { Northeastern Iran }\end{array}$ & $\begin{array}{c}{[5]} \\
\text { Amiri and Joharchi } 2013\end{array}$ \\
\hline 86. & $\begin{array}{l}\text { Descurainia } \\
\text { Sophia (L.) Schr. } \\
\text { Descurainia } \\
\text { sophia }(\text { L.) Webb } \\
\text { ex Prantl }\end{array}$ & $\begin{array}{l}\text { Brassicaceae } \\
\text { Brassicaceae }\end{array}$ & $\begin{array}{l}\text { Khakeshir } \\
\text { Khakshir }\end{array}$ & $\begin{array}{l}\text { Fruit } \\
\text { Seed }\end{array}$ & $\begin{array}{l}\text { Fresh food } \\
\text { n.r. }\end{array}$ & $\begin{array}{c}\text { Antiparasitic } \\
\text { Blood and Liver Cleanser, } \\
\text { Jaundice, Febrifuge, Treatment } \\
\text { of Furuncles, Anti-thirst, } \\
\text { Laxative }\end{array}$ & $\begin{array}{c}\text { Shiraz, Fars } \\
\text { province } \\
\text { Mashhad city, } \\
\text { Northeastern Iran }\end{array}$ & $\begin{array}{l}\text { [6] Bahmani et al. } 2016 \\
\text { [5] } \\
\text { Amiri and Joharchi } 2013\end{array}$ \\
\hline 87. & $\begin{array}{l}\text { Dorema } \\
\text { ammoniacum } \mathrm{D} . \\
\text { Don }\end{array}$ & Apiaceae & Kandal & Gum- Root & n.r. & $\begin{array}{c}\text { Cystitis, Digestive, Treatment } \\
\text { of Colic, Treatment of } \\
\text { Furuncles, Expectorant, } \\
\text { Anthelmintic, Emmenagogue, } \\
\text { Anticovulsion }\end{array}$ & $\begin{array}{l}\text { Mashhad city, } \\
\text { Northeastern Iran }\end{array}$ & $\begin{array}{c}{[5]} \\
\text { Amiri and Joharchi } 2013\end{array}$ \\
\hline 88. & $\begin{array}{l}\text { Drimia maritima } \\
\text { (L.) Stearn }\end{array}$ & Asparagaceae & Onsol & Bulb & n.r. & $\begin{array}{c}\text { Arthrodynia, Emmenagogue, } \\
\text { Hair Tonic }\end{array}$ & $\begin{array}{l}\text { Mashhad city, } \\
\text { Northeastern Iran }\end{array}$ & $\begin{array}{c}{[5]} \\
\text { Amiri and Joharchi } 2013\end{array}$ \\
\hline 89. & $\begin{array}{l}\text { Dysphania botrys } \\
\text { (L.) Mosyakin \& } \\
\text { Clemants }\end{array}$ & Amaranthaceae & $\begin{array}{l}\text { Dermaneh } \\
\text { Torki }\end{array}$ & $\begin{array}{l}\text { Aerial } \\
\text { parts }\end{array}$ & n.r. & $\begin{array}{l}\text { Diabetes, Treatment of } \\
\text { Sinusitis, Respiratory } \\
\text { Disorders, Anthelmintic, } \\
\text { Antacid, Antidiarrhea, } \\
\text { Carminative, Urinary } \\
\text { Antiseptic }\end{array}$ & $\begin{array}{l}\text { Mashhad city, } \\
\text { Northeastern Iran }\end{array}$ & $\begin{array}{c}{[5]} \\
\text { Amiri and Joharchi } 2013\end{array}$ \\
\hline 90. & $\begin{array}{c}\text { Echinops } \\
\text { cephalotes DC. }\end{array}$ & Asteraceae & $\begin{array}{l}\text { Shekar } \\
\text { Tighal }\end{array}$ & Manna & n.r. & $\begin{array}{l}\text { Antitussive, Anti-asthmatic, } \\
\text { Pharyngitis, Febrifuge }\end{array}$ & $\begin{array}{l}\text { Mashhad city, } \\
\text { Northeastern Iran }\end{array}$ & $\begin{array}{c}{[5]} \\
\text { Amiri and Joharchi } 2013\end{array}$ \\
\hline 91. & $\begin{array}{l}\text { Echium amoenum } \\
\text { Fisch. \& } \\
\text { C.A.Mey. }\end{array}$ & Boraginaceae & $\begin{array}{c}\text { Gole } \\
\text { Gavzaban }\end{array}$ & Flower & n.r. & $\begin{array}{l}\text { Antihypertensive, Nerve Tonic, } \\
\text { Diuretic, Anti-stress, Blood } \\
\text { Cleanser Cardiac Tonic }\end{array}$ & $\begin{array}{l}\text { Mashhad city, } \\
\text { Northeastern Iran }\end{array}$ & $\begin{array}{c}{[5]} \\
\text { Amiri and Joharchi } 2013\end{array}$ \\
\hline
\end{tabular}


Table 1. Cont

\begin{tabular}{|c|c|c|c|c|c|c|c|c|}
\hline & $\begin{array}{l}\text { Scientific } \\
\text { Name }\end{array}$ & Family & $\begin{array}{l}\text { Local } \\
\text { Name }\end{array}$ & $\begin{array}{l}\text { Part } \\
\text { Used }\end{array}$ & $\begin{array}{l}\text { Type of } \\
\text { Extract }\end{array}$ & $\begin{array}{l}\text { Medicinal } \\
\text { Uses }\end{array}$ & Area & Author (s) \\
\hline 92. & $\begin{array}{c}\text { Elaeagnus } \\
\text { angustifolia } \mathrm{L} .\end{array}$ & Elaeagnaceae & Senjed & Fruit & n.r. & $\begin{array}{l}\text { Arthrodynia, Antidiarrhea, } \\
\text { Treatment of Rheumatism, } \\
\text { Female Aphrodisiac }\end{array}$ & $\begin{array}{l}\text { Mashhad city, } \\
\text { Northeastern Iran }\end{array}$ & $\begin{array}{c}{[5]} \\
\text { Amiri and Joharchi } 2013\end{array}$ \\
\hline 93. & $\begin{array}{c}\text { Ephedra major } \\
\text { Host }\end{array}$ & Ephedraceae & $\begin{array}{l}\text { Khakestar } \\
\text { Koshtar }\end{array}$ & $\begin{array}{l}\text { Aerial } \\
\text { parts }\end{array}$ & n.r. & Treatment of Joints Pain & $\begin{array}{l}\text { Mashhad city, } \\
\text { Northeastern Iran }\end{array}$ & $\begin{array}{c}{[5]} \\
\text { Amiri and Joharchi } 2013\end{array}$ \\
\hline 94. & $\begin{array}{l}\text { Equisetum } \\
\text { arvense } \mathrm{L} . \\
\text { Equisetum } \\
\text { arvense } \mathrm{L} . \\
\text { Equisetum } \\
\text { arvense } \mathrm{L} .\end{array}$ & $\begin{array}{l}\text { Equisetaceae } \\
\text { Equisetaceae } \\
\text { Equisetaceae }\end{array}$ & $\begin{array}{c}\text { Dome Asb } \\
\text { Dome Asb } \\
\text { n.r. }\end{array}$ & $\begin{array}{l}\text { Aerial } \\
\text { parts } \\
\text { Aerial } \\
\text { parts } \\
\text { Aeration } \\
\text { organ }\end{array}$ & $\begin{array}{l}\text { n.r. } \\
\text { Boiled } \\
\text { Boiled }\end{array}$ & $\begin{array}{c}\text { Obesity, Anti-lithiasis, } \\
\text { Antihypertensive, Prostate } \\
\text { Disorders, Treatment of kidney } \\
\text { Disorders } \\
\text { Hair Loss, Nails Strengthening } \\
\text { Antidiabetic }\end{array}$ & $\begin{array}{l}\text { Mashhad city, } \\
\text { Northeastern Iran } \\
\text { Khiregah-e Jangali, } \\
\text { Ghasemloo valley } \\
\text { Urmia county, } \\
\text { Northwest Iran }\end{array}$ & $\begin{array}{c}{[5]} \\
\text { Amiri and Joharchi } 2013 \\
{[9]} \\
\text { Baharvand-Ahmadi et } \\
\text { al. 2015 } \\
\text { [7] } \\
\text { Bahmani et al. } 2014\end{array}$ \\
\hline 95. & $\begin{array}{c}\text { Eremurus } \\
\text { spectabilis M. } \\
\text { Bieb. }\end{array}$ & Xanthorrhoeaceae & Serish & Root & n.r. & $\begin{array}{l}\text { Dermal Infection, Sticking, } \\
\text { Antihyperlipidemia }\end{array}$ & $\begin{array}{c}\text { Mashhad city, } \\
\text { Northeastern Iran }\end{array}$ & $\begin{array}{c}{[5]} \\
\text { Amiri and Joharchi } 2013\end{array}$ \\
\hline 96. & $\begin{array}{l}\text { Eruca sativa (L.) } \\
\text { Mill. }\end{array}$ & Brassicaceae & $\begin{array}{l}\text { Mandab } \\
\text { (Roghan } \\
\text { cheragh) }\end{array}$ & Seed & n.r. & $\begin{array}{l}\text { Sedative, Laxative Diuretic, } \\
\text { Stomach Tonic, }\end{array}$ & $\begin{array}{c}\text { Mashhad city, } \\
\text { Northeastern Iran }\end{array}$ & $\begin{array}{c}{[5]} \\
\text { Amiri and Joharchi } 2013\end{array}$ \\
\hline 97. & $\begin{array}{c}\text { Euphorbia } \\
\text { macroclada Boiss. }\end{array}$ & Euphorbiaceae & Ferfion & Leaves & Paste & Wart & $\begin{array}{l}\text { Khiregah-e Jangali, } \\
\text { Ghasemloo valley }\end{array}$ & $\begin{array}{c}{[9]} \\
\text { Baharvand-Ahmadi et } \\
\text { al. } 2015\end{array}$ \\
\hline 98. & $\begin{array}{l}\text { Falcaria vulgaris } \\
\text { Bernh. }\end{array}$ & Apiaceae & $\begin{array}{l}\text { Ghaz } \\
\text { Yaghi }\end{array}$ & $\begin{array}{l}\text { Leaves - } \\
\text { Fruit }\end{array}$ & n.r. & $\begin{array}{c}\text { Treatment of Vitiligo, Cut, } \\
\text { Wound }\end{array}$ & $\begin{array}{c}\text { Mashhad city, } \\
\text { Northeastern Iran }\end{array}$ & $\begin{array}{c}{[5]} \\
\text { Amiri and Joharchi } 2013 \\
\end{array}$ \\
\hline 99. & $\begin{array}{c}\text { Ferula assa } \\
\text { foetida } L \\
\text { Ferula foetida } \\
\text { (Bunge) Regel }\end{array}$ & $\begin{array}{l}\text { Apiaceae } \\
\text { Apiaceae }\end{array}$ & $\begin{array}{l}\text { Anghozeh } \\
\text { Anghuzeh }\end{array}$ & $\begin{array}{l}\text { Leaf } \\
\text { Gum }\end{array}$ & $\begin{array}{c}\text { Herbal } \\
\text { tea/decoction } \\
\text { n.r. }\end{array}$ & $\begin{array}{c}\text { Antiparasitic } \\
\text { Anthelmintic, Treatment of } \\
\text { Colic, Emmenagogue }\end{array}$ & $\begin{array}{c}\text { Shiraz, Fars } \\
\text { province } \\
\text { Mashhad city, } \\
\text { Northeastern Iran }\end{array}$ & $\begin{array}{l}\text { [6] Bahmani et al. } 2016 \\
\quad \text { [5] } \\
\text { Amiri and Joharchi } 2013\end{array}$ \\
\hline 100. & $\begin{array}{l}\text { Ferula gummosa } \\
\text { Boiss. }\end{array}$ & Apiaceae & Barijeh & Gum- Root & n.r. & $\begin{array}{l}\text { Anthelmintic Anticatarrhal, } \\
\text { Anti-allergic, Dyspepsia, } \\
\text { Appetizer, Emmenagogue }\end{array}$ & $\begin{array}{l}\text { Mashhad city, } \\
\text { Northeastern Iran }\end{array}$ & $\begin{array}{c}{[5]} \\
\text { Amiri and Joharchi } 2013\end{array}$ \\
\hline 101. & Ficus carica L. & Moraceae & Anjir & Fruit & n.r. & $\begin{array}{l}\text { Anti-hemorrhoids, Laxative, } \\
\text { Tonic }\end{array}$ & $\begin{array}{c}\text { Mashhad city, } \\
\text { Northeastern Iran }\end{array}$ & $\begin{array}{c}{[5]} \\
\text { Amiri and Joharchi } 2013 \\
\end{array}$ \\
\hline 102. & $\begin{array}{c}\text { Ficus johannis } \\
\text { Boiss. }\end{array}$ & Moraceae & Anjirevahshi & Fruit & $\begin{array}{l}\text { Fresh food and } \\
\text { herbal } \\
\text { tea/decoction }\end{array}$ & Antiparasitic & $\begin{array}{l}\text { Shiraz, Fars } \\
\text { province }\end{array}$ & [6] Bahmani et al. 2016 \\
\hline
\end{tabular}


Table 1. Cont

\begin{tabular}{|c|c|c|c|c|c|c|c|c|}
\hline & $\begin{array}{c}\text { Scientific } \\
\text { Name }\end{array}$ & Family & $\begin{array}{l}\text { Local } \\
\text { Name }\end{array}$ & $\begin{array}{c}\text { Part } \\
\text { Used }\end{array}$ & $\begin{array}{l}\text { Type of } \\
\text { Extract }\end{array}$ & $\begin{array}{l}\text { Medicinal } \\
\text { Uses }\end{array}$ & Area & Author (s) \\
\hline 103. & $\begin{array}{l}\text { Foeniculum } \\
\text { vulgare Mill. } \\
\text { Foeniculum } \\
\text { vulgaris }\end{array}$ & $\begin{array}{l}\text { Apiaceae } \\
\text { Apiaceae }\end{array}$ & $\begin{array}{c}\text { Razianeh } \\
\text { Raziane }\end{array}$ & $\begin{array}{l}\text { Fruit } \\
\text { Seed }\end{array}$ & $\begin{array}{c}\text { n.r. } \\
\text { Decoction }\end{array}$ & $\begin{array}{c}\text { Galactogogue, Digestive, } \\
\text { Bronchitis, Appetizer, Antacid, } \\
\text { Flatulence } \\
\text { Peptic Ulcer }\end{array}$ & $\begin{array}{l}\text { Mashhad city, } \\
\text { Northeastern Iran } \\
\text { Lorestan province }\end{array}$ & $\begin{array}{c}\text { [5] } \\
\text { Amiri and Joharchi } 2013 \\
\text { [8] Delfan et al. } 2015\end{array}$ \\
\hline 104. & $\begin{array}{l}\text { Fraxinus } \\
\text { excelsior } \mathrm{L} \text {. }\end{array}$ & Oleaceae & $\begin{array}{c}\text { Zaban } \\
\text { Gonjeshk }\end{array}$ & Fruit & n.r. & $\begin{array}{c}\text { Aphrodisiac, Treatment of } \\
\text { Stammering }\end{array}$ & $\begin{array}{l}\text { Mashhad city, } \\
\text { Northeastern Iran }\end{array}$ & $\begin{array}{c}{[5]} \\
\text { Amiri and Joharchi } 2013 \\
\end{array}$ \\
\hline 105. & $\begin{array}{c}\text { Fritillaria } \\
\text { imperialis L. }\end{array}$ & Liliaceae & $\begin{array}{c}\text { Laleh } \\
\text { Sarnegun }\end{array}$ & Root & n.r. & Treatment of Joints Pain & $\begin{array}{l}\text { Mashhad city, } \\
\text { Northeastern Iran }\end{array}$ & $\begin{array}{c}{[5]} \\
\text { Amiri and Joharchi } 2013\end{array}$ \\
\hline 106. & $\begin{array}{c}\text { Fumaria asepala } \\
\text { Boiss. }\end{array}$ & Fumariaceae & Shahtareh & $\begin{array}{c}\text { Aerial } \\
\text { parts }\end{array}$ & Boiled & $\begin{array}{c}\text { Head and Face Itching, Allergy, } \\
\text { Face Acne }\end{array}$ & $\begin{array}{l}\text { Khiregah-e Jangali, } \\
\text { Ghasemloo valley }\end{array}$ & $\begin{array}{l}{[9]} \\
\text { Baharvand-Ahmadi et } \\
\text { al. } 2015 \\
\end{array}$ \\
\hline 107. & $\begin{array}{l}\text { Fumaria vaillantii } \\
\text { Loisel. }\end{array}$ & Papaveraceae & Shatareh & $\begin{array}{c}\text { Aerial } \\
\text { parts }\end{array}$ & n.r. & $\begin{array}{c}\text { Pimples, Febrifuge, Blood } \\
\text { Cleansing, Psoriasis, Appetizer, } \\
\text { Antiacid, Jaundice }\end{array}$ & $\begin{array}{l}\text { Mashhad city, } \\
\text { Northeastern Iran }\end{array}$ & $\begin{array}{c}{[5]} \\
\text { Amiri and Joharchi } 2013\end{array}$ \\
\hline 108. & $\begin{array}{l}\text { Gentiana olivieri } \\
\text { Griseb. }\end{array}$ & Gentianaceae & Suloo & Flower & n.r. & Cardiac Ailments & $\begin{array}{l}\text { Mashhad city, } \\
\text { Northeastern Iran }\end{array}$ & $\begin{array}{c}{[5]} \\
\text { Amiri and Joharchi } 2013 \\
\end{array}$ \\
\hline 109. & $\begin{array}{l}\text { Glycyrrhiza } \\
\text { glabra L. }\end{array}$ & Fabaceae & $\begin{array}{l}\text { Shirin } \\
\text { Bayan }\end{array}$ & Root & n.r. & $\begin{array}{c}\text { Antitussive, Antacid, Tonic, } \\
\text { Gastric Ulcer, Treatment of } \\
\text { Hypotension, Treatment of } \\
\text { Anemia }\end{array}$ & $\begin{array}{l}\text { Mashhad city, } \\
\text { Northeastern Iran }\end{array}$ & $\begin{array}{c}{[5]} \\
\text { Amiri and Joharchi } 2013\end{array}$ \\
\hline 110. & $\begin{array}{c}\text { Gundelia } \\
\text { tournefortii } \mathrm{L} .\end{array}$ & Asteraceae & Kangar & $\begin{array}{c}\text { Aerial } \\
\text { parts }\end{array}$ & n.r. & $\begin{array}{c}\text { Liver Tonic, Treatment of } \\
\text { Hepatitis }\end{array}$ & $\begin{array}{l}\text { Mashhad city, } \\
\text { Northeastern Iran }\end{array}$ & $\begin{array}{c}{[5]} \\
\text { Amiri and Joharchi } 2013\end{array}$ \\
\hline 111. & Gundeliatournefortii & Asteraceae & Kanghar & Fruit & Fresh food & Antiparasitic & $\begin{array}{l}\text { Shiraz, Fars } \\
\text { province }\end{array}$ & [6] Bahmani et al. 2016 \\
\hline 112. & $\begin{array}{l}\text { Helichrysum } \\
\text { graveolens (M. } \\
\text { Bieb.) Sweet }\end{array}$ & Asteraceae & Afsantin & $\begin{array}{c}\text { Aerial } \\
\text { parts }\end{array}$ & n.r. & $\begin{array}{l}\text { Anodyne, Anthelmintic, } \\
\text { Appetizer, Nerve Tonic }\end{array}$ & $\begin{array}{l}\text { Mashhad city, } \\
\text { Northeastern Iran }\end{array}$ & $\begin{array}{c}{[5]} \\
\text { Amiri and Joharchi } 2013\end{array}$ \\
\hline 113. & $\begin{array}{l}\text { Heracleum } \\
\text { persicum } \\
\text { Heracleum } \\
\text { persicum Desf. }\end{array}$ & $\begin{array}{l}\text { Apiaceae } \\
\text { Apiaceae }\end{array}$ & $\begin{array}{l}\text { Kolpar } \\
\text { Golpar }\end{array}$ & $\begin{array}{l}\text { Leaf, } \\
\text { flower } \\
\text { Fruit }\end{array}$ & $\begin{array}{l}\text { Decoction } \\
\text { n.r. }\end{array}$ & $\begin{array}{c}\text { Stomach Ache } \\
\text { Treatment of Hiccup, } \\
\text { Appetizer, Flavoring, } \\
\text { Carminative, Anthelmintic, } \\
\text { Stomach Tonic }\end{array}$ & $\begin{array}{l}\text { Lorestan province } \\
\text { Mashhad city, } \\
\text { Northeastern Iran }\end{array}$ & $\begin{array}{c}\text { [8] Delfan et al. } 2015 \\
\text { [5] } \\
\text { Amiri and Joharchi } 2013\end{array}$ \\
\hline
\end{tabular}


Table 1. Cont.

\begin{tabular}{|c|c|c|c|c|c|c|c|c|}
\hline & $\begin{array}{l}\text { Scientific } \\
\text { Name }\end{array}$ & Family & $\begin{array}{l}\text { Local } \\
\text { Name }\end{array}$ & $\begin{array}{l}\text { Part } \\
\text { Used }\end{array}$ & $\begin{array}{l}\text { Type of } \\
\text { Extract }\end{array}$ & $\begin{array}{l}\text { Medicinal } \\
\text { Uses }\end{array}$ & Area & Author (s) \\
\hline 114. & $\begin{array}{l}\text { Hibiscus syriacus } \\
\text { L. }\end{array}$ & Malvaceae & $\begin{array}{l}\text { Gole } \\
\text { Khatmi }\end{array}$ & Flower & n.r. & Febrifuge, Antitussive & $\begin{array}{l}\text { Mashhad city, } \\
\text { Northeastern Iran }\end{array}$ & $\begin{array}{c}{[5]} \\
\text { Amiri and Joharchi } 2013\end{array}$ \\
\hline 115. & $\begin{array}{l}\text { Hibiscus trionum } \\
\text { L. }\end{array}$ & Malvaceae & $\begin{array}{l}\text { Khatmi-e } \\
\text { seh rang }\end{array}$ & Flower & $\begin{array}{l}\text { Boiled, boiled } \\
\text { and brewed for } \\
\text { washing }\end{array}$ & $\begin{array}{c}\text { Head Itching, Strengthening of } \\
\text { Hair Root }\end{array}$ & $\begin{array}{l}\text { Khiregah-e Jangali, } \\
\text { Ghasemloo valley }\end{array}$ & $\begin{array}{c}\text { [9] } \\
\text { Baharvand-Ahmadi et } \\
\text { al. } 2015\end{array}$ \\
\hline 116. & $\begin{array}{l}\text { Humulus lupulus } \\
\text { L. }\end{array}$ & Cannabinaceae & Razak & Hops & n.r. & $\begin{array}{c}\text { Diuretic, Treatment of } \\
\text { Sleeplessness, Kidney Tonic, } \\
\text { Calming, Sedative for } \\
\text { Digestion }\end{array}$ & $\begin{array}{l}\text { Mashhad city, } \\
\text { Northeastern Iran }\end{array}$ & $\begin{array}{c}{[5]} \\
\text { Amiri and Joharchi } 2013\end{array}$ \\
\hline 117. & $\begin{array}{c}\text { Hymenocrater } \\
\text { spp. }\end{array}$ & Lamiaceae & Badranjbuyeh & $\begin{array}{l}\text { Aerial } \\
\text { parts }\end{array}$ & n.r. & $\begin{array}{c}\text { Cardiac Tonic, Hypnotic, } \\
\text { Antitussive, Carminative, } \\
\text { Dyspnoea, Anti-stress } \\
\text { Convulsion }\end{array}$ & $\begin{array}{l}\text { Mashhad city, } \\
\text { Northeastern Iran }\end{array}$ & $\begin{array}{c}{[5]} \\
\text { Amiri and Joharchi } 2013\end{array}$ \\
\hline 118 & $\begin{array}{l}\text { Hyoscyamus } \\
\text { niger L. }\end{array}$ & Solanaceae & Bangdaneh & Seed & n.r. & $\begin{array}{c}\text { Sedative, Treatment of } \\
\text { Addiction, Treatment of } \\
\text { Toothache, Treatment of } \\
\text { Headache, Antigout }\end{array}$ & $\begin{array}{l}\text { Mashhad city, } \\
\text { Northeastern Iran }\end{array}$ & $\begin{array}{c}{[5]} \\
\text { Amiri and Joharchi } 2013\end{array}$ \\
\hline 119. & $\begin{array}{l}\text { Hypecum } \\
\text { pendulum }\end{array}$ & Apiaceae & Shah tare & $\begin{array}{c}\text { flowering } \\
\text { shoot }\end{array}$ & Boiled & Skin Allergy & $\begin{array}{l}\text { Khiregah-e Jangali, } \\
\text { Ghasemloo valley }\end{array}$ & $\begin{array}{c}{[9]} \\
\text { Baharvand-Ahmadi et } \\
\text { al. } 2015\end{array}$ \\
\hline 120. & $\begin{array}{l}\text { Hypericum } \\
\text { scabrum L. }\end{array}$ & Hypericaceae & Hufarighun & Flower & n.r. & $\begin{array}{c}\text { Antimigraine, Gastric Ulcer, } \\
\text { Anti hemorrhage, Urinary } \\
\text { Incontinence, Treatment of } \\
\text { Headache }\end{array}$ & $\begin{array}{l}\text { Mashhad city, } \\
\text { Northeastern Iran }\end{array}$ & $\begin{array}{c}{[5]} \\
\text { Amiri and Joharchi } 2013\end{array}$ \\
\hline 121. & $\begin{array}{l}\text { Indigofera } \\
\text { argentea Burm.f. }\end{array}$ & Fabaceae & Rang & Leaves & n.r. & $\begin{array}{c}\text { Antifungal, Hair Color, Hair } \\
\text { Tonic }\end{array}$ & $\begin{array}{l}\text { Mashhad city, } \\
\text { Northeastern Iran }\end{array}$ & $\begin{array}{c}{[5]} \\
\text { Amiri and Joharchi } 2013\end{array}$ \\
\hline 122. & Iris spuria $\mathrm{L}$. & Iridaceae & Zanbagh & Root & n.r. & Arthrodynia, Diuretic & $\begin{array}{l}\text { Mashhad city, } \\
\text { Northeastern Iran }\end{array}$ & $\begin{array}{c}{[5]} \\
\text { Amiri and Joharchi } 2013\end{array}$ \\
\hline 123. & $\begin{array}{c}\text { Ixillirion } \\
\text { tataricum (Pall.) } \\
\text { Roem et Schult }\end{array}$ & Amaryllidaceae & Khiarak & $\begin{array}{l}\text { Gland, } \\
\text { flowering } \\
\text { shoot }\end{array}$ & Paste & $\begin{array}{c}\text { Washing of Skin Abscess and } \\
\text { Disinfection of Infectious } \\
\text { Wounds }\end{array}$ & $\begin{array}{l}\text { Khiregah-e Jangali, } \\
\text { Ghasemloo valley }\end{array}$ & $\begin{array}{c}{[9]} \\
\text { Baharvand-Ahmadi et } \\
\text { al. } 2015\end{array}$ \\
\hline
\end{tabular}


Table 1. Cont

\begin{tabular}{|c|c|c|c|c|c|c|c|c|}
\hline & $\begin{array}{l}\text { Scientific } \\
\text { Name }\end{array}$ & Family & $\begin{array}{l}\text { Local } \\
\text { Name }\end{array}$ & $\begin{array}{l}\text { Part } \\
\text { Used }\end{array}$ & $\begin{array}{l}\text { Type of } \\
\text { Extract }\end{array}$ & $\begin{array}{l}\text { Medicinal } \\
\text { Uses }\end{array}$ & Area & Author (s) \\
\hline 124. & $\begin{array}{l}\text { Juglans regia } \\
\text { Juglans regia } \\
\text { Juglans regia L. }\end{array}$ & $\begin{array}{l}\text { Juglandaceae } \\
\text { Juglandaceae } \\
\text { Juglandaceae }\end{array}$ & $\begin{array}{l}\text { Gerdou } \\
\text { n.r. } \\
\text { Gerdu }\end{array}$ & $\begin{array}{l}\text { Fruit, } \\
\text { trunk } \\
\text { palm, } \\
\text { leaves } \\
\text { Fruit, leaf, } \\
\text { and skin } \\
\text { Fruit- } \\
\text { Leaves }\end{array}$ & $\begin{array}{c}\text { Boiled } \\
\text { Boiled } \\
\text { n.r. }\end{array}$ & $\begin{array}{l}\text { Anti-allergic, Hematopoietic } \\
\text { Antidiabetic } \\
\text { Eczema, Antidiarrhea, Hair } \\
\text { Color }\end{array}$ & $\begin{array}{l}\text { Khiregah-e Jangali, } \\
\text { Ghasemloo valley } \\
\text { Urmia county, } \\
\text { Northwest Iran } \\
\text { Mashhad city, } \\
\text { Northeastern Iran }\end{array}$ & $\begin{array}{c}{[9]} \\
\text { Baharvand-Ahmadi et } \\
\text { al. } 2015 \\
{[7]} \\
\text { Bahmani et al. } 2014 \\
{[5]} \\
\text { Amiri and Joharchi } 2013\end{array}$ \\
\hline 125. & $\begin{array}{l}\text { Juniperus sabina } \\
\text { L. }\end{array}$ & Cupressaceae & Abhal & Fruit & n.r. & $\begin{array}{l}\text { Diuretic, Anti-lithiasis, Food } \\
\text { Digestion, Urinary Antiseptic }\end{array}$ & $\begin{array}{c}\text { Mashhad city, } \\
\text { Northeastern Iran }\end{array}$ & $\begin{array}{c}{[5]} \\
\text { Amiri and Joharchi } 2013\end{array}$ \\
\hline 126. & Lamium album $\mathrm{L}$. & Lamiaceae & n.r. & $\begin{array}{c}\text { Flowering } \\
\text { offshoot }\end{array}$ & Boiled & Antidiabetic & $\begin{array}{l}\text { Urmia county, } \\
\text { Northwest Iran }\end{array}$ & $\begin{array}{c}\text { [7] } \\
\text { Bahmani et al. } 2014\end{array}$ \\
\hline 127. & Lactuca sativa $\mathrm{L}$. & Asteraceae & Kahu & Seed & n.r. & Anti-thirst, Hypnotic & $\begin{array}{c}\text { Mashhad city, } \\
\text { Northeastern Iran }\end{array}$ & $\begin{array}{c}{[5]} \\
\text { Amiri and Joharchi } 2013\end{array}$ \\
\hline 128. & $\begin{array}{l}\text { Lagenaria } \\
\text { vulgaris }\end{array}$ & Cucurbitaceae & Kadoo & Seed & $\begin{array}{c}\text { Herbal } \\
\text { tea/decoction }\end{array}$ & Antiparasitic & $\begin{array}{l}\text { Shiraz, Fars } \\
\text { province }\end{array}$ & [6] Bahmani et al. 2016 \\
\hline 129. & $\begin{array}{l}\text { Lallemantia } \\
\text { iberica (M.Bieb.) } \\
\text { Fisch. \& C.A. } \\
\text { Mey. }\end{array}$ & Lamiaceae & $\begin{array}{l}\text { Tokhm } \\
\text { Sharbati }\end{array}$ & Seed & n.r. & $\begin{array}{c}\text { Gastric Ulcer, Antitussive, } \\
\text { Laxative, Hoarseness, } \\
\text { Anti-thirst }\end{array}$ & $\begin{array}{l}\text { Mashhad city, } \\
\text { Northeastern Iran }\end{array}$ & $\begin{array}{c}{[5]} \\
\text { Amiri and Joharchi } 2013\end{array}$ \\
\hline 130. & Laurus nobilis L. & Lauraceae & Barg Bu & Leaves & n.r. & Carminative Appetizer, Flavor & $\begin{array}{c}\text { Mashhad city, } \\
\text { Northeastern Iran }\end{array}$ & $\begin{array}{c}{[5]} \\
\text { Amiri and Joharchi } 2013\end{array}$ \\
\hline 131. & $\begin{array}{l}\text { Lawsonia inermis } \\
\text { L. }\end{array}$ & Lythraceae & Hana & Leaves & n.r. & $\begin{array}{c}\text { Hair Color, Treatment of } \\
\text { Headache, Hair Tonic, } \\
\text { Washing, Antifungal, } \\
\text { Antiseptic }\end{array}$ & $\begin{array}{l}\text { Mashhad city, } \\
\text { Northeastern Iran }\end{array}$ & $\begin{array}{c}{[5]} \\
\text { Amiri and Joharchi } 2013\end{array}$ \\
\hline 132. & $\begin{array}{l}\text { Lepidium } \\
\text { sativum } \mathrm{L} .\end{array}$ & Brassicaceae & $\begin{array}{l}\text { Shahi } \\
\text { (Tartizak) }\end{array}$ & Seed & n.r. & $\begin{array}{l}\text { Appetizer, Anthelmintic, } \\
\text { Laxative, Sore Throat }\end{array}$ & $\begin{array}{l}\text { Mashhad city, } \\
\text { Northeastern Iran }\end{array}$ & $\begin{array}{c}{[5]} \\
\text { Amiri and Joharchi } 2013\end{array}$ \\
\hline 133. & $\begin{array}{l}\text { Levisticum } \\
\text { officinale } \\
\text { W.D.J.Koch }\end{array}$ & Apiaceae & $\begin{array}{l}\text { Angedane } \\
\text { roomi }\end{array}$ & Fruit & n.r. & $\begin{array}{l}\text { Nerve Diseases, Heart Tonic, } \\
\text { Indigestion }\end{array}$ & $\begin{array}{l}\text { Mashhad city, } \\
\text { Northeastern Iran }\end{array}$ & $\begin{array}{c}{[5]} \\
\text { Amiri and Joharchi } 2013\end{array}$ \\
\hline
\end{tabular}


Table 1. Cont

\begin{tabular}{|c|c|c|c|c|c|c|c|c|}
\hline & $\begin{array}{l}\text { Scientific } \\
\text { Name }\end{array}$ & Family & $\begin{array}{l}\text { Local } \\
\text { Name }\end{array}$ & $\begin{array}{l}\text { Part } \\
\text { Used }\end{array}$ & $\begin{array}{l}\text { Type of } \\
\text { Extract }\end{array}$ & $\begin{array}{l}\text { Medicinal } \\
\text { Uses }\end{array}$ & Area & Author (s) \\
\hline 134. & $\begin{array}{l}\text { Linum } \\
\text { usitatissimum } \mathrm{L} . \\
\text { Linum } \\
\text { usititassimum } \mathrm{L} \text {. }\end{array}$ & $\begin{array}{l}\text { Linaceae } \\
\text { Linaceae }\end{array}$ & $\begin{array}{l}\text { Katan } \\
\text { Katan }\end{array}$ & $\begin{array}{l}\text { Seed } \\
\text { Seed }\end{array}$ & $\begin{array}{c}\text { n.r. } \\
\text { Boiled }\end{array}$ & $\begin{array}{c}\text { Cholesterol-lowering, } \\
\text { Antitussive, Laxative, Obesity } \\
\text { Bedsore }\end{array}$ & $\begin{array}{l}\text { Mashhad city, } \\
\text { Northeastern Iran } \\
\text { Khiregah-e Jangali, } \\
\text { Ghasemloo valley }\end{array}$ & $\begin{array}{c}{[5]} \\
\text { Amiri and Joharchi } 2013 \\
{[9]} \\
\text { Baharvand-Ahmadi et } \\
\text { al. } 2015\end{array}$ \\
\hline 135. & $\begin{array}{l}\text { Malva neglecta } \\
\text { Wallr. }\end{array}$ & Malvaceae & $\begin{array}{l}\text { Nan } \\
\text { Kalagh }\end{array}$ & $\begin{array}{l}\text { Flower - } \\
\text { Fruit }\end{array}$ & n.r. & $\begin{array}{c}\text { Sore Throat, Antitussive, } \\
\text { Febrifuge }\end{array}$ & $\begin{array}{l}\text { Mashhad city, } \\
\text { Northeastern Iran }\end{array}$ & $\begin{array}{c}{[5]} \\
\text { Amiri and Joharchi } 2013\end{array}$ \\
\hline 136. & $\begin{array}{l}\text { Malva sylvestris } \\
\text { L. }\end{array}$ & Malvaceae & $\begin{array}{l}\text { Panirak } \\
\text { (Khatmi } \\
\text { khabbzi) }\end{array}$ & $\begin{array}{l}\text { Flower - } \\
\text { Fruit }\end{array}$ & n.r. & $\begin{array}{c}\text { Pharyngitis, Furuncles, } \\
\text { Aphthous Ulcers, Febrifuge, } \\
\text { Antitussive, Jaundice, Laxative, } \\
\text { Gastric Ulcer, Treatment of } \\
\text { Wounds }\end{array}$ & $\begin{array}{l}\text { Mashhad city, } \\
\text { Northeastern Iran }\end{array}$ & $\begin{array}{c}{[5]} \\
\text { Amiri and Joharchi } 2013\end{array}$ \\
\hline 137. & $\begin{array}{l}\text { Marrubium } \\
\text { vulgare L. }\end{array}$ & Lamiaceae & Ferasion & $\begin{array}{l}\text { Aerial } \\
\text { parts }\end{array}$ & n.r. & Liver Tonic, Antitussive & $\begin{array}{c}\text { Mashhad city, } \\
\text { Northeastern Iran }\end{array}$ & $\begin{array}{c}{[5]} \\
\text { Amiri and Joharchi } 2013\end{array}$ \\
\hline 138. & $\begin{array}{l}\text { Matricaria } \\
\text { chamomilla L. }\end{array}$ & Asteraceae & $\begin{array}{c}\text { Gole } \\
\text { babooneh }\end{array}$ & Flower & n.r. & $\begin{array}{c}\text { Eczema, Antitussive, } \\
\text { Anticatarrhal, Hair Tonic, } \\
\text { Treatment of Colic, Menstrual } \\
\text { Pains }\end{array}$ & $\begin{array}{l}\text { Mashhad city, } \\
\text { Northeastern Iran }\end{array}$ & $\begin{array}{c}{[5]} \\
\text { Amiri and Joharchi } 2013\end{array}$ \\
\hline 139. & $\begin{array}{l}\text { Matricaria } \\
\text { recutita }\end{array}$ & Asteraceae & Babooneh & $\begin{array}{l}\text { Flower, } \\
\text { leaf }\end{array}$ & $\begin{array}{c}\text { Herbal } \\
\text { tea/decoction }\end{array}$ & Antiparasitic & $\begin{array}{l}\text { Shiraz, Fars } \\
\text { province }\end{array}$ & [6] Bahmani et al. 2016 \\
\hline 140. & $\begin{array}{l}\text { Medicago sativa } \\
\text { L. }\end{array}$ & Fabaceae & Yunjeh & $\begin{array}{l}\text { Aerial } \\
\text { parts }\end{array}$ & n.r. & $\begin{array}{l}\text { Appetizer, Tonic, Osteomalacia, } \\
\text { Anti-hemorrhage }\end{array}$ & $\begin{array}{l}\text { Mashhad city, } \\
\text { Northeastern Iran }\end{array}$ & $\begin{array}{c}{[5]} \\
\text { Amiri and Joharchi } 2013\end{array}$ \\
\hline 141. & $\begin{array}{l}\text { Melissa officinalis } \\
\text { L. }\end{array}$ & Lamiaceae & Badranjbuyeh & $\begin{array}{l}\text { Aerial } \\
\text { parts }\end{array}$ & n.r. & $\begin{array}{c}\text { Nerve Tonic, Cardiac Tonic, } \\
\text { Hypnotic, Antitussive, } \\
\text { Carminative, Anti-stress, } \\
\text { Convulsion }\end{array}$ & $\begin{array}{l}\text { Mashhad city, } \\
\text { Northeastern Iran }\end{array}$ & $\begin{array}{c}{[5]} \\
\text { Amiri and Joharchi } 2013\end{array}$ \\
\hline 142. & $\begin{array}{l}\text { Mentha longifolia } \\
\text { (L.) Hudson }\end{array}$ & Lamiaceae & Puneh & $\begin{array}{l}\text { Aerial } \\
\text { parts }\end{array}$ & n.r. & $\begin{array}{c}\text { Herpes, Anthelmintic, Antacid, } \\
\text { Carminative, Antidiarrhea, } \\
\text { Digestive }\end{array}$ & $\begin{array}{l}\text { Mashhad city, } \\
\text { Northeastern Iran }\end{array}$ & $\begin{array}{c}{[5]} \\
\text { Amiri and Joharchi } 2013\end{array}$ \\
\hline 143. & Mentha spicata $\mathrm{L}$. & Lamiaceae & Naana & $\begin{array}{l}\text { Aerial } \\
\text { parts }\end{array}$ & n.r. & $\begin{array}{c}\text { Appetizer, Antacid, } \\
\text { Carminative, Antidiarrhea, } \\
\text { Digestive, Anodyne, } \\
\text { Anthelmintic }\end{array}$ & $\begin{array}{l}\text { Mashhad city, } \\
\text { Northeastern Iran }\end{array}$ & $\begin{array}{c}{[5]} \\
\text { Amiri and Joharchi } 2013\end{array}$ \\
\hline
\end{tabular}


Table 1. Cont

\begin{tabular}{|c|c|c|c|c|c|c|c|c|}
\hline & $\begin{array}{c}\text { Scientific } \\
\text { Name }\end{array}$ & Family & $\begin{array}{l}\text { Local } \\
\text { Name }\end{array}$ & $\begin{array}{c}\text { Part } \\
\text { Used }\end{array}$ & $\begin{array}{l}\text { Type of } \\
\text { Extract }\end{array}$ & $\begin{array}{c}\text { Medicinal } \\
\text { Uses }\end{array}$ & Area & Author (s) \\
\hline 144. & Morus nigra $\mathrm{L}$. & Moraceae & Shatut & Root & n.r. & Abortion & $\begin{array}{l}\text { Mashhad city, } \\
\text { Northeastern Iran }\end{array}$ & $\begin{array}{c}{[5]} \\
\text { Amiri and Joharchi } 2013\end{array}$ \\
\hline 145. & $\begin{array}{l}\text { Myrtus } \\
\text { communis L. }\end{array}$ & Myrtaceae & Murd & $\begin{array}{l}\text { Leaves - } \\
\text { Fruit }\end{array}$ & n.r. & $\begin{array}{c}\text { Psoriasis, Treatment of } \\
\text { Sinusitis, Mouth Ulcers, } \\
\text { Antifungal, Treatment of Cold, } \\
\text { Strengthening of Hair, Herpes }\end{array}$ & $\begin{array}{l}\text { Mashhad city, } \\
\text { Northeastern Iran }\end{array}$ & $\begin{array}{c}{[5]} \\
\text { Amiri and Joharchi } 2013\end{array}$ \\
\hline 146. & $\begin{array}{l}\text { Nasturtium } \\
\text { officinale R. Br. }\end{array}$ & Brassicaceae & $\begin{array}{c}\text { Alafe } \\
\text { cheshmeh }\end{array}$ & $\begin{array}{l}\text { Aerial } \\
\text { parts }\end{array}$ & n.r. & Diabetes, Dyspepsia & $\begin{array}{l}\text { Mashhad city, } \\
\text { Northeastern Iran }\end{array}$ & $\begin{array}{c}{[5]} \\
\text { Amiri and Joharchi } 2013\end{array}$ \\
\hline 147. & $\begin{array}{c}\text { Nasturtium } \\
\text { officinalis (L.) R. } \\
\text { Br. }\end{array}$ & Cruciferae & n.r. & Leaf, root & Boiled & Antidiabetic & $\begin{array}{l}\text { Urmia county, } \\
\text { Northwest Iran }\end{array}$ & $\begin{array}{c}\text { [7] } \\
\text { Bahmani et al. } 2014\end{array}$ \\
\hline 148. & $\begin{array}{l}\text { Nepeta } \\
\text { binaloudensis } \\
\text { Jamzad }\end{array}$ & Lamiaceae & Ostokhodus & $\begin{array}{l}\text { Aerial } \\
\text { parts }\end{array}$ & n.r. & $\begin{array}{c}\text { Treatment of Cold, } \\
\text { Carminative, Nerve Tonic, } \\
\text { Treatment of Sinusitis, } \\
\text { Pulmonary Infections, } \\
\text { Treatment of Rheumatism, } \\
\text { Anti-asthmatic, Antitussive, } \\
\text { Cardiac Tonic }\end{array}$ & $\begin{array}{l}\text { Mashhad city, } \\
\text { Northeastern Iran }\end{array}$ & $\begin{array}{c}{[5]} \\
\text { Amiri and Joharchi } 2013\end{array}$ \\
\hline 149. & $\begin{array}{l}\text { Nepeta bracteata } \\
\text { Benth. } \\
\text { Nepeta bracteata } \\
\text { Benth. }\end{array}$ & $\begin{array}{l}\text { Lamiaceae } \\
\text { Lamiaceae }\end{array}$ & $\begin{array}{l}\text { Zufa } \\
\text { n.r. }\end{array}$ & $\begin{array}{l}\text { Aerial } \\
\text { parts } \\
\text { Flowering } \\
\text { offshoot }\end{array}$ & $\begin{array}{c}\text { n.r. } \\
\text { Boiled, steamed }\end{array}$ & $\begin{array}{c}\text { Pulmonary Infections, } \\
\text { Anti-asthmatic, Treatment of } \\
\text { cold, Febrifuge, Treatment of } \\
\text { Colic, Antitussive } \\
\text { Antidiabetic }\end{array}$ & $\begin{array}{l}\text { Mashhad city, } \\
\text { Northeastern Iran } \\
\text { Urmia county, } \\
\text { Northwest Iran }\end{array}$ & $\begin{array}{c}{[5]} \\
\text { Amiri and Joharchi } 2013 \\
{[7]} \\
\text { Bahmani et al. } 2014\end{array}$ \\
\hline 150. & $\begin{array}{l}\text { Nepeta } \\
\text { menthoides Boiss. } \\
\text { \& Buhse }\end{array}$ & Lamiaceae & Ostokhodus & $\begin{array}{l}\text { Aerial } \\
\text { parts }\end{array}$ & n.r. & $\begin{array}{l}\text { Treatment of Cold, Nerve } \\
\text { Tonic, Expectorant }\end{array}$ & $\begin{array}{l}\text { Mashhad city, } \\
\text { Northeastern Iran }\end{array}$ & $\begin{array}{c}{[5]} \\
\text { Amiri and Joharchi } 2013\end{array}$ \\
\hline 151. & $\begin{array}{l}\text { Nepeta meyeri } \\
\text { Benth. }\end{array}$ & Lamiaceae & n.r. & $\begin{array}{c}\text { Flowering } \\
\text { offshoot }\end{array}$ & Boiled, steamed & Antidiabetic & $\begin{array}{l}\text { Urmia county, } \\
\text { Northwest Iran }\end{array}$ & $\begin{array}{c}\text { [7] } \\
\text { Bahmani et al. } 2014\end{array}$ \\
\hline 152. & $\begin{array}{l}\text { Nigella sativa } \\
\text { Nigella sativa } \mathrm{L} \text {. }\end{array}$ & $\begin{array}{l}\text { Ranunculaceae } \\
\text { Ranunculaceae }\end{array}$ & $\begin{array}{l}\text { Siah doom } \\
\text { Siah } \\
\text { Daneh }\end{array}$ & $\begin{array}{l}\text { Seed } \\
\text { Seed }\end{array}$ & $\begin{array}{c}\text { Herbal } \\
\text { tea/decoction } \\
\text { n.r. }\end{array}$ & $\begin{array}{c}\text { Antiparasitic } \\
\text { Kidney Stone, Carminative, } \\
\text { Antacid, Galactogogue, } \\
\text { Anthelmintic, Food Digestion, } \\
\text { Antitussive, Treatment of Colic }\end{array}$ & $\begin{array}{c}\text { Shiraz, Fars } \\
\text { province } \\
\text { Mashhad city, } \\
\text { Northeastern Iran }\end{array}$ & $\begin{array}{l}\text { [6] Bahmani et al. } 2016 \\
\text { [5] } \\
\text { Amiri and Joharchi } 2013\end{array}$ \\
\hline
\end{tabular}


Table 1. Cont.

\begin{tabular}{|c|c|c|c|c|c|c|c|c|}
\hline & $\begin{array}{l}\text { Scientific } \\
\text { Name }\end{array}$ & Family & $\begin{array}{l}\text { Local } \\
\text { Name }\end{array}$ & $\begin{array}{c}\text { Part } \\
\text { Used }\end{array}$ & $\begin{array}{l}\text { Type of } \\
\text { Extract }\end{array}$ & $\begin{array}{l}\text { Medicinal } \\
\text { Uses }\end{array}$ & Area & Author (s) \\
\hline 153. & Nymphaea alba L. & Nymphaeaceae & $\begin{array}{l}\text { Nilufar } \\
\text { Abi }\end{array}$ & Flower & n.r. & $\begin{array}{l}\text { Expectorant, Hypnotic, } \\
\text { Antitussive, Calmative }\end{array}$ & $\begin{array}{l}\text { Mashhad city, } \\
\text { Northeastern Iran }\end{array}$ & $\begin{array}{c}{[5]} \\
\text { Amiri and Joharchi } 2013\end{array}$ \\
\hline 154. & $\begin{array}{l}\text { Ocimum } \\
\text { basilicum L. }\end{array}$ & Lamiaceae & $\begin{array}{l}\text { Reyhan } \\
\text { (Tokhm } \\
\text { sharbati) }\end{array}$ & Seed & n.r. & $\begin{array}{c}\text { Aphthous Ulcers, Antiseptic, } \\
\text { Antidiarrhea, Antitussive, } \\
\text { Carminative, Laxative, } \\
\text { Digestive, Antacid }\end{array}$ & $\begin{array}{l}\text { Mashhad city, } \\
\text { Northeastern Iran }\end{array}$ & $\begin{array}{c}{[5]} \\
\text { Amiri and Joharchi } 2013\end{array}$ \\
\hline 155. & $\begin{array}{l}\text { Origanum } \\
\text { vulgare } \mathrm{L} \text {. }\end{array}$ & Lamiaceae & Marzanjush & $\begin{array}{l}\text { Aerial } \\
\text { parts }\end{array}$ & n.r. & $\begin{array}{c}\text { Treatment of Colic, Treatment } \\
\text { of Sinusitis, Sedative, Cardiac } \\
\text { Tonic, Nerve Tonic, Treatment } \\
\text { of Dyspnoea }\end{array}$ & $\begin{array}{l}\text { Mashhad city, } \\
\text { Northeastern Iran }\end{array}$ & $\begin{array}{c}\text { [5] } \\
\text { Amiri and Joharchi } 2013\end{array}$ \\
\hline 156. & Oryza sativa L. & Poaceae & $\begin{array}{l}\text { Chaltooke } \\
\text { Berenj }\end{array}$ & Seed coat & n.r. & $\begin{array}{c}\text { Hair Tonic, Treatment of } \\
\text { Anemia }\end{array}$ & $\begin{array}{l}\text { Mashhad city, } \\
\text { Northeastern Iran }\end{array}$ & $\begin{array}{c}{[5]} \\
\text { Amiri and Joharchi } 2013\end{array}$ \\
\hline 157. & $\begin{array}{l}\text { Papaver rhoeas } \mathrm{L} . \\
\text { Papaver rhoeas } \mathrm{L} .\end{array}$ & $\begin{array}{l}\text { Papaveraceae } \\
\text { Papaveraceae }\end{array}$ & $\begin{array}{l}\text { Shaghayegh } \\
\text { n.r. }\end{array}$ & $\begin{array}{c}\text { Flower } \\
\text { Seed, } \\
\text { capsule }\end{array}$ & $\begin{array}{c}\text { n.r. } \\
\text { Boiled }\end{array}$ & $\begin{array}{c}\text { Treatment of Addiction, } \\
\text { Calmative, Sleeplessness, } \\
\text { Sedative, Expectorant, } \\
\text { Antitussive, Anti-asthmatic } \\
\text { Antidiabetic }\end{array}$ & $\begin{array}{l}\text { Mashhad city, } \\
\text { Northeastern Iran } \\
\text { Urmia county, } \\
\text { Northwest Iran }\end{array}$ & $\begin{array}{c}{[5]} \\
\text { Amiri and Joharchi } 2013 \\
\text { [7] } \\
\text { Bahmani et al. } 2014\end{array}$ \\
\hline 158. & $\begin{array}{c}\text { Papaver } \\
\text { somniferum } \mathrm{L} .\end{array}$ & Papaveraceae & Khashkhash & Fruit- Seed & n.r. & $\begin{array}{c}\text { Anodyne, Laxative, Tonic, } \\
\text { Hypnotic }\end{array}$ & $\begin{array}{l}\text { Mashhad city, } \\
\text { Northeastern Iran }\end{array}$ & $\begin{array}{c}{[5]} \\
\text { Amiri and Joharchi } 2013 \\
\end{array}$ \\
\hline 159. & $\begin{array}{l}\text { Peganum harmala } \\
\text { L. }\end{array}$ & Nitrariaceae & Espand & Seed & n.r. & $\begin{array}{l}\text { Diabetes, Antiseptic, Hypnotic, } \\
\text { Treatment of Rheumatism and } \\
\text { Sciatica Disorders, } \\
\text { Anthelmintic, Emmenagogue }\end{array}$ & $\begin{array}{l}\text { Mashhad city, } \\
\text { Northeastern Iran }\end{array}$ & $\begin{array}{c}\text { [5] } \\
\text { Amiri and Joharchi } 2013\end{array}$ \\
\hline 160. & $\begin{array}{c}\text { Perouskia } \\
\text { abrotanoides Kar. }\end{array}$ & Lamiaceae & Gol Kabud & $\begin{array}{l}\text { Aerial } \\
\text { parts }\end{array}$ & n.r. & $\begin{array}{l}\text { Treatment of Sinusitis, } \\
\text { Treatment of Toothache, } \\
\text { Antitussive, Nerve Tonic, } \\
\text { Carminative, Sedative, } \\
\text { Antiseptic, Anthelmintic, } \\
\text { Treatment of Colic }\end{array}$ & $\begin{array}{l}\text { Mashhad city, } \\
\text { Northeastern Iran }\end{array}$ & $\begin{array}{c}{[5]} \\
\text { Amiri and Joharchi } 2013\end{array}$ \\
\hline 161. & $\begin{array}{c}\text { Petroselinum } \\
\text { crispum (Mill.) } \\
\text { Nyman ex A. W. } \\
\text { Hill }\end{array}$ & Apiaceae & Jafari & Fruit & n.r. & $\begin{array}{c}\text { Emmenagogue, Diuretic, } \\
\text { Carminative, Kidney Disorders }\end{array}$ & $\begin{array}{l}\text { Mashhad city, } \\
\text { Northeastern Iran }\end{array}$ & $\begin{array}{c}{[5]} \\
\text { Amiri and Joharchi } 2013\end{array}$ \\
\hline
\end{tabular}


Table 1. Cont

\begin{tabular}{|c|c|c|c|c|c|c|c|c|}
\hline & $\begin{array}{l}\text { Scientific } \\
\text { Name }\end{array}$ & Family & $\begin{array}{l}\text { Local } \\
\text { Name }\end{array}$ & $\begin{array}{c}\text { Part } \\
\text { Used }\end{array}$ & $\begin{array}{l}\text { Type of } \\
\text { Extract }\end{array}$ & $\begin{array}{l}\text { Medicinal } \\
\text { Uses }\end{array}$ & Area & Author (s) \\
\hline 162. & $\begin{array}{c}\text { Phleum pratense } \\
\text { L. }\end{array}$ & Poaceae & Kalake-gorbe & Branch & Brew & Stomach Ache & Lorestan province & [8] Delfan et al. 2015 \\
\hline 163. & $\begin{array}{c}\text { Physalis alkekengi } \\
\text { L. }\end{array}$ & Solanaceae & $\begin{array}{c}\text { Arusak } \\
\text { Posht } \\
\text { Pardeh }\end{array}$ & Fruit & n.r. & $\begin{array}{c}\text { Emmenagogue, Treatment of } \\
\text { Kidney Stones, Blood } \\
\text { Cleansing }\end{array}$ & $\begin{array}{l}\text { Mashhad city, } \\
\text { Northeastern Iran }\end{array}$ & $\begin{array}{c}\text { [5] } \\
\text { Amiri and Joharchi } 2013\end{array}$ \\
\hline 164. & $\begin{array}{l}\text { Pimpinella } \\
\text { anisum L. }\end{array}$ & Apiaceae & $\begin{array}{l}\text { Anison } \\
\text { (Badian } \\
\text { roomi) }\end{array}$ & Fruit & n.r. & $\begin{array}{c}\text { Treatment of Flatulence, } \\
\text { Anthelmintic, Treatment of } \\
\text { Colic, Antacid, Stomach Ache, } \\
\text { Antidiarrhea }\end{array}$ & $\begin{array}{l}\text { Mashhad city, } \\
\text { Northeastern Iran }\end{array}$ & $\begin{array}{c}{[5]} \\
\text { Amiri and Joharchi } 2013\end{array}$ \\
\hline 165. & $\begin{array}{l}\text { Pistacia atlantica } \\
\text { Desf. ssp. } \\
\text { kurdica }\end{array}$ & Anacardiaceae & Saghez & Oleore sin & n.r. & Appetizer, Digestive, Antacid & $\begin{array}{l}\text { Mashhad city, } \\
\text { Northeastern Iran }\end{array}$ & $\begin{array}{c}{[5]} \\
\text { Amiri and Joharchi } 2013\end{array}$ \\
\hline 166. & $\begin{array}{l}\text { Pistacia atlantica } \\
\text { Desf. ssp mutica }\end{array}$ & Anacardiaceae & Baneh & Fruit & n.r. & $\begin{array}{l}\text { Laxative, Tonic Stimulant, } \\
\text { Treatment of Anemia }\end{array}$ & $\begin{array}{l}\text { Mashhad city, } \\
\text { Northeastern Iran }\end{array}$ & $\begin{array}{c}{[5]} \\
\text { Amiri and Joharchi } 2013\end{array}$ \\
\hline 167. & Plantago major $\mathrm{L}$. & Plantaginaceae & Barhang & $\begin{array}{l}\text { Seed- } \\
\text { Leaves }\end{array}$ & n.r. & $\begin{array}{c}\text { Eczema, Anti-allergic, } \\
\text { Febrifuge, Jaundice, } \\
\text { Antitussive, Antidiarrhea, } \\
\text { Toothache, Depurative, Gastric } \\
\text { Ulcer }\end{array}$ & $\begin{array}{l}\text { Mashhad city, } \\
\text { Northeastern Iran }\end{array}$ & $\begin{array}{c}{[5]} \\
\text { Amiri and Joharchi } 2013\end{array}$ \\
\hline 168. & $\begin{array}{l}\text { Plantago ovata } \\
\text { Forssk. }\end{array}$ & Plantaginaceae & Esfarzeh & Seed & n.r. & $\begin{array}{l}\text { Obesity, Depilator, Tonsillitis, } \\
\text { Antacid, Antitussive, Gastric } \\
\text { Ulcer, Febrifuge, Laxative, } \\
\text { Jaundice, Anti-hemorrhoids }\end{array}$ & $\begin{array}{l}\text { Mashhad city, } \\
\text { Northeastern Iran }\end{array}$ & $\begin{array}{c}{[5]} \\
\text { Amiri and Joharchi } 2013\end{array}$ \\
\hline 169. & $\begin{array}{l}\text { Platanus } \\
\text { orientalis L. }\end{array}$ & Platanaceae & Chenar & Fruit & n.r. & Prostate Diseases & $\begin{array}{l}\text { Mashhad city, } \\
\text { Northeastern Iran }\end{array}$ & $\begin{array}{c}{[5]} \\
\text { Amiri and Joharchi } 2013 \\
\end{array}$ \\
\hline 170. & $\begin{array}{c}\text { Polygonatum } \\
\text { orientale Desf. }\end{array}$ & Asparagaceae & Shaghaghol & Root & n.r. & $\begin{array}{c}\text { Tonic, Diuretic, Nerve Tonic, } \\
\text { Aphrodisiac }\end{array}$ & $\begin{array}{c}\text { Mashhad city, } \\
\text { Northeastern Iran }\end{array}$ & $\begin{array}{c}{[5]} \\
\text { Amiri and Joharchi } 2013 \\
\end{array}$ \\
\hline 171. & $\begin{array}{l}\text { Polygonum } \\
\text { aviculare } \mathrm{L} . \\
\text { Polygonum } \\
\text { aviculare } \mathrm{L} .\end{array}$ & $\begin{array}{l}\text { Polygonaceae } \\
\text { Polygonaceae }\end{array}$ & $\begin{array}{l}\text { Alaf } \\
\text { Haftband } \\
\text { n.r. }\end{array}$ & $\begin{array}{l}\text { Aerial } \\
\text { parts } \\
\text { Aeration } \\
\text { organ }\end{array}$ & $\begin{array}{c}\text { n.r. } \\
\text { Boiled }\end{array}$ & $\begin{array}{c}\text { Diabetes, Treatment of Colic, } \\
\text { Antidiarrhea } \\
\text { Antidiabetic }\end{array}$ & $\begin{array}{l}\text { Mashhad city, } \\
\text { Northeastern Iran } \\
\text { Urmia county, } \\
\text { Northwest Iran }\end{array}$ & $\begin{array}{c}{[5]} \\
\text { Amiri and Joharchi } 2013 \\
{[7]} \\
\text { Bahmani et al. } 2014 \\
\end{array}$ \\
\hline 172. & $\begin{array}{l}\text { Polypodium } \\
\text { vulgare } \mathrm{L} .\end{array}$ & Polypodiaceae & Baspayak & Root & n.r. & $\begin{array}{c}\text { Expectorant, Jaundice, } \\
\text { Digestive }\end{array}$ & $\begin{array}{l}\text { Mashhad city, } \\
\text { Northeastern Iran }\end{array}$ & $\begin{array}{c}{[5]} \\
\text { Amiri and Joharchi } 2013\end{array}$ \\
\hline
\end{tabular}


Table 1. Cont.

\begin{tabular}{|c|c|c|c|c|c|c|c|c|}
\hline & $\begin{array}{l}\text { Scientific } \\
\text { Name }\end{array}$ & Family & $\begin{array}{l}\text { Local } \\
\text { Name }\end{array}$ & $\begin{array}{l}\text { Part } \\
\text { Used }\end{array}$ & $\begin{array}{l}\text { Type of } \\
\text { Extract }\end{array}$ & $\begin{array}{l}\text { Medicinal } \\
\text { Uses }\end{array}$ & Area & Author (s) \\
\hline 173. & $\begin{array}{c}\text { Portulaca oleracea } \\
\text { L. }\end{array}$ & Portulacaceae & Khorfeh & $\begin{array}{l}\text { Seed- } \\
\text { Leaves }\end{array}$ & n.r. & $\begin{array}{c}\text { Antitussive, Febrifuge, } \\
\text { Anti-thirst, Food Digestion, } \\
\text { Depurative, Diuretic, } \\
\text { Anti-hemorrhoids }\end{array}$ & $\begin{array}{l}\text { Mashhad city, } \\
\text { Northeastern Iran }\end{array}$ & $\begin{array}{c}{[5]} \\
\text { Amiri and Joharchi } 2013\end{array}$ \\
\hline 174. & $\begin{array}{l}\text { Punica granatum } \\
\text { Punica granatum } \\
\text { L. }\end{array}$ & $\begin{array}{l}\text { Punicaceae } \\
\text { Punicaceae }\end{array}$ & $\begin{array}{l}\text { Anar-doun } \\
\text { Gole Anar }\end{array}$ & $\begin{array}{c}\text { Seed } \\
\text { Flower-Root }\end{array}$ & $\begin{array}{c}\text { Pomegranate } \\
\text { fruits cooked } \\
\text { under hot wood } \\
\text { ashes and eat } \\
\text { n.r. }\end{array}$ & $\begin{array}{c}\text { Peptic Ulcer } \\
\text { Anti-hemorrhage, Blood Flux, } \\
\text { Anthelmintic }\end{array}$ & $\begin{array}{l}\text { Lorestan province } \\
\text { Mashhad city, } \\
\text { Northeastern Iran }\end{array}$ & $\begin{array}{c}\text { [8] Delfan et al. } 2015 \\
\text { [5] } \\
\text { Amiri and Joharchi } 2013\end{array}$ \\
\hline 175. & Quercus branti & Fagaceae & Bali & $\begin{array}{l}\text { Pith leaf } \\
\text { peel }\end{array}$ & $\begin{array}{l}\text { Oak fruit } \\
\text { crushed and } \\
\text { mixed with } \\
\text { yogurt and eat }\end{array}$ & Stomach Ache & Lorestan province & [8] Delfan et al. 2015 \\
\hline 176. & $\begin{array}{c}\text { Quercus } \\
\text { infectoria Oliv. }\end{array}$ & Fagaceae & $\begin{array}{l}\text { Mazuye } \\
\text { sabz }\end{array}$ & Insect gull & n.r. & $\begin{array}{l}\text { Nosebleed, Anti-hemorrhage, } \\
\text { Uterus Ailments, Mouth } \\
\text { Wounds, Anti-hemorrhoids }\end{array}$ & $\begin{array}{l}\text { Mashhad city, } \\
\text { Northeastern Iran }\end{array}$ & $\begin{array}{c}{[5]} \\
\text { Amiri and Joharchi } 2013\end{array}$ \\
\hline 177. & Quercus spp. & Fagaceae & $\begin{array}{c}\text { Balut } \\
(\mathrm{Mazu})\end{array}$ & Fruit & n.r. & Antidiarrhea, Anti-hemorrhage & $\begin{array}{c}\text { Mashhad city, } \\
\text { Northeastern Iran }\end{array}$ & $\begin{array}{c}{[5]} \\
\text { Amiri and Joharchi } 2013 \\
\end{array}$ \\
\hline 178. & Rheum ribes $\mathrm{L}$. & Polygonaceae & Rivas & $\begin{array}{l}\text { Fruit- } \\
\text { Petiole }\end{array}$ & n.r. & $\begin{array}{l}\text { Jaundice, Urinary Antiseptic, } \\
\text { Diuretic, Depurative, Liver } \\
\text { Tonic, Antiseptic, Hair Tonic }\end{array}$ & $\begin{array}{c}\text { Mashhad city, } \\
\text { Northeastern Iran }\end{array}$ & $\begin{array}{c}{[5]} \\
\text { Amiri and Joharchi } 2013\end{array}$ \\
\hline 179. & $\begin{array}{l}\text { Rheum } \\
\text { turkestanicum } \\
\text { Janisch. }\end{array}$ & Polygonaceae & Eshghan & Root & n.r. & $\begin{array}{l}\text { Diabetes, Antihypertensive, } \\
\text { Anticancer, Depurative }\end{array}$ & $\begin{array}{l}\text { Mashhad city, } \\
\text { Northeastern Iran }\end{array}$ & $\begin{array}{c}{[5]} \\
\text { Amiri and Joharchi } 2013\end{array}$ \\
\hline 180. & $\begin{array}{l}\text { Rhus coriaria } \mathrm{L} \text {. } \\
\text { Rhus coriaria } \mathrm{L} \text {. }\end{array}$ & $\begin{array}{l}\text { Anacardiaceae } \\
\text { Anacardiaceae }\end{array}$ & $\begin{array}{l}\text { Somagh } \\
\text { n.r. }\end{array}$ & $\begin{array}{l}\text { Fruit } \\
\text { Fruit, leaf, } \\
\text { resin }\end{array}$ & $\begin{array}{c}\text { n.r. } \\
\text { Boiled }\end{array}$ & $\begin{array}{c}\text { Jaundice, Cholesterol-lowering, } \\
\text { Diabetes, Antihypertensive, } \\
\text { Antidiarrhea, } \\
\text { Anti-hemorrhage, Flavoring, } \\
\text { Blood Refining }\end{array}$ & $\begin{array}{l}\text { Mashhad city, } \\
\text { Northeastern Iran } \\
\text { Urmia county, } \\
\text { Northwest Iran }\end{array}$ & $\begin{array}{c}{[5]} \\
\text { Amiri and Joharchi } 2013 \\
{[7]} \\
\text { Bahmani et al. } 2014\end{array}$ \\
\hline 181. & $\begin{array}{c}\text { Ribes } \\
\text { khorasanicum } \\
\text { Saghafi \& } \\
\text { Assadi }\end{array}$ & Grossulariaceae & $\begin{array}{l}\text { Ghareh } \\
\text { Ghat }\end{array}$ & Fruit & n.r. & $\begin{array}{l}\text { Antihypertensive, Diabetes, } \\
\text { Depurative }\end{array}$ & $\begin{array}{l}\text { Mashhad city, } \\
\text { Northeastern Iran }\end{array}$ & $\begin{array}{c}{[5]} \\
\text { Amiri and Joharchi } 2013\end{array}$ \\
\hline 182. & $\begin{array}{l}\text { Ricinus } \\
\text { communis L. }\end{array}$ & Euphorbiaceae & Karchak & Seed & n.r. & Purgative & $\begin{array}{l}\text { Mashhad city, } \\
\text { Northeastern Iran }\end{array}$ & $\begin{array}{c}{[5]} \\
\text { Amiri and Joharchi } 2013\end{array}$ \\
\hline
\end{tabular}


Table 1. Cont.

\begin{tabular}{|c|c|c|c|c|c|c|c|c|}
\hline & $\begin{array}{l}\text { Scientific } \\
\text { Name }\end{array}$ & Family & $\begin{array}{l}\text { Local } \\
\text { Name }\end{array}$ & $\begin{array}{l}\text { Part } \\
\text { Used }\end{array}$ & $\begin{array}{l}\text { Type of } \\
\text { Extract }\end{array}$ & $\begin{array}{l}\text { Medicinal } \\
\text { Uses }\end{array}$ & Area & Author (s) \\
\hline 183. & $\begin{array}{l}\text { Rosa beggeriana } \\
\text { Schrenk }\end{array}$ & Rosaceae & Nastaran & Fruit & n.r. & $\begin{array}{l}\text { Antihypertensive, Diuretic, } \\
\text { Kidney Stone }\end{array}$ & $\begin{array}{l}\text { Mashhad city, } \\
\text { Northeastern Iran }\end{array}$ & $\begin{array}{c}{[5]} \\
\text { Amiri and Joharchi } 2013\end{array}$ \\
\hline 184. & $\begin{array}{l}\text { Rosa damascena } \\
\text { Mill. }\end{array}$ & Rosaceae & $\begin{array}{c}\text { Gole } \\
\text { Mohammadi }\end{array}$ & Flower & n.r. & $\begin{array}{c}\text { Anti-hemorrhoid, Laxative, } \\
\text { Calmative }\end{array}$ & $\begin{array}{l}\text { Mashhad city, } \\
\text { Northeastern Iran }\end{array}$ & $\begin{array}{c}\text { [5] } \\
\text { Amiri and Joharchi } 2013\end{array}$ \\
\hline 185. & $\begin{array}{l}\text { Rosa foetida } \\
\text { Hermam. } \\
\text { Rosa foetida } \\
\text { Herrm. }\end{array}$ & $\begin{array}{l}\text { Rosaceae } \\
\text { Rosaceae }\end{array}$ & $\begin{array}{c}\text { n.r. } \\
\text { Gole Zard }\end{array}$ & $\begin{array}{l}\text { Petal } \\
\text { Flower }\end{array}$ & $\begin{array}{l}\text { Boiled } \\
\text { n.r. }\end{array}$ & $\begin{array}{c}\text { Antidiabetic } \\
\text { Ovary Tonic, Emmenagogue }\end{array}$ & $\begin{array}{c}\text { Urmia county, } \\
\text { Northwest Iran } \\
\text { Mashhad city, } \\
\text { Northeastern Iran }\end{array}$ & $\begin{array}{c}\text { [7] } \\
\text { Bahmani et al. } 2014 \\
{[5]} \\
\text { Amiri and Joharchi } 2013\end{array}$ \\
\hline 186. & $\begin{array}{l}\text { Rubia tinctorum } \\
\text { L. } \\
\text { Rubia tinctorum } \\
\text { L. }\end{array}$ & $\begin{array}{l}\text { Rubiaceae } \\
\text { Rubiaceae }\end{array}$ & $\begin{array}{l}\text { Ronas } \\
\text { Ronnas }\end{array}$ & $\begin{array}{c}\text { Root } \\
\text { Root, fruit }\end{array}$ & $\begin{array}{l}\text { n.r. } \\
\text { Boiled }\end{array}$ & $\begin{array}{l}\text { Strengthening of Hair, Hair } \\
\text { Color } \\
\text { Hair Loss, Hair Coloring }\end{array}$ & $\begin{array}{l}\text { Mashhad city, } \\
\text { Northeastern Iran } \\
\text { Khiregah-e Jangali, } \\
\text { Ghasemloo valley }\end{array}$ & $\begin{array}{c}{[5]} \\
\text { Amiri and Joharchi } 2013 \\
{[9]} \\
\text { Baharvand-Ahmadi et } \\
\text { al. } 2015\end{array}$ \\
\hline 187. & $\begin{array}{l}\text { Rumex acetosella } \\
\text { L. }\end{array}$ & Polygonaceae & $\begin{array}{l}\text { Sagh } \\
\text { Torshak }\end{array}$ & Root & n.r. & Jaundice, Febrifuge & $\begin{array}{l}\text { Mashhad city, } \\
\text { Northeastern Iran }\end{array}$ & $\begin{array}{c}{[5]} \\
\text { Amiri and Joharchi } 2013\end{array}$ \\
\hline 188. & $\begin{array}{l}\text { Rumex sculantus } \\
\text { L. }\end{array}$ & Polygonaceae & n.r. & Fruit, leaf & Raw use, boiled & Blood Refining & $\begin{array}{l}\text { Urmia county, } \\
\text { Northwest Iran }\end{array}$ & $\begin{array}{c}\text { [7] } \\
\text { Bahmani et al. } 2014\end{array}$ \\
\hline 189. & $\begin{array}{l}\text { Ruta graveolens } \\
\text { L. }\end{array}$ & Rutaceae & Sodab & $\begin{array}{l}\text { Aerial } \\
\text { parts }\end{array}$ & n.r. & $\begin{array}{l}\text { Abortion, Sedative, } \\
\text { Emmenagogue }\end{array}$ & $\begin{array}{c}\text { Mashhad city, } \\
\text { Northeastern Iran }\end{array}$ & $\begin{array}{c}{[5]} \\
\text { Amiri and Joharchi } 2013\end{array}$ \\
\hline 190. & $\begin{array}{l}\text { Salix aegyptiaca } \\
\text { L. }\end{array}$ & Salicaceae & Bidmeshk & Flower & n.r. & $\begin{array}{l}\text { Calmative, Cardiac Tonic, } \\
\text { Painful Menstruation }\end{array}$ & $\begin{array}{l}\text { Mashhad city, } \\
\text { Northeastern Iran }\end{array}$ & $\begin{array}{c}\text { [5] } \\
\text { Amiri and Joharchi } 2013\end{array}$ \\
\hline 191. & Salix alba $\mathrm{L}$. & Salicaceae & Bid & Leaves-Bark & n.r. & $\begin{array}{l}\text { Menstrual Pains, Anodyne, } \\
\text { Jaundice, Antitussive }\end{array}$ & $\begin{array}{l}\text { Mashhad city, } \\
\text { Northeastern Iran }\end{array}$ & $\begin{array}{c}{[5]} \\
\text { Amiri and Joharchi } 2013\end{array}$ \\
\hline 192. & $\begin{array}{l}\text { Salix excelsa J.F. } \\
\text { Gmel. }\end{array}$ & Salicaceae & Bidkhesht & Manna & n.r. & Febrifuge, Jaundice, Laxative & $\begin{array}{l}\text { Mashhad city, } \\
\text { Northeastern Iran }\end{array}$ & $\begin{array}{c}\text { [5] } \\
\text { Amiri and Joharchi } 2013\end{array}$ \\
\hline 193. & $\begin{array}{l}\text { Salvia leriifolia } \\
\text { Benth. }\end{array}$ & Lamiaceae & Noruzak & $\begin{array}{l}\text { Aerial } \\
\text { parts }\end{array}$ & n.r. & Diabetes, Period Regulator & $\begin{array}{c}\text { Mashhad city, } \\
\text { Northeastern Iran }\end{array}$ & $\begin{array}{c}{[5]} \\
\text { Amiri and Joharchi } 2013\end{array}$ \\
\hline 194. & $\begin{array}{l}\text { Salvia } \\
\text { macrosiphon } \\
\text { Boiss. }\end{array}$ & Lamiaceae & Kenocheh & Seed & n.r. & $\begin{array}{l}\text { Jaundice, Antitussive, } \\
\text { Febrifuge, Gastric Ulcer, } \\
\text { Pharyngitis, Laxative }\end{array}$ & $\begin{array}{l}\text { Mashhad city, } \\
\text { Northeastern Iran }\end{array}$ & $\begin{array}{c}{[5]} \\
\text { Amiri and Joharchi } 2013\end{array}$ \\
\hline 195. & $\begin{array}{c}\text { Salvia nemorosa } \\
\text { L. }\end{array}$ & Lamiaceae & n.r. & $\begin{array}{c}\text { Flowering } \\
\text { offshoot }\end{array}$ & Boiled & Antidiabetic & $\begin{array}{l}\text { Urmia county, } \\
\text { Northwest Iran }\end{array}$ & $\begin{array}{c}\text { [7] } \\
\text { Bahmani et al. } 2014\end{array}$ \\
\hline
\end{tabular}


Table 1. Cont

\begin{tabular}{|c|c|c|c|c|c|c|c|c|}
\hline & $\begin{array}{c}\text { Scientific } \\
\text { Name }\end{array}$ & Family & $\begin{array}{l}\text { Local } \\
\text { Name }\end{array}$ & $\begin{array}{c}\text { Part } \\
\text { Used }\end{array}$ & $\begin{array}{l}\text { Type of } \\
\text { Extract }\end{array}$ & $\begin{array}{l}\text { Medicinal } \\
\text { Uses }\end{array}$ & Area & Author (s) \\
\hline 196. & $\begin{array}{l}\text { Sanguisorba } \\
\text { minor Scop. } \\
\text { Sanguisorba } \\
\text { minor Scop. }\end{array}$ & $\begin{array}{l}\text { Rosaceae } \\
\text { Rosaceae }\end{array}$ & $\begin{array}{l}\text { Tout-e } \\
\text { roubahi } \\
\text { n.r. }\end{array}$ & $\begin{array}{c}\text { Fruit } \\
\text { Fruit, leaf }\end{array}$ & $\begin{array}{l}\text { Boiled and } \\
\text { edible raw } \\
\text { Raw use, boiled }\end{array}$ & $\begin{array}{c}\text { Skin Wounds Disinfection } \\
\text { Antidiabetic }\end{array}$ & $\begin{array}{l}\text { Khiregah-e Jangali, } \\
\text { Ghasemloo valley } \\
\text { Urmia county, } \\
\text { Northwest Iran }\end{array}$ & $\begin{array}{c}\text { [9] } \\
\text { Baharvand-Ahmadi et } \\
\text { al. 2015 } \\
\text { [7] } \\
\text { Bahmani et al. } 2014 \\
\end{array}$ \\
\hline 197. & $\begin{array}{l}\text { Satureja hortensis } \\
\text { L. }\end{array}$ & Lamiaceae & Marzeh & $\begin{array}{l}\text { Aerial } \\
\text { parts }\end{array}$ & n.r. & $\begin{array}{l}\text { Indigestion, Anthelmintic, } \\
\text { Appetizer, Antacid, } \\
\text { Antidiarrhea }\end{array}$ & $\begin{array}{l}\text { Mashhad city, } \\
\text { Northeastern Iran }\end{array}$ & $\begin{array}{c}{[5]} \\
\text { Amiri and Joharchi } 2013\end{array}$ \\
\hline 198. & $\begin{array}{c}\text { Satureja } \\
\text { khozistanica }\end{array}$ & Lamiaceae & Jataneh & Branch & $\begin{array}{c}\text { Dried leaves } \\
\text { poured on food }\end{array}$ & Stomach Ache & Lorestan province & [8] Delfan et al. 2015 \\
\hline 199. & $\begin{array}{l}\text { Scrophularia } \\
\text { striata Boiss. }\end{array}$ & Scrophulariaceae & Mokhallaseh & $\begin{array}{c}\text { Aerial } \\
\text { parts }\end{array}$ & n.r. & $\begin{array}{c}\text { Kidney Troubles, Antidiarrhea, } \\
\text { Treatment of Colic, } \\
\text { Carminative, Treatment of } \\
\text { Joints Pain }\end{array}$ & $\begin{array}{l}\text { Mashhad city, } \\
\text { Northeastern Iran }\end{array}$ & $\begin{array}{c}{[5]} \\
\text { Amiri and Joharchi } 2013\end{array}$ \\
\hline 200. & $\begin{array}{c}\text { Securigera } \\
\text { securidaca }(\text { L.) } \\
\text { Degen \& Dorfl. }\end{array}$ & Fabaceae & $\begin{array}{l}\text { Gandeh } \\
\text { Talkheh }\end{array}$ & Seed & n.r. & Diabetes, Antihyperlipidemia & $\begin{array}{l}\text { Mashhad city, } \\
\text { Northeastern Iran }\end{array}$ & $\begin{array}{c}{[5]} \\
\text { Amiri and Joharchi } 2013\end{array}$ \\
\hline 201. & $\begin{array}{l}\text { Sesamum } \\
\text { indicum } \mathrm{L} \text {. }\end{array}$ & Pedaliaceae & Konjed & Seed & n.r. & $\begin{array}{l}\text { Blood Tonic, Hair Loss, } \\
\text { Strengthening of Memory, } \\
\text { Increase Sperm Count, } \\
\text { Treatment of Skin's Split, } \\
\text { Laxative }\end{array}$ & $\begin{array}{l}\text { Mashhad city, } \\
\text { Northeastern Iran }\end{array}$ & $\begin{array}{c}{[5]} \\
\text { Amiri and Joharchi } 2013\end{array}$ \\
\hline 202. & $\begin{array}{l}\text { Silybum } \\
\text { marianum (L.) } \\
\text { Gaertn. }\end{array}$ & Asteraceae & $\begin{array}{l}\text { Khare } \\
\text { Maryam }\end{array}$ & Seed & n.r. & $\begin{array}{c}\text { Jaundice, Febrifuge, } \\
\text { Antihepatitis, Liver Tonic }\end{array}$ & $\begin{array}{l}\text { Mashhad city, } \\
\text { Northeastern Iran }\end{array}$ & $\begin{array}{c}{[5]} \\
\text { Amiri and Joharchi } 2013\end{array}$ \\
\hline 203. & $\begin{array}{c}\text { Solanum } \\
\text { americanum Mill. }\end{array}$ & Solanaceae & Tajrizi & Fruit & n.r. & $\begin{array}{c}\text { Treatment of Osteoarthritis, } \\
\text { Mastitis, Expectorant, } \\
\text { Hypnotic, Sedative, Treatment } \\
\text { of Gastritis }\end{array}$ & $\begin{array}{l}\text { Mashhad city, } \\
\text { Northeastern Iran }\end{array}$ & $\begin{array}{c}{[5]} \\
\text { Amiri and Joharchi } 2013\end{array}$ \\
\hline 204. & $\begin{array}{c}\text { Sophora } \\
\text { alopecuroides }\end{array}$ & Fabaceae & n.r. & Inflorescence & Boiled & Antidiabetic & $\begin{array}{l}\text { Urmia county, } \\
\text { Northwest Iran }\end{array}$ & $\begin{array}{c}\text { [7] } \\
\text { Bahmani et al. } 2014\end{array}$ \\
\hline 205. & $\begin{array}{c}\text { Stachys } \\
\text { lavandulifolia } \\
\text { Vahl }\end{array}$ & Lamiaceae & Chai Kuhi & Flower & n.r. & $\begin{array}{c}\text { Nerve Tonic, Treatment of cold, } \\
\text { Cardiac Tonic, Treatment of } \\
\text { Colic }\end{array}$ & $\begin{array}{l}\text { Mashhad city, } \\
\text { Northeastern Iran }\end{array}$ & $\begin{array}{c}{[5]} \\
\text { Amiri and Joharchi } 2013\end{array}$ \\
\hline
\end{tabular}


Table 1. Cont.

\begin{tabular}{|c|c|c|c|c|c|c|c|c|}
\hline & $\begin{array}{l}\text { Scientific } \\
\text { Name }\end{array}$ & Family & $\begin{array}{l}\text { Local } \\
\text { Name }\end{array}$ & $\begin{array}{l}\text { Part } \\
\text { Used }\end{array}$ & $\begin{array}{l}\text { Type of } \\
\text { Extract }\end{array}$ & $\begin{array}{l}\text { Medicinal } \\
\text { Uses }\end{array}$ & Area & Author (s) \\
\hline 206. & $\begin{array}{l}\text { Tanacetum } \\
\text { parthenium (L.) } \\
\text { Sch. Bip. }\end{array}$ & Asteraceae & $\begin{array}{c}\text { Gole } \\
\text { babooneh }\end{array}$ & Flower & n.r. & $\begin{array}{l}\text { Antitussive, Anticatarrhal, } \\
\text { Hair Tonic, Treatment of Colic, } \\
\text { Menstrual Pains }\end{array}$ & $\begin{array}{l}\text { Mashhad city, } \\
\text { Northeastern Iran }\end{array}$ & $\begin{array}{c}{[5]} \\
\text { Amiri and Joharchi } 2013\end{array}$ \\
\hline 207. & $\begin{array}{c}\text { Teucrium } \\
\text { orientale } \mathrm{L} .\end{array}$ & Lamiaceae & n.r. & Leaf & Boiled & Antidiabetic & $\begin{array}{l}\text { Urmia county, } \\
\text { Northwest Iran }\end{array}$ & $\begin{array}{c}\text { [7] } \\
\text { Bahmani et al. } 2014\end{array}$ \\
\hline 208. & $\begin{array}{l}\text { Teucrium polium } \\
\text { Teucrium polium } \\
\text { L. } \\
\text { Teucrium polium } \\
\text { L. }\end{array}$ & $\begin{array}{l}\text { Lamiaceae } \\
\text { Lamiaceae } \\
\text { Lamiaceae }\end{array}$ & $\begin{array}{l}\text { Maryam-nokhc } \\
\text { Kalpureh } \\
\text { n.r. }\end{array}$ & $\begin{array}{l}\text { Flower, } \\
\text { Seed } \\
\text { od Aerial } \\
\text { parts } \\
\text { Flowering } \\
\text { offshoot }\end{array}$ & $\begin{array}{l}\text { Brew } \\
\text { n.r. } \\
\text { Boiled }\end{array}$ & $\begin{array}{c}\text { Stomach Ache } \\
\text { Antacid, Indigestion, Diabetes, } \\
\text { Treatment of Colic, } \\
\text { Antidiarrhea } \\
\text { Antidiabetic }\end{array}$ & $\begin{array}{l}\text { Lorestan province } \\
\text { Mashhad city, } \\
\text { Northeastern Iran } \\
\text { Urmia county, } \\
\text { Northwest Iran }\end{array}$ & $\begin{array}{c}\text { [8] Delfan et al. } 2015 \\
\text { [5] } \\
\text { Amiri and Joharchi } 2013 \\
\text { [7] } \\
\text { Bahmani et al. } 2014\end{array}$ \\
\hline 209. & $\begin{array}{l}\text { Thalictrum } \\
\text { sultanabadense } \\
\text { Stapf }\end{array}$ & Ranunculaceae & Parsiavashan & $\begin{array}{l}\text { Aerial } \\
\text { parts }\end{array}$ & n.r. & Antitussive, Febrifuge & $\begin{array}{l}\text { Mashhad city, } \\
\text { Northeastern Iran }\end{array}$ & $\begin{array}{c}{[5]} \\
\text { Amiri and Joharchi } 2013\end{array}$ \\
\hline 210. & $\begin{array}{l}\text { Thymus } \\
\text { daenensis }\end{array}$ & Lamiaceae & Azboue & $\begin{array}{l}\text { Flower, } \\
\text { leaf, } \\
\text { branch }\end{array}$ & Decoction & Stomach Ache & Lorestan province & [8] Delfan et al. 2015 \\
\hline 211. & $\begin{array}{l}\text { Thymus } \\
\text { kotschyanus }\end{array}$ & Lamiaceae & Azboue & $\begin{array}{l}\text { Flower, } \\
\text { leaf, } \\
\text { branch }\end{array}$ & Decoction & Stomach Ache & Lorestan province & [8] Delfan et al. 2015 \\
\hline 212. & $\begin{array}{l}\text { Thymus } \\
\text { pubescens }\end{array}$ & Lamiaceae & Azboue & $\begin{array}{l}\text { Flower, } \\
\text { leaf, } \\
\text { branch }\end{array}$ & Decoction & Stomach Ache & Lorestan province & [8] Delfan et al. 2015 \\
\hline 213. & Thymus fallax & Lamiaceae & Azboue & $\begin{array}{l}\text { Flower, } \\
\text { leaf, } \\
\text { branch }\end{array}$ & Decoction & Stomach Ache & Lorestan province & [8] Delfan et al. 2015 \\
\hline 214. & $\begin{array}{l}\text { Thymus. } \\
\text { eriocalyx }\end{array}$ & Lamiaceae & Azboue & $\begin{array}{l}\text { Flower, } \\
\text { leaf, } \\
\text { branch }\end{array}$ & Decoction & Stomach Ache & Lorestan province & [8] Delfan et al. 2015 \\
\hline 215. & Tilia cordata Mill. & Malvaceae & Zirfun & $\begin{array}{l}\text { Leaves - } \\
\text { Fruit }\end{array}$ & n.r. & $\begin{array}{l}\text { Nerve Tonic, Sudorific, } \\
\text { Diuretic, Calmative }\end{array}$ & $\begin{array}{l}\text { Mashhad city, } \\
\text { Northeastern Iran }\end{array}$ & $\begin{array}{c}{[5]} \\
\text { Amiri and Joharchi } 2013\end{array}$ \\
\hline 216. & $\begin{array}{l}\text { Trachyspermum } \\
\text { ammi (L.) } \\
\text { Sprague }\end{array}$ & Apiaceae & $\begin{array}{l}\text { Zenyan } \\
\text { (Khordaneh) }\end{array}$ & Fruit & n.r. & $\begin{array}{l}\text { Carminative, Anthelmintic, } \\
\text { Antidiarrhea, Treatment of } \\
\text { Colic, Antacid, Galactogogue }\end{array}$ & $\begin{array}{l}\text { Mashhad city, } \\
\text { Northeastern Iran }\end{array}$ & $\begin{array}{c}{[5]} \\
\text { Amiri and Joharchi } 2013\end{array}$ \\
\hline
\end{tabular}


Table 1. Cont

\begin{tabular}{|c|c|c|c|c|c|c|c|c|}
\hline & $\begin{array}{l}\text { Scientific } \\
\text { Name }\end{array}$ & Family & $\begin{array}{l}\text { Local } \\
\text { Name }\end{array}$ & $\begin{array}{l}\text { Part } \\
\text { Used }\end{array}$ & $\begin{array}{l}\text { Type of } \\
\text { Extract }\end{array}$ & $\begin{array}{l}\text { Medicinal } \\
\text { Uses }\end{array}$ & Area & Author (s) \\
\hline 217. & $\begin{array}{l}\text { Tragapogon } \\
\text { caricifolius }\end{array}$ & Compositae & Sheng & Flower & Brew, raw, dried & Stomach Ache & Lorestan province & [8] Delfan et al. 2015 \\
\hline 218 & $\begin{array}{c}\text { Tribulus terrestris } \\
\text { L. }\end{array}$ & Zygophyllaceae & Kharkhasak & $\begin{array}{l}\text { Aerial } \\
\text { parts }\end{array}$ & n.r. & $\begin{array}{c}\text { Diuretic, Kidney Stone, Tonic, } \\
\text { Treatment of Prostate, } \\
\text { Hypertrophy, Anthelmintic, } \\
\text { Jaundice, Treatment of } \\
\text { Flooding, Treatment of } \\
\text { Dysuria, Urinary Antiseptic }\end{array}$ & $\begin{array}{l}\text { Mashhad city, } \\
\text { Northeastern Iran }\end{array}$ & $\begin{array}{c}\text { [5] } \\
\text { Amiri and Joharchi } 2013\end{array}$ \\
\hline 219. & $\begin{array}{c}\text { Trichodesma } \\
\text { incanum (Bunge) } \\
\text { A. DC. }\end{array}$ & Boraginaceae & Alaf-e-simkesh & $\begin{array}{l}\text { Aerial } \\
\text { parts }\end{array}$ & n.r. & Treatment of Bone Fracture & $\begin{array}{l}\text { Mashhad city, } \\
\text { Northeastern Iran }\end{array}$ & $\begin{array}{c}\text { [5] } \\
\text { Amiri and Joharchi } 2013\end{array}$ \\
\hline 220. & $\begin{array}{l}\text { Trifolium } \\
\text { pratense } \mathrm{L} .\end{array}$ & Fabaceae & n.r. & $\begin{array}{c}\text { Flowering } \\
\text { offshoot }\end{array}$ & Boiled & Antidiabetic & $\begin{array}{l}\text { Urmia county, } \\
\text { Northwest Iran }\end{array}$ & $\begin{array}{c}{[7]} \\
\text { Bahmani et al. } 2014 \\
\end{array}$ \\
\hline 221. & $\begin{array}{l}\text { Trifolium } \\
\text { purpureum } \\
\text { Loisel. }\end{array}$ & Fabaceae & n.r. & $\begin{array}{c}\text { Flowering } \\
\text { offshoot }\end{array}$ & Boiled & Antidiabetic & $\begin{array}{l}\text { Urmia county, } \\
\text { Northwest Iran }\end{array}$ & $\begin{array}{c}{[7]} \\
\text { Bahmani et al. } 2014\end{array}$ \\
\hline 222. & $\begin{array}{c}\text { Trigonella } \\
\text { foenum-graecum } \\
\text { L. }\end{array}$ & Fabaceae & $\begin{array}{l}\text { Shanbalileh } \\
\text { (Holbeh) }\end{array}$ & Seed & n.r. & $\begin{array}{c}\text { Diabetes, Bronchitis, } \\
\text { Osteomalacia, } \\
\text { Antihyperlipidemia, Tonic, } \\
\text { Treatment of Anemia }\end{array}$ & $\begin{array}{l}\text { Mashhad city, } \\
\text { Northeastern Iran }\end{array}$ & $\begin{array}{c}{[5]} \\
\text { Amiri and Joharchi } 2013\end{array}$ \\
\hline 223. & $\begin{array}{l}\text { Tripleurospermum } \\
\text { disciforme (C. A. } \\
\text { Mey.) } \\
\text { Sch.Bip. } \\
\end{array}$ & Asteraceae & $\begin{array}{c}\text { Gole } \\
\text { babooneh }\end{array}$ & Flower & n.r. & Treatment of Cough, Febrifuge & $\begin{array}{l}\text { Mashhad city, } \\
\text { Northeastern Iran }\end{array}$ & $\begin{array}{c}\text { [5] } \\
\text { Amiri and Joharchi } 2013\end{array}$ \\
\hline 224. & $\begin{array}{l}\text { Tussilago } \\
\text { farfara L. }\end{array}$ & Asteraceae & Pa Khari & $\begin{array}{l}\text { Aerial } \\
\text { parts }\end{array}$ & n.r. & $\begin{array}{c}\text { Expectorant, Antitussive, } \\
\text { Mouth Wounds, Treatment of } \\
\text { Furuncles }\end{array}$ & $\begin{array}{l}\text { Mashhad city, } \\
\text { Northeastern Iran }\end{array}$ & $\begin{array}{c}{[5]} \\
\text { Amiri and Joharchi } 2013\end{array}$ \\
\hline 225. & $\begin{array}{l}\text { Urtica dioica } \mathrm{L} \text {. } \\
\text { Urtica. dioica } \mathrm{L} \text {. }\end{array}$ & $\begin{array}{l}\text { Urticaceae } \\
\text { Urticaceae }\end{array}$ & $\begin{array}{l}\text { Gazaneh } \\
\text { n.r. }\end{array}$ & $\begin{array}{l}\text { Whole } \\
\text { plant } \\
\text { Seed, } \\
\text { aeration } \\
\text { organ }\end{array}$ & $\begin{array}{l}\text { n.r. } \\
\text { Boiled }\end{array}$ & $\begin{array}{c}\text { Hypoglycemic, Enlarged } \\
\text { Prostate, Anemia, } \\
\text { Anti-inflammatory, Digestive } \\
\text { Antidiabetic }\end{array}$ & $\begin{array}{l}\text { Mashhad city, } \\
\text { Northeastern Iran } \\
\text { Urmia county, } \\
\text { Northwest Iran }\end{array}$ & $\begin{array}{c}{[5]} \\
\text { Amiri and Joharchi } 2013 \\
\text { [7] } \\
\text { Bahmani et al. } 2014\end{array}$ \\
\hline 226. & $\begin{array}{c}\text { Urtica pilulifera } \\
\text { L. }\end{array}$ & Urticaceae & Anjareh & Seed & n.r. & Laxative, Treatment of Cough & $\begin{array}{l}\text { Mashhad city, } \\
\text { Northeastern Iran }\end{array}$ & $\begin{array}{c}{[5]} \\
\text { Amiri and Joharchi } 2013\end{array}$ \\
\hline
\end{tabular}


Table 1. Cont.

\begin{tabular}{|c|c|c|c|c|c|c|c|c|}
\hline & $\begin{array}{l}\text { Scientific } \\
\text { Name }\end{array}$ & Family & $\begin{array}{l}\text { Local } \\
\text { Name }\end{array}$ & $\begin{array}{l}\text { Part } \\
\text { Used }\end{array}$ & $\begin{array}{l}\text { Type of } \\
\text { Extract }\end{array}$ & $\begin{array}{l}\text { Medicinal } \\
\text { Uses }\end{array}$ & Area & Author (s) \\
\hline 227. & $\begin{array}{c}\text { Vaccaria } \\
\text { oxyodonta Boiss. }\end{array}$ & Caryophyllaceae & $\begin{array}{l}\text { Sabounak-e } \\
\text { dane-ye } \\
\text { zard }\end{array}$ & Flower & Boiled & Skin Allergy and Constipation & $\begin{array}{l}\text { Khiregah-e Jangali, } \\
\text { Ghasemloo valley }\end{array}$ & $\begin{array}{l}\text { [9] } \\
\text { Baharvand-Ahmadi et } \\
\text { al. } 2015\end{array}$ \\
\hline 228. & $\begin{array}{c}\text { Vaccinium } \\
\text { arctostaphylos } \mathrm{L} \text {. }\end{array}$ & Ericaceae & $\begin{array}{c}\text { Ghareh } \\
\text { Ghat }\end{array}$ & Fruit & n.r. & $\begin{array}{c}\text { Diabetes, Depurative, } \\
\text { Antihypertensive, Calmative }\end{array}$ & $\begin{array}{c}\text { Mashhad city, } \\
\text { Northeastern Iran }\end{array}$ & $\begin{array}{c}{[5]} \\
\text { Amiri and Joharchi } 2013\end{array}$ \\
\hline 229. & $\begin{array}{c}\text { Verbascum } \\
\text { agrimonifolium }\end{array}$ & Scropholariacae & $\begin{array}{l}\text { Gol-e } \\
\text { mahour }\end{array}$ & $\begin{array}{l}\text { Leaves, } \\
\text { flower }\end{array}$ & Boiled & Wound Microbial Infection & $\begin{array}{l}\text { Khiregah-e Jangali, } \\
\text { Ghasemloo valley }\end{array}$ & $\begin{array}{l}{[9]} \\
\text { Baharvand-Ahmadi et } \\
\text { al. } 2015\end{array}$ \\
\hline 230. & $\begin{array}{c}\text { Verbascum } \\
\text { cheiranthifolium } \\
\text { Boiss. }\end{array}$ & Scrophulariaceae & Dome Gav & $\begin{array}{l}\text { Aerial } \\
\text { parts }\end{array}$ & n.r. & $\begin{array}{l}\text { Dyspepsia, Antidiarrhea, } \\
\text { Expectorant, Antiacid, } \\
\text { Stomach Tonic }\end{array}$ & $\begin{array}{l}\text { Mashhad city, } \\
\text { Northeastern Iran }\end{array}$ & $\begin{array}{c}{[5]} \\
\text { Amiri and Joharchi } 2013\end{array}$ \\
\hline 231. & $\begin{array}{l}\text { Verbascum } \\
\text { macrocarpum } \\
\text { Boiss. }\end{array}$ & Scropholariacae & $\begin{array}{l}\text { Gol-e } \\
\text { mahour }\end{array}$ & $\begin{array}{l}\text { Leaves, } \\
\text { flower }\end{array}$ & Boiled & Nails Fungal Infection & $\begin{array}{l}\text { Khiregah-e Jangali, } \\
\text { Ghasemloo valley }\end{array}$ & $\begin{array}{c}{[9]} \\
\text { Baharvand-Ahmadi et } \\
\text { al. } 2015\end{array}$ \\
\hline 232. & $\begin{array}{l}\text { Verbascum } \\
\text { speciosum } \\
\text { Schord. }\end{array}$ & Scropholariacae & $\begin{array}{l}\text { Gol-e } \\
\text { mahour }\end{array}$ & $\begin{array}{l}\text { Leaves, } \\
\text { flower }\end{array}$ & Paste & Wound Microbial Infection & $\begin{array}{l}\text { Khiregah-e Jangali, } \\
\text { Ghasemloo valley }\end{array}$ & $\begin{array}{l}{[9]} \\
\text { Baharvand-Ahmadi et } \\
\text { al. } 2015\end{array}$ \\
\hline 234. & $\begin{array}{l}\text { Verbena officinalis } \\
\text { L. }\end{array}$ & Verbenaceae & Shahpasand & $\begin{array}{l}\text { Aerial } \\
\text { parts }\end{array}$ & n.r. & Appetizer, Indigestion & $\begin{array}{c}\text { Mashhad city, } \\
\text { Northeastern Iran }\end{array}$ & $\begin{array}{c}{[5]} \\
\text { Amiri and Joharchi } 2013 \\
\end{array}$ \\
\hline 235. & Viola odorata $\mathrm{L}$. & Violaceae & Banafsheh & Flower & n.r. & $\begin{array}{c}\text { Eczema, Febrifuge, } \\
\text { Anti-allergic, Blood Cleansing, } \\
\text { Jaundice, Treatment of Cold, } \\
\text { Expectorant }\end{array}$ & $\begin{array}{l}\text { Mashhad city, } \\
\text { Northeastern Iran }\end{array}$ & $\begin{array}{c}{[5]} \\
\text { Amiri and Joharchi } 2013\end{array}$ \\
\hline 236. & Viola tricolor & Umbelliferae & $\begin{array}{c}\text { Gole- } \\
\text { benoushe }\end{array}$ & $\begin{array}{l}\text { Flower } \\
\text { branch }\end{array}$ & Decoction & Stomach Ache & Lorestan province & [8] Delfan et al. 2015 \\
\hline 237. & Vitex negundo L. & Lamiaceae & Felfel Kuhi & Fruit & n.r. & $\begin{array}{l}\text { Menstrual Regulator, Obesity, } \\
\text { Treatment of Sinusitis }\end{array}$ & $\begin{array}{c}\text { Mashhad city, } \\
\text { Northeastern Iran }\end{array}$ & $\begin{array}{c}{[5]} \\
\text { Amiri and Joharchi } 2013\end{array}$ \\
\hline 238. & $\begin{array}{l}\text { Zataria multiflora } \\
\text { Boiss. }\end{array}$ & Lamiaceae & $\begin{array}{l}\text { Avishan } \\
\text { Shirazi }\end{array}$ & $\begin{array}{l}\text { Aerial } \\
\text { parts }\end{array}$ & n.r. & $\begin{array}{l}\text { Treatment of Sinusitis, } \\
\text { Menstrual Pains, } \\
\text { Dysmenorrheal, Anthelmintic, } \\
\text { Antacid, Treatment of Colic, } \\
\text { Anti-asthmatic, Dyspnoea, } \\
\text { Arthrodynia, Carminative }\end{array}$ & $\begin{array}{l}\text { Mashhad city, } \\
\text { Northeastern Iran }\end{array}$ & $\begin{array}{c}{[5]} \\
\text { Amiri and Joharchi } 2013\end{array}$ \\
\hline
\end{tabular}


Table 1. Cont

\begin{tabular}{|c|c|c|c|c|c|c|c|c|}
\hline & $\begin{array}{l}\text { Scientific } \\
\text { Name }\end{array}$ & Family & $\begin{array}{l}\text { Local } \\
\text { Name }\end{array}$ & $\begin{array}{l}\text { Part } \\
\text { Used }\end{array}$ & $\begin{array}{l}\text { Type of } \\
\text { Extract }\end{array}$ & $\begin{array}{l}\text { Medicinal } \\
\text { Uses }\end{array}$ & Area & Author (s) \\
\hline 239. & Zataria multiflora & Lamiceae & Avishan & Leaf & $\begin{array}{c}\text { Herbal } \\
\text { tea/decoction }\end{array}$ & Antiparasitic & $\begin{array}{l}\text { Shiraz, Fars } \\
\text { province }\end{array}$ & [6] Bahmani et al. 2016 \\
\hline 240. & Zea mays $\mathrm{L}$. & Poaceae & $\begin{array}{l}\text { Kakole } \\
\text { Zorat }\end{array}$ & Style & n.r. & $\begin{array}{c}\text { Obesity, Anti-inflammatory, } \\
\text { Anti-lithiasis, Kidney } \\
\text { Disorders, Prostate Disorders, } \\
\text { Diuretic }\end{array}$ & $\begin{array}{l}\text { Mashhad city, } \\
\text { Northeastern Iran }\end{array}$ & $\begin{array}{c}{[5]} \\
\text { Amiri and Joharchi } 2013\end{array}$ \\
\hline 241. & $\begin{array}{l}\text { Ziziphora } \\
\text { clinopodioides } \\
\text { Lam. }\end{array}$ & Lamiaceae & $\begin{array}{l}\text { Avishan } \\
\text { kuhi }\end{array}$ & $\begin{array}{l}\text { Aerial } \\
\text { parts }\end{array}$ & n.r. & $\begin{array}{c}\text { Kidney Pain, Antacid, } \\
\text { Carminative, Treatment of } \\
\text { Colic, Anthelmintic, } \\
\text { Antitussive, Antidiarrhea, } \\
\text { Digestive }\end{array}$ & $\begin{array}{l}\text { Mashhad city, } \\
\text { Northeastern Iran }\end{array}$ & $\begin{array}{c}{[5]} \\
\text { Amiri and Joharchi } 2013\end{array}$ \\
\hline 242. & $\begin{array}{c}\text { Ziziphora teniuor } \\
\text { L. }\end{array}$ & Lamiaceae & Kakuti & $\begin{array}{l}\text { Aerial } \\
\text { parts }\end{array}$ & n.r. & $\begin{array}{c}\text { Digestive, Treatment of Colic, } \\
\text { Calefacient, Antacid, } \\
\text { Antiseptic }\end{array}$ & $\begin{array}{l}\text { Mashhad city, } \\
\text { Northeastern Iran }\end{array}$ & $\begin{array}{c}{[5]} \\
\text { Amiri and Joharchi } 2013\end{array}$ \\
\hline 243. & $\begin{array}{l}\text { Ziziphus jujuba } \\
\text { Miller }\end{array}$ & Rhamnaceae & Annab & Fruit & n.r. & $\begin{array}{c}\text { Depurative, Febrifuge, } \\
\text { Laxative, Jaundice, Antitussive, } \\
\text { Treatment of Thirst }\end{array}$ & $\begin{array}{l}\text { Mashhad city, } \\
\text { Northeastern Iran }\end{array}$ & $\begin{array}{c}{[5]} \\
\text { Amiri and Joharchi } 2013\end{array}$ \\
\hline 244. & $\begin{array}{c}\text { Ziziphus } \\
\text { spina-christi } \\
\text { Ziziphus } \\
\text { spina-christi (L.) } \\
\text { Willd. }\end{array}$ & $\begin{array}{l}\text { Rhamnaceae } \\
\text { Rhamnaceae }\end{array}$ & $\begin{array}{l}\text { Konar } \\
\text { Sedr }\end{array}$ & $\begin{array}{l}\text { Flower, } \\
\text { leaf } \\
\text { Leaves }\end{array}$ & $\begin{array}{l}\text { Decoction } \\
\text { n.r. }\end{array}$ & $\begin{array}{c}\text { Stomach Ache } \\
\text { Eczema, Hair Tonic, } \\
\text { Antifungal, Antipruritic, } \\
\text { Washing }\end{array}$ & $\begin{array}{l}\text { Lorestan province } \\
\text { Mashhad city, } \\
\text { Northeastern Iran }\end{array}$ & $\begin{array}{c}\text { [8] Delfan et al. } 2015 \\
\text { [5] } \\
\text { Amiri and Joharchi } 2013\end{array}$ \\
\hline 245. & $\begin{array}{c}\text { Ziziphus } \\
\text { nummularia }\end{array}$ & Rhamnaceae & Melim & Leaf, root & Decoction & Peptic Ulcer & Lorestan province & [8] Delfan et al. 2015 \\
\hline 246. & $\begin{array}{l}\text { Zosima orientalis } \\
\text { Hoffm. }\end{array}$ & Apiaceae & $\begin{array}{l}\text { Angedane } \\
\text { roomi }\end{array}$ & Fruit & n.r. & Nerve Diseases, Indigestion & $\begin{array}{l}\text { Mashhad city, } \\
\text { Northeastern Iran }\end{array}$ & $\begin{array}{c}{[5]} \\
\text { Amiri and Joharchi } 2013\end{array}$ \\
\hline
\end{tabular}




\subsection{Biological Activities of Plants Grown and Collected in Iran}

A bibliographic search was conducted, focusing on biological activities of plants collected in the Iranian territory. The purpose of this section is to collect data related to scientific studies in order to evidence potential correlations between traditional treatments and proved biological activities of plants and phytocomplexes obtained from them. The results are summarized in Table 2.

\subsubsection{Antibacterial Activity}

Abedini et al. (2014) [13] tested the antimicrobic activity of forty-four methanolic extracts, obtained from plants grown and collected in the Iranian territory, against thirty-five pathogenic bacteria and one yeast. The biological activity was evaluated with Müller-Hinton agar in Petri dishes seeded by a multiple inoculator and minimal inhibition concentration (MIC) method. The authors identified four candidates that deserve further chemical characterization and biological evaluation: Dorema ammoniacum, Ferula assa-foetida, Ferulago contracta (Seeds), and Perovskia abrotanoides (Aerial parts). These plants showed broad-spectrum activity and interesting MIC values against one or several strains (MIC= $78 \mu \mathrm{g} / \mathrm{mL}$ ). The lowest MIC value of $78 \mu \mathrm{g} / \mathrm{mL}$ was achieved by Dorema ammoniacum against Staphylococcus aureus, Staphylococcus epidermidis, Staphylococcus lugdunensis. Ferula assa-foetida against Staphylococcus aureus and Staphylococcus epidermidis. Ferulago contracta against Staphylococcus epidermidis [13].

Bonjar (2004) [11] evaluated the antibacterial properties of forty-five plant species used in Iranian traditional medicine practices against eleven bacterial species. The extracts were prepared by maceration of the plant material with methanol for three days, and the result was lyophilized after filtration. The lyophilized methanol extracts were diluted to a concentration of $20 \mathrm{mg} / \mathrm{mL}$ in dimethylsulfoxide (DMSO): methanol (1/1: v/v) solvent in order to perform antimicrobial bioassay. The author declared that the following plant extracts showed broad spectra antimicrobial activity:

Rhus coriaria L., Trachyspermum ammi L., Alhagi maurorum Medik., Trigonella foenum-graecum L., Lawsonia inermis L., Rheum ribes L., and Cuminum cyminum L. Further studies are needed to find out which compounds are responsible for this activity. Particular plants, such as Lawsonia inermis L., which is active against Pseudomonas fluorescens and Trachyspermum ammi L., Nymphaea alba L. active against Pseudomonas aeruginosa, are proper candidates for further studies as possible sources of active compounds [11].

Chitsazian-Yazdi et al. (2015) [15] studied an Iranian medicinal plant known for its various biological activities, including antispasmodic and anthelmintic, named Ferula foetida Regel (Apiaceae).

Sulfur compounds obtained by methanolic extract of the roots of the plant were isolated and characterized to test their antimicrobial activity and cytotoxic activity. Six compounds were isolated: foetithiophene $C$, foetithiophene $F$, foetithiophene $A$, foetithiophene B, coniferaldehyde, and sinapic aldehyde.

Their antimicrobial activities and cytotoxicity were evaluated using broth microdilution method and Alamar blue assay. Antimicrobial activity was evidenced against Gram-positive bacteria, more in particular foetithiophene F, which showed interesting antimicrobial activity with MIC value $50 \mathrm{mg} / \mathrm{mL}$ against the Gram-positive Bacillus cereus. No cytotoxic activity was detected against MCF-7 and K562 cells [15].

Koochak et al. (2010) [12] conducted a preliminary study regarding the antibacterial activity of ethanolic extracts obtained by four plant species used in traditional medicinal practices in Iran. The studied plants were Beta vulgaris L., Amaranthus graecizans L., Rumex obtusifolius L., Polygonum patulum M. Bieb. The antibacterial activity was tested using the agar disc diffusion method against Gram-positive and Gram-negative bacteria. No one of the used extracts had significant antibacterial activity against Gram-negative bacteria. The highest activity was evidenced by the ethanolic extract of Polygonum patulum against Streptococcus pyogenes (inhibitory zone $=28 \mathrm{~mm}$ ) followed by Beta vulgaris against Staphylococcus epidermidis (inhibitory zone $=23 \mathrm{~mm}$ ) and Rumex obtusifolius against Streptococcus pyogenes. Minimum inhibitory concentration $(\mathrm{MIC})=$ minimum bactericidal concentration (MBC) $=5 \mathrm{mg} / \mathrm{mL}$. Further studies are needed to define which compounds contained in the extracts are responsible for the antimicrobial activity [12]. 
Table 2. Biological activities of plants collected in the Iranian territory. Scientific name, family, type of extract, part of the plant used, Authors. (N.r. = not reported).

\begin{tabular}{|c|c|c|c|c|}
\hline & Family & Plant Extract & $\begin{array}{l}\text { Plant Part (s) } \\
\text { Used }\end{array}$ & Author (s) \\
\hline \multicolumn{5}{|c|}{ Antibacterial Activity } \\
\hline Achillea millefolium & Asteraceae & Methanolic extract & Aerial parts & [10] Lotfipour et al. 2008 \\
\hline Alhagi maurorum Medik. & Leguminosae & Methanolic extract (Lyophilized) & Leaves & [11] Bonjar et al. 2004 \\
\hline Beta vulgaris & Amaranthaceae & Ethanolic extract & Aerial parts & [12] Koochak et al. 2010 \\
\hline Cuminum cyminum $\mathrm{L}$. & Apiaceae & Methanolic extract (Lyophilized) & Leaves & [11] Bonjar et al. 2004 \\
\hline Dorema ammoniacum & Apiaceae & Methanolic extract & Seeds & [13] Abedini et al. 2014 \\
\hline Echinophora orientalis & Apiaceae & Aqueous extract & Leaves & [14] Sepahi et al. 2014 \\
\hline Etchium italicum & Boraginaceae & Methanolic extract & Aerial parts & [10] Lotfipour et al. 2008 \\
\hline Ferula assa-foetida & Apiaceae & Methanolic extract & Seeds & [13] Abedini et al. 2014 \\
\hline Ferula foetida Regel & Apiaceae & Methanolic extract & Roots & [15] Chitsazian-Yazdi et al. 2015 \\
\hline Ferula gummosa & Apiaceae & Aqueous extract & Leaves & [14] Sepahi et al. 2014 \\
\hline Ferulago contracta & Apiaceae & Methanolic extract & Seeds & [13] Abedini et al. 2014 \\
\hline Lawsonia inermis L. & Lythraceae & Methanolic extract (Lyophilized) & Leaves & [11] Bonjar et al. 2004 \\
\hline Malva sylvestris $\mathrm{L}$. & Malvaceae & Methanolic extract & Flowers & [16] Razavi et al. 2011 \\
\hline Nasturtium microphyllum & Brassicaceae & Aqueous extract & Leaves & [14] Sepahi et al. 2014 \\
\hline Nymphaea alba $\mathrm{L}$ & Nymphaeaceae & Methanolic extract (Lyophilized) & Leaves & [11] Bonjar et al. 2004 \\
\hline Perovskia abrotanoides & Lamiaceae & Methanolic extract & Aerial parts & [13] Abedini et al. 2014 \\
\hline $\begin{array}{c}\text { Polygonum patulum } \\
\text { M. Bieb. }\end{array}$ & Polygonaceae & Ethanolic extract & Aerial parts & [12] Koochak et al. 2010 \\
\hline Rheum ribes $\mathrm{L}$. & Polygonaceae & Methanolic extract (Lyophilized) & Leaves & [11] Bonjar et al. 2004 \\
\hline Rhus coriaria $\mathrm{L}$. & Anacardiaceae & Methanolic extract (Lyophilized) & Leaves & [11] Bonjar et al. 2004 \\
\hline Rumex obtusifolius & Polygonaceae & Ethanolic extract & Aerial parts & [12] Koochak et al. 2010 \\
\hline Salvia sahendica & Lamiaceae & Methanolic extract & Aerial parts & [10] Lotfipour et al. 2008 \\
\hline
\end{tabular}


Table 2. Cont

\begin{tabular}{|c|c|c|c|c|}
\hline & Family & Plant Extract & $\begin{array}{l}\text { Plant Part (s) } \\
\text { Used }\end{array}$ & Author (s) \\
\hline Satureja bachtiarica & Lamiaceae & $\begin{array}{l}\text { Hydro-distillation and } \\
\text { ethanolic extract }\end{array}$ & $\begin{array}{l}\text { Leaves and } \\
\text { flowers }\end{array}$ & [17] Pirbalouti et al. 2010 \\
\hline Thalictrum minus & Ranunculaceae & Methanolic extract & Aerial parts & [10] Lotfipour et al. 2008 \\
\hline Thymus daenensis & Lamiaceae & $\begin{array}{c}\text { Hydro-distillation and } \\
\text { ethanolic extract }\end{array}$ & $\begin{array}{c}\text { Leaves and } \\
\text { flowers }\end{array}$ & [17] Pirbalouti et al. 2010 \\
\hline Trachyspermum ammi $\mathrm{L}$. & Apiaceae & Methanolic extract (Lyophilized) & Leaves & [11] Bonjar et al. 2004 \\
\hline Trachyspermum copticum & Apiaceae & $\begin{array}{c}\text { Aqueous extract, } \\
\text { Methanol/petroleum benzene/diethyl } \\
\text { ether extract }\end{array}$ & Aerial parts & [18] Nariman et al. 2004 \\
\hline Trigonella foenum-graecum $\mathrm{L}$. & Leguminosae & Methanolic extract (Lyophilized) & Leaves & [11] Bonjar et al. 2004 \\
\hline Verbascum Thapsus & Scrophulariaceae & Aqueous extract & Leaves & [14] Sepahi et al. 2014 \\
\hline Xanthium brasilicum & Compositae & $\begin{array}{c}\text { Aqueous extract, } \\
\text { Methanol/petroleum benzene/diethyl } \\
\text { ether extract }\end{array}$ & Aerial parts & [18] Nariman et al. 2004 \\
\hline \multicolumn{5}{|c|}{ Antifungal Activity } \\
\hline Satureja bachtiarica & Lamiaceae & Hydro-distillation & Leaves & [19] Pirbalouti et al. 2009 \\
\hline Scrophularia striata & Scrophulariaceae & Infusion & Leaves and stems & [19] Pirbalouti et al. 2009 \\
\hline Thymus daenensis & Lamiaceae & Hydro-distillation & Leaves & [19] Pirbalouti et al. 2009 \\
\hline Trachyspermum ammi & Apiaceae & Hydro-distillation & Fruits & [19] Pirbalouti et al. 2009 \\
\hline Zhumeria majdae & Lamiaceae & Hydro-distillation & Aerial parts & [20] Imani et al. 2015 \\
\hline Ziziphus spinachristi & Rhamnaceae & Infusion & Fruits & [19] Pirbalouti et al. 2009 \\
\hline \multicolumn{5}{|c|}{ Antimalarial Activity } \\
\hline Citrullus colocynthis & Cucurbitaceae & Methanolic extract & Fruits & [21] Feiz Haddad et al. 2017 \\
\hline
\end{tabular}


Table 2. Cont

\begin{tabular}{|c|c|c|c|c|}
\hline & Family & Plant Extract & $\begin{array}{l}\text { Plant Part (s) } \\
\text { Used }\end{array}$ & Author (s) \\
\hline Physalis alkekengi & Solanaceae & Methanolic extract & Leaves and fruits & [21] Feiz Haddad et al. 2017 \\
\hline Scrophularia frigida & Scrophulariaceae & Dichloromethane extract & Aerial parts & [22] Afshar et al. 2018 \\
\hline Solanum nigrum & Solanaceae & Methanolic extract & Fruits & [21] Feiz Haddad et al. 2017 \\
\hline \multicolumn{5}{|c|}{ Antioxidant Activity } \\
\hline Convolvulus persicus & Convolvulaceae & Methanol extract & Roots & [23] Dehghan et al. 2016 \\
\hline Heracleum persicum & Apiaceae & $\begin{array}{l}\text { n-Hexane extract (subsequently } \\
\text { fractionated) }\end{array}$ & Roots & [24] Dehghan et al. 2017 \\
\hline Hyssopus angustifolius & Lamiaceae & Ethyl acetate extracts & $\begin{array}{l}\text { Stems, Leaves, } \\
\text { Owes }\end{array}$ & [25] Alinezhad et al. 2012 \\
\hline Hyssopus officinalis L. & Lamiaceae & Ethyl acetate and n-butanol extracts & Aerial parts & [26] Fathiazad et al. 2011 \\
\hline Mellilotus officinalis & Leguminosae & Methanolic extract & Whole plant & [27] Pourmorad et al. 2006 \\
\hline Primula heterochroma & Primulaceae & $\begin{array}{l}\text { Methanolic extract } \\
\text { Ethyl acetate extract } \\
\text { Methanolic extract }\end{array}$ & $\begin{array}{l}\text { Leaves } \\
\text { Roots }\end{array}$ & [23] Dehghan et al. 2016 \\
\hline Pyrus boissieriana & Rosacee & Methanolic extract & $\begin{array}{c}\text { Leaves and } \\
\text { steams }\end{array}$ & [23] Dehghan et al.2016 \\
\hline Quercus infectoria & Fagaceae & Methanolic extract & Galls & [28] Khazaeli et al. 2009 \\
\hline Salix aegyptiaca $L$. & Salicaceae & Methanolic extract & $\begin{array}{c}\text { Male } \\
\text { inflorescences }\end{array}$ & [29] Sonboli et al. 2010 \\
\hline Stachys inflata & Lamiaceae & $\begin{array}{l}\text { Methanolic extract polar and non-polar } \\
\text { fractions }\end{array}$ & Aerial parts & [30] Ebrahimabadi et al. 2010 \\
\hline Terminalia chebula & Combretaceae & Methanolic extract & Fruits & [28] Khazaeli et al. 2009 \\
\hline Tetrataenium lasiopetalum & Apiaceae & Hydro-alcoholic extract & $\begin{array}{c}\text { Laminas, Stems, } \\
\text { Petioles, Fruits, } \\
\text { Peduncle, } \\
\text { Flowers }\end{array}$ & [31] Dehshiri et al. 2013 \\
\hline \multicolumn{5}{|c|}{ Anticancer/Cytotoxic Activity } \\
\hline Anthemis mirheydari & Compositae & Dichloromethane extract & Whole plant & [32] Jassbi et al. 2016 \\
\hline
\end{tabular}


Table 2. Cont

\begin{tabular}{|c|c|c|c|c|}
\hline & Family & Plant Extract & $\begin{array}{l}\text { Plant Part (s) } \\
\text { Used }\end{array}$ & Author (s) \\
\hline $\begin{array}{l}\text { Euphorbia szovitsii Fisch. \& } \\
\text { C.A. Mey. }\end{array}$ & Euphorbiaceae & Hydro-alcoholic extract & Aerial parts & [33] Asadi-Samani et al. 2018 \\
\hline Ferula foetida Regel & Apiaceae & Methanolic extract & Roots & [15] Chitsazian-Yazdi et al. 2015 \\
\hline Ferula szowitsiana & Apiaceae & Methanolic extract (fractionated) & Roots & [34] Sahranavard et al. 2009 \\
\hline Hypericum scabrum & Hypericaceae & Methanolic extract (fractionated) & Leaves & $\begin{array}{l}\text { [35] Hamzeloo-Moghadam et al. } \\
2015\end{array}$ \\
\hline Malva sylvestris L. & Malvaceae & Methanolic extract & $\begin{array}{l}\text { Flowers and } \\
\text { leaves }\end{array}$ & [16] Razavi et al. 2011 \\
\hline Medicago sativa & Leguminosae & Hydro-alcoholic extract & Aerial parts & [33] Asadi-Samani et al. 2018 \\
\hline Mentha lonigfolia & Lamiaceae & Methanolic extract & Aerial parts & [36] Esmaeilbeig et al. 2015 \\
\hline Satureja bachtiarica & Lamiaceae & Methanolic extract & Aerial parts & [36] Esmaeilbeig et al. 2015 \\
\hline Satureja hortensis & Lamiaceae & Methanolic extract & Aerial parts & [36] Esmaeilbeig et al. 2015 \\
\hline Thymus daenensis & Lamiaceae & Methanolic extract & Aerial parts & [36] Esmaeilbeig et al. 2015 \\
\hline Thymus vulgaris & Lamiaceae & Methanolic extract & Aerial parts & [36] Esmaeilbeig et al. 2015 \\
\hline \multirow[t]{2}{*}{ Urtica dioica } & Urticaceae & Hydro-alcoholic extract & Aerial parts & [33] Asadi-Samani et al. 2018 \\
\hline & & Antidiabetic Activity & & \\
\hline Heracleum persicum & Apiaceae & $\begin{array}{c}\text { n-hexane extract } \\
\text { n-hexane extract (subsequently } \\
\text { fractionated) }\end{array}$ & $\begin{array}{l}\text { Aerial parts, } \\
\text { roots } \\
\text { Roots }\end{array}$ & $\begin{array}{l}\text { [23] Dehghan et al. } 2016 \text { and } \\
\text { [24] Dehghan et al. } 2017\end{array}$ \\
\hline Parrotia persica & Hamamelidaceae & Ethyl acetate and methanolic extract & Leaves & [23] Dehghan et al.2016 \\
\hline Primula heterochroma & Primulaceae & Methanolic and ethyl acetate extract & Leaves and roots & [23] Dehghan et al. 2016 \\
\hline Pyrus boissieriana & Rosacee & $\begin{array}{c}\text { Methanolic, n-hexane, Ethyl acetate } \\
\text { extract }\end{array}$ & Leaves and stems & [23] Dehghan et al.2016 \\
\hline Salvia officinalis $\mathbf{L}$ & Lamiaceae & Hydro-alcoholic extract & Leaves & [37] Hasanein et al. 2016 \\
\hline Smilax excelsa & Smilacaceae & Ethyl acetate and n-hexane extract & Stems and leaves & [23] Dehghan et al.2016 \\
\hline
\end{tabular}


Table 2. Cont

\begin{tabular}{|c|c|c|c|c|}
\hline & Family & Plant Extract & $\begin{array}{l}\text { Plant Part (s) } \\
\text { Used }\end{array}$ & Author (s) \\
\hline \multicolumn{5}{|c|}{ Iron Chelating Activity } \\
\hline Epilobium hirsutum & Onagraceae & n.r. & Leaves & [38] Ebrahimzadeh et al. 2008 \\
\hline Feijoa sellowiana & Myrtaceae & Infusion and methanolic extract & Fruits and leaves & [38] Ebrahimzadeh et al. 2008 \\
\hline Melilotus arvensis & Fabaceae & n.r. & Leaves & [38] Ebrahimzadeh et al. 2008 \\
\hline Pistacia lentiscus & Anacardiaceae & n.r. & Gum & [38] Ebrahimzadeh et al. 2008 \\
\hline \multicolumn{5}{|c|}{ Anti-Platelet Aggregation Activity } \\
\hline Allium atroviolaceum & Amaryllidaceae & Hydro-distillation & Aerial parts & [39] Lorigooini et al. 2014 \\
\hline \multicolumn{5}{|c|}{ Inhibition of Mushroom Tyrosinase } \\
\hline Quercus infectoria & Fagaceae & Methanolic extract & Galls & [28] Khazaeli et al. 2009 \\
\hline Terminalia chebula & Combretaceae & Methanolic extract & Fruits & [28] Khazaeli et al. 2009 \\
\hline \multicolumn{5}{|c|}{ Acetylcholinesterase-Inhibitory Activity } \\
\hline Brassica nigra & Brassicaceae & Aqueous-methanolic extract & Seeds & [40] Jazayeri et al. 2014 \\
\hline Camellia sinensis & Theaceae & Aqueous-methanolic extract & Leaves & [40] Jazayeri et al. 2014 \\
\hline Citrus aurantifolia & Rutaceae & Aqueous-methanolic extract & Fruits & [40] Jazayeri et al. 2014 \\
\hline Peganum harmala $\mathrm{L}$. & Nitrariaceae & $\begin{array}{c}\text { Methanolic extract, } \\
\text { Dichloromethane extract }\end{array}$ & Seeds & [41] Adhami et al. 2011 \\
\hline Prangos ferulacea & Apiaceae & n-hexane extract & Aerial parts & $\begin{array}{l}\text { [42] Abbas-Mohammadi et al. } \\
2018\end{array}$ \\
\hline Rosa damascena & Rosaceae & Aqueous-methanolic extract & Flowers & [40] Jazayeri et al. 2014 \\
\hline Zizyphus vulgaris & Rhamnaceae & Aqueous-methanolic extract & Fruits & [40] Jazayeri et al. 2014 \\
\hline
\end{tabular}


Table 2. Cont

\begin{tabular}{|c|c|c|c|c|}
\hline & Family & Plant Extract & $\begin{array}{l}\text { Plant Part (s) } \\
\text { Used }\end{array}$ & Author (s) \\
\hline \multicolumn{5}{|c|}{ Antihyperlipidemic and Antihypertensive Activities } \\
\hline Achillea wilhelmsii C. Koch & Compositae & Hydro-alcoholic extract & Aerial parts & [43] Asgary et al. 2000 \\
\hline \multicolumn{5}{|c|}{ Gastric Antiulcerogenic Activity } \\
\hline Portulaca oleracea $\mathrm{L}$. & Portulacaceae & $\begin{array}{l}\text { Aqueous extract } \\
\text { Ethanolic extract }\end{array}$ & Leaves & [44] Karimi et al. 2004 \\
\hline \multicolumn{5}{|c|}{ Anti-Dyspepsia Activity } \\
\hline Mentha pulegium $\mathrm{L}$. & Lamiaceae & Hydro-alcoholic extract & Leaves & [45] Khonche et al. 2017 \\
\hline \multicolumn{5}{|c|}{ Inhibitory Effect on Gastric Acid Output } \\
\hline Achillea wilhelmsii & Compositae & Aqueous-ethanolic extract & Aerial parts & [46] Niazmand et al. 2010 \\
\hline \multicolumn{5}{|c|}{ Anti-Colitic Activity } \\
\hline Rosmarinus officinalis & Lamiaceae & $\begin{array}{l}\text { Hydro-alcoholic extract and } \\
\text { hydro-distillation (EO) }\end{array}$ & Leaves & [47] Minaiyan et al. 2011 \\
\hline
\end{tabular}


Lotfipour et al. (2008) [10] tested the antimicrobial activity of thirty-six extracts obtained from ten plans collected in north-west Iran against some Gram-negative strains.

Among them, the methanol extract of Thalictrum minus was the most active one with a minimum inhibitory concentration (MIC) value of $0.3125 \mathrm{mg} / \mathrm{mL}$ against Staphylococcus aureus.

Furthermore, the broad spectra of activity of some plant extracts (especially methanolic extracts) studied, obtained by the plants Thalictrum minus, Salvia sahendica, Achillea millefollum, and Echium italicum, were promising [10].

Mehdi Razavi et al. (2011) [16] tested the in vitro antimicrobial activity and cytotoxic activity of different extracts obtained by the plant Malva sylvestris L. (flowers and leaves); this plant is commonly used in traditional medicine practices in Iran. Flowers and leaves of the plant were collected from Tabriz, Iran. The flowers methanolic extract showed high antibacterial effects against some human pathogenic bacteria strains, such as Staphylococcus aureus, Streptococcus agalactiae, Enterococcus faecalis, with MIC values of 192, 200, and $256 \mu \mathrm{g} / \mathrm{mL}$, respectively. Further studies are needed to identify the main active compounds [16].

Nariman et al. (2004) [18] tested the antibacterial activity of six plants collected (and endemic) in Iran, against Helicobacter pylori: Glycyrrhiza aspera, Juglans regia, Ligustrum vulgare, Thymus kotschyanus, Trachyspermum copticum, and Xanthium brasilicum. A disk susceptibility assay was used for the evaluation. All of the studied extracts showed anti-H. pylori activity; the most active were obtained from Xanthium brasilicum and Trachyspermum copticum; the solvents used to obtain the extracts were water and an equal mixture of methanol, petroleum benzene, diethyl ether. Minimum inhibitory concentrations (MIC) of the extracts obtained from the two plants range from 31.25 to $250 \mu \mathrm{g} / \mathrm{mL}$ [18].

Pirbalouti et al. (2010) [17] tested the antibacterial activity of essential oils and ethanolic extracts obtained by ten plants traditionally used as medicaments grown and collected in Iran. The tested vegetal extracts were investigated against Staphylococcus aureus, Escherichia coli, Pseudomonas aeruginosa, and Klebsiella pneumoniae by agar disc diffusion assay. Most of the samples showing antibacterial activity were considered as interesting by the authors against the tested bacteria with the diameter of inhibition zone ranging between 8 and $23 \mathrm{~mm}$. The most interesting plants were Satureja bachtiarica and Thymus daenensis (leaves and flowers), with MIC values ranging from 0.039 to $10 \mathrm{mg} / \mathrm{mL}$ [17].

Sepahi et al. (2014) [14] tested the antibacterial activity of aqueous extracts obtained by four plants collected in Iran: Ferula gummosa, Echinophora orientalis, Nasturtium microphyllum, and Verbascum thapsus. The radial diffusion assay was performed using Staphylococcus aureus and Escherichia coli; moreover, hemolysis assay was used to test eventual toxic effects on human red blood cells. All the studied extracts showed interesting activity with MIC values lower than $750 \mu \mathrm{g} / \mathrm{mL}$, and these extracts deserve further studies to identify the main active compounds [14].

\subsubsection{Antifungal Activity}

Imani et al. (2015) [20] studied the essential oil obtained by hydro-distillation of aerial parts of Zhumeria majdae, which is a traditionally used medicinal plant endemic in Iran. The antifungal activity was determined using the serial dilution method. The essential oil (EO) was tested on six pathogenic fungal species and one yeast, and all of them resulted as sensitive to Z. majdae essential oil. Moreover, in particular, the essential oil was interestingly effective against Candida albicans, with a MIC (minimal inhibitory concentration) of $0.031 \mu \mathrm{L} / \mathrm{mL}$. This evidence confirmed the value of Zhumeria majdae as an antifungal agent, and further studies are needed to identify the compounds responsible for this biological activity [20].

In a study conducted by Pirbalouti et al. (2009) [19], the anti-Candida activity of essential oils and extracts of nine plants grown and collected in Iran was tested by agar disc diffusion assay. The studied plants are used in ethnomedical practices. Most of the tested samples showed diameters of inhibition zone ranging from 7 to $46 \mathrm{~mm}$; moreover, in particular, the extracts of Ziziphus spinachristi and Scrophularia striata and the essential oil of Satureja bachtiarica showed the best anti-Candida activity, followed by the essential oils of Thymus daenensis and Trachyspermum ammi [19]. 


\subsubsection{Antimalarial Activity}

Afshar et al. (2018) [22] studied the in vitro antimalarial activity of different extracts of three Iranian endemic species belonging to the Scrophularia genus, including Scrophularia frigida, Scrophularia subaphylla, and Scrophularia atropatana. The antimalarial activity was tested by the cell-free $\beta$-hematin formation assay. Among the studied extracts, the dichloromethane one, obtained by aerial parts of Scrophularia frigida, exhibited strong antimalarial activity with inhibitory capacity $\left(\mathrm{IC}_{50}\right)$ value of $0.67 \pm 0.11 \mathrm{mg} / \mathrm{mL}$. Scrophularia frigida represented a deserving candidate for further studies focused on the identification of the main active compounds [22].

Feiz Haddad et al. (2017) [21] tested the in vitro and in vivo antimalarial activity of ten Iranian plants used in traditional medicine practices. All the plants' samples were collected in the Iranian territory. Methanolic extracts were tested for in vitro antimalarial activity against chloroquine-sensitive 3D7 and multi-drug resistant K1 strains of Plasmodium falciparum. The in vivo activity against Plasmodium berghei infection in mice was determined. Citrullus colocynthis fruits, Physalis alkekengi leaves and fruits, and Solanum nigrum fruits displayed potent in vitro antimalarial activity against both 3D7 and K1 strains; the in vivo studies comparisons between mice treated with the three plant extracts and untreated controls showed reduced parasitemia by $65.08 \%, 57.97 \%$, and $60.68 \%$, respectively [21]. Moreover, no toxicity was evidenced. Further studies can be designed to identify the active constituents and clarify their mechanism of action.

\subsubsection{Antioxidant Activity}

Alinezhad et al. (2012) [25] tested the antioxidant activity of ethyl acetate extracts of stems and leaves and owes of the plant Hyssopus angustifolius, collected in Iran. Antioxidant activity of extracts was evaluated with six different tests: nitric oxide, hydrogen peroxide scavenging, 2,2-diphenyl-1-picrylhydrazyl (DPPH), metal chelating, reducing power activities, and hemoglobin-induced linoleic acid system. The results confirmed the interesting antioxidant profile of this plant; it could be a natural source of active compounds. Further studies are necessary to identify the main active compounds present in the different parts of the plant [25].

Dehghan et al. (2016) [23] evaluated the antioxidant activity and $\alpha$-amylase and $\alpha$-glucosidase inhibition activity of $n$-hexane, ethyl acetate, and methanolic extracts obtained by various parts of eleven plants grown and collected in Hyrcania region, Iran. As regards the antioxidant activity, methanolic extract of Convolvulus persicus roots $\left(\mathrm{IC}_{50}=38.9 \mathrm{mg} / \mathrm{mL}\right)$, methanolic extract of Pyrus boissieriana stems $\left(\mathrm{IC}_{50}=39.3 \mathrm{mg} / \mathrm{mL}\right)$, and methanolic extract of Primula heterochroma leaves, and ethyl acetate and methanolic extracts of its roots $\left(\mathrm{IC}_{50}=41.7 \mathrm{mg} / \mathrm{mL}, 37.9 \mathrm{mg} / \mathrm{mL}\right.$, and $30.1 \mathrm{mg} / \mathrm{mL}$, respectively) evidenced strong activity if compared with butylated hydroxytoluene (BHT) $\left(\mathrm{IC}_{50}=16.7 \mathrm{mg} / \mathrm{mL}\right.$; used as a positive control) [23].

Dehghan et al. (2017) [24] evaluated the antioxidant and antidiabetic activity of extracts obtained by the plant Heracleum persicum. This work led to the isolation of eleven furanocoumarins. These compounds were identified as psoralen, bergapten, xanthotoxin, iso-pimpinellin, angelicin, isobergapten, sphondin, pimpinellin, heratomin, 5-methoxyheratomin, moellendorffiline, and fraxetin. As the antioxidant activity concerns, among the listed compounds, moellendorffiline exhibited strong antioxidant activity with $\mathrm{IC}_{50}=0.2 \mu \mathrm{M}$, a value that was interesting if compared with butylated hydroxytoluene (BHT) $\left(\mathrm{IC}_{50}=0.1 \mu \mathrm{M}\right.$; used as a positive control) [24].

Ebrahimabadi et al. (2010) [30] tested the antioxidant activity of polar and non-polar fractions of the methanolic extract obtained by the plant Stachys inflata. Aerial parts of the plant were collected from Kashan area, Isfahan province, Iran. The biological activity was tested using 2,2-diphenyl-1-picrylhydrazyl (DPPH) and $\beta$-carotene/linoleic acid assays. In the DPPH test, interesting results were shown by the methanolic extract polar subfraction with an $\mathrm{IC}_{50}$ of $89.50 \mu \mathrm{g} / \mathrm{mL}$, indicating an antioxidant potency of about $22 \%$ of that of butylated hydroxytoluene $\left(\mathrm{IC}_{50}=19.72 \mu \mathrm{g} / \mathrm{mL}\right)$. In $\beta$-carotene/linoleic acid assay, the best inhibition belonged to the nonpolar subfraction, with an inhibition percentage of $77.08 \%$. Further studies are needed to identify the main active compounds [30]. 
Fathiazad et al. (2011) [26] studied the ethyl acetate and n-butanol extracts obtained by aerial parts of the plant Hyssopus officinalis L., a medicinal herb collected from north of Iran. Total phenolic content and antioxidant activity were tested by Folin-Ciocalteau and DPPH tests. Apigenin 7-O- $\beta$-D-glucuronide was also isolated as the major flavon. Phenolic content of n-butanol and ethyl acetate extracts was determined and expressed as milligrams of gallic acid equivalents-246 mgGAE/g and $51 \mathrm{mg} \mathrm{GAE/g,} \mathrm{respectively.} \mathrm{The} \mathrm{antioxidant} \mathrm{activity} \mathrm{of} \mathrm{apigenin} \mathrm{7-O-} \beta$-D-glucuronide, ethyl acetate extract, and the n-butanol extract was determined, obtaining $\mathrm{IC}_{50}$ values of $116 \times 10^{-3}$, $103 \times 10^{-3}, 25 \times 10^{-3} \mathrm{mg} / \mathrm{mL}$, respectively. The purified apigenin $7-\mathrm{O}-\beta$ - D-glucuronide showed weak activity. The extract that showed interesting antioxidant activity values, because of the highest content of total phenolic compounds, was the n-butanol one [26].

Khazaeli et al. (2009) [28] tested five traditional medicinal plants from Iran on free radicals scavenging activity and on the inhibition of mushroom tyrosinase activity. Focusing on the radical scavenging activity, methanolic extracts of Quercus infectoria and Terminalia chebula showed a strong radical scavenging effect in the 2,2'-diphenyl-1-picrylhydrazyl (DPPH) assay with values of $\mathrm{IC}_{50}$ (concentration providing 50\% inhibition of the DPPH radical) of 15.3 and $82.2 \mu \mathrm{g} / \mathrm{mL}$, respectively. This study encouraged further investigations on Quercus infectoria and Terminalia chebula in the field of solar protection (due to the radical scavenging activity) and of skin depigmentation agents (due to inhibitory effects on mushroom tyrosinase) [28].

Dehshiri et al. (2013) [31] tested the antioxidant activity of laminas, stems, petioles, fruits, peduncles, and flowers in the hydro-alcoholic extracts from the plant Tetrataenium lasiopetalum. The plant samples were collected from Oshtoran Kuh, Azna, Lorestan, Iran. Antioxidant activities of the extracts were examined by different in vitro assays: 2,2'-diphenyl-1-picrylhydrazyl (DPPH) radical scavenging, metal chelating, reducing power activities, and hemoglobin-induced linoleic acid system. All the tested extracts showed interesting antioxidant activity, confirming hypotheses based on traditional knowledge. Moreover, in particular, the hydro-alcoholic extract of the flower showed the highest activity in the DPPH test $\left(\mathrm{IC}_{50}=170 \pm 7 \mu \mathrm{g} / \mathrm{mL}\right)$. In the metal chelating assay, lamina extract showed the best iron ion chelating activity among the other extracts $\left(\mathrm{IC}_{50}=230 \pm 10 \mu \mathrm{g} / \mathrm{mL}\right)$. Lamina hydro-alcoholic extract demonstrated better activity in the hemoglobin-induced linoleic acid system test than other parts of T. lasiopetalum [31]. Further studies could identify the main active compounds.

Pourmorad et al. (2006) [27] worked on the antioxidant activity, phenol, and flavonoid content of five plants (Mellilotus officinalis, Equisetum maximum, Plantago major, Adiantum capillus-veneris, and Urtica dioica) collected from Northern provinces of Iran (Gilan and Mazandaran). Methanolic extraction was performed after drying at room temperature, and the result was freeze-dried. The extract of Mellilotus officinalis showed a high amount of flavonoid (57 $\pm 5.4 \mathrm{mg} / \mathrm{g})$ and phenolic compounds $(289.5 \pm 5 \mathrm{mg} / \mathrm{g})$ and exhibited the greatest radical scavenging activity $\left(\mathrm{IC}_{50}=0.018 \mathrm{mg} / \mathrm{mL}\right)$ in a DPPH test among the tested extracts [27].

Sonboli et al. (2010) [29] assessed antioxidant activities and total phenolic contents of methanolic extracts obtained from male inflorescences of Salix aegyptiaca L., grown and collected in Ashena Abad village, Urmia (West Azarbaijan province), Iran. 2,2-diphenyl-1-picrylhydrazyl (DPPH) free radical scavenging assay and Folin-Ciocalteu method were performed on the whole methanolic extract and on three fractions (water fraction, butanol fraction, and chloroform fraction) obtained from it. The butanol fraction evidenced, among the others, the best antioxidant activity and the highest phenolic content with an $\mathrm{IC}_{50}$ value of $27.7 \mu \mathrm{g} / \mathrm{mL}$ and total phenols of $313.8 \mathrm{ppm}$; the results were interesting because this extract was comparable with the synthetic antioxidant butylated hydroxytoluene $(\mathrm{BHT})\left(\mathrm{IC} \mathrm{C}_{50}=\right.$ $26.5 \mu \mathrm{g} / \mathrm{mL}$ ) [29]. The detected antioxidant activity encouraged the use of this plant for its antioxidant properties in food industries and in cosmetic and pharmaceutical preparations. 


\subsubsection{Anticancer Activity/Cytotoxic Activity}

Asadi-Samani et al. (2018) [33] tested the in vitro antiproliferative activity of twenty Iranian medicinal plants against prostate cancer. The plant samples were collected in Chaharmahal and Bakhtiari provinces, Iran. The extraction of the powdered aerial parts was conducted by maceration in ethanol $70 \%$ for $72 \mathrm{~h}$ and was concentrated under reduced pressure. Antiproliferative activity of the tested extracts on PC-3, DU145 (prostate cancer cell lines), and HDF (non-cancer cell line) cell lines was evaluated by MTT (3-[4,5-dimethylthiazol-2-yl]-2,5 diphenyl tetrazolium bromide) assay. The hydro-alcoholic extract obtained by the plant Euphorbia szovitsii Fisch. \& C. A. Mey showed good antiproliferative activity against PC-3 and DU145 cell lines. Urtica dioica and Medicago sativa resulted active only on the DU-145 cell line. These results could be a starting point in the development of new anticancer drugs, and further studies are needed in order to identify the main active compounds [33].

Esmaeilbeig et al. (2015) [36] tested the in vitro anticancer activities of ten species of plants grown and collected in southern Iran using the MTT colorimetric assay. Methanolic extracts obtained by aerial parts of the plants Arctium lappa, Cichorium intybus, Glycyrrhiza glabra, Alhagi psuedalhahi, Mentha longifolia, Thymus daenensis, Thymus vulgaris, Satureja bachtiarica, Satureja hortensis, and Rheum ribes were tested against five tumor cell lines: K562 (myelogenous leukemia), Jurkat (T cell leukemia), and Raji (Burkitt's lymphoma), Fen (bladder carcinoma), and HeLa (human cervical epithelioid carcinoma). No activity was detected against solid tumor cell lines Fen and HeLa, and leukemic cell lines demonstrated to be more sensitive to the extracts. Satureja hortensis, Satureja bachtiarica, Thymus vulgaris, Thymus daenensis, and Mentha longifolia showed strong inhibitory activity on Jurkat cells with inhibition values higher than $80 \%$ at a concentration of $200 \mu \mathrm{g} / \mathrm{mL}$. At the same concentration, these extracts inhibited the K562 cell line with more than 50\% of inhibition [36]. Further studies are needed to identify the main active compounds.

Hamzeloo-Moghadam et al. (2015) [35] tested the cytotoxic activity and the apoptosis induction activity of different fractions obtained by methanolic extract of Hypericum scabrum leaves. The plant was collected from Alborz province, Iran. The petroleum ether, dichloromethane, and methanol fractions were evaluated for cytotoxicity against M-CF7, A-549, HT-29, and HepG-2 cell lines. The apoptosis induction ability was assessed by activated caspase- 3 inspection and Annexin V FITC/PI (propidium iodide) assays.

The results evidenced strong cytotoxicity against HT-29 and HepG-2 cell lines and interesting apoptosis induction ability; the authors suggested further studies in this field [35].

Jassbi et al. (2016) [32] tested the cytotoxic activity, against three human cancer cell lines (LS180, MCF-7, and MOLT-4), of dichloromethane and methanol extracts of Anthemis mirheydari, an endemic plant from Iran. The plant samples were collected in Jahrom in Fars province, Iran, and the whole plant was used for the extraction. The dichloromethane extract evidenced interesting $\mathrm{IC}_{50}$ values, $30.8,25.2$, and $8.6 \mathrm{mg} / \mathrm{mL}$ for the three cell lines, respectively. Four compounds were isolated from the dichloromethane extract: taraxasterol, pseudotaraxasterol, $\beta$-sitosterol, and 7-methoxycoumarin. Taraxasterol and 7-methoxycoumarin are known in scientific literature to present anticancer properties; this fact, along with the encouraging results of the study, makes Anthemis mirheydari a new potential anticancer medicinal plant that certainly deserves further investigations [32].

Mehdi Razavi et al. 2011 [16] tested the in vitro cytotoxic activity of different extracts obtained by the plant Malva sylvestris L. (flowers and leaves); this plant is commonly used in traditional medicine practices in Iran. Flowers and leaves of the plant were collected from Tabriz, Iran. The methanolic extracts of flowers and leaves evidenced interesting cytotoxic activity against the MacCoy cell line, reducing their viability with $\mathrm{IC}_{50}$ values of 265.3 and $311.0 \mu \mathrm{g} / \mathrm{mL}$, respectively. The authors declared that Malva sylvestris L. plant extracts could be considered as an antiproliferative agent [16]. Further studies are needed to identify the main active compounds.

Sahranavard et al. (2009) [34] tested the cytotoxic activity of methanolic extracts of fifteen Iranian medicinal plants against three cancer cell lines (MCF7, HepG2, WEHI164). The extract obtained by Ferula szowitsiana root showed $\mathrm{IC}_{50}$ values lower than $100 \mu \mathrm{g} / \mathrm{mL}$ in all the tested cell lines, and it 
was chosen for further studies. Fractionation was performed, which led to the isolation of two monoterpenoids; both of them were bornyl esters that were identified as Chimganin and Chimgin. These compounds showed interesting cytotoxic effects with values of $\mathrm{IC}_{50}$ significantly lower if compared to the whole extract; they performed a little less than tamoxifen, which was used as a positive control. These results demonstrated that the two compounds were mostly responsible for the cytotoxic activity of this plant [34].

\subsubsection{Antidiabetic Activity}

Dehghan et al. (2016) [23] evaluated $\alpha$-amylase and $\alpha$-glucosidase inhibition activities of $n$-hexane, ethyl acetate, and methanol extracts obtained by various parts of eleven plants grown and collected in Hyrcania region, Iran.

The n-hexane extract of Heracleum persicum (aerial parts, roots), ethyl acetate and n-hexane extract of Smilax excelsa (stem and leaves), methanolic, n-hexane, ethyl acetate extract of Pyrus boissieriana (leaves and steam), ethyl acetate and methanolic extract of Parrotia persica (leaves), and methanolic and ethyl acetate extract of Primula heterochroma (leaves and roots) exhibited significant antidiabetic activities in $\alpha$-glucosidase and $\alpha$-amylase assays, more effective than acarbose used as a positive control [23]. These plants, in conclusion, are deserving candidates for further studies in the antidiabetic field.

Dehghan et al. (2017) [24] evaluated the antidiabetic activity of extracts obtained by the plant Heracleum persicum. This work led to the isolation of eleven furanocoumarins. These compounds were identified as psoralen, bergapten, xanthotoxin, iso-pimpinellin, angelicin, isobergapten, sphondin, pimpinellin, heratomin, 5-methoxyheratomin, moellendorffiline, and fraxetin. Among them, moellendorffiline showed significant inhibitory activity against $\alpha$-glucosidase with an $\mathrm{IC}_{50}$ value of $17.9 \mathrm{nM}$, and it was more active than acarbose ( $\mathrm{IC}_{50}=23.5 \mathrm{nM}$; used as a positive control) [24].

Hasanein et al. (2016) [37] studied the effects of Salvia officinalis L. against learning and memory deficit induced by diabetes. This plant has been used in Iranian traditional medicine practices against diabetes. The plant samples were collected in Hamedan, Iran. The effects of the leaves' hydro-alcoholic extract on passive avoidance learning (PAL) and memory in streptozocin-induced diabetic and non-diabetic rats were evaluated. Administration for thirty days demonstrated to alleviate the negative influence of diabetes on learning and memory. Positive effects on hyperglycemia and oxidative stress were evidenced. Therefore, Salvia officinalis L. and its constituent rosmarinic acid represented a potential therapeutic option against diabetic memory impairment, and further studies are needed to clarify the mechanisms involved in this activity [37].

\subsubsection{Iron chelating Activity}

Ebrahimzadeh et al. (2008) [38] tested the iron chelating activity, phenol, and flavonoid content of eleven medicinal plants from Iran. The extraction was performed by maceration of the vegetal dried material for three days. The solvent was evaporated under reduced pressure and then lyophilized. Epilobium hirsutum leaves and Melilotus arvensis showed the best chelating activity with $\mathrm{IC}_{50}$ values of $0.49 \pm 0.01 \mathrm{mg} / \mathrm{mL}$ and $0.08 \pm 0.01 \mathrm{mg} / \mathrm{mL}$, respectively. These plant extracts also showed high phenol and flavonoid contents. Feijoa sellowiana leaves and Pistacia lentiscus showed good chelating activity [38].

\subsubsection{Anti-Platelet Aggregation Activity}

Lorigooini et al. (2014) [39] studied the essential oil obtained by aerial parts of Allium atroviolaceum. The plant was collected in Rig mountain, Shahr-e-kord province, Iran. In this work, the anti-platelet aggregation activity of the essential oil was examined using arachidonic acid (AA) and adenosine diphosphate (ADP) as platelet aggregation inducers.

The essential oil evidenced dose-dependent inhibitory effect against AA and ADP-induced aggregation with $\mathrm{IC}_{50}$ values of $0.25 \mathrm{mg} / \mathrm{mL}$ and $0.47 \mathrm{mg} / \mathrm{mL}$, respectively [39]. Further studies are required to identify the main active compounds of the essential oil. 


\subsubsection{Mushroom Tyrosinase Inhibition Activity}

Khazaeli et al. (2009) [28] tested five traditional medicinal plants from Iran on the inhibition of mushroom tyrosinase activity. Methanolic extracts obtained from Quercus infectoria galls and Terminalia chebula fruits showed inhibitory effects on mushroom tyrosinase in the hydroxylation of L-tyrosine (85.9\% and $82.2 \%$ of inhibition, respectively). Furthermore, these two plants inhibited the oxidation of Levodopa (L-DOPA), performing similarly to kojic acid (used as a positive control) with values of $\mathrm{IC}_{50}$ $=102.8$ and $192.6 \mu \mathrm{g} / \mathrm{mL}$, respectively [28]. This study encouraged further investigations on the two plants in the field of solar protection due to the radical scavenging activity and of skin depigmentation agents due to inhibitory effects on mushroom tyrosinase.

\subsubsection{Acetylcholinesterase-Inhibitory Activity}

Abbas-Mohammadi et al. (2018) [42] tested the acetylcholinesterase-inhibitory activity of n-hexane, ethyl acetate, and methanolic extracts obtained by aerial parts of twenty-five plants grown and collected in Iran. The evaluation was conducted by an in vitro enzymatic Ellman method and molecular docking study. The n-hexane extract obtained by the plant Prangos ferulacea showed the highest acetylcholinesterase (AChE)-inhibitory activity with $75.6 \%$ inhibition at a concentration of $50 \mu \mathrm{g} / \mathrm{mL}$. The chemical characterization of the extract led to the identification of seventeen compounds. Further studies led to the identification of a subfraction (named $F_{10 f}$ ) that resulted as the most potent inhibitor of $\mathrm{AChE}$ in this extract with an $\mathrm{IC}_{50}$ value of $25.2 \mu \mathrm{g} / \mathrm{mL}$ [42]. Prangos ferulacea deserves further in vivo and in vitro studies as the discovery of new acetylcholinesterase (AChE) inhibitors might lead to new tools for the treatment of Alzheimer's disease.

Adhami et al. (2011) [41] tested the acetylcholinesterase-inhibitory activity of forty herbal drugs traditionally used against cognitive disorders in Iran. Eighty drugs were tested by TLC bioautography method and microplate colorimetric assay, and, due to the interesting activity, the seeds of Peganum harmala L. were investigated in detail. The alkaloids harmaline and harmine were identified as active compounds. The $\mathrm{IC}_{50}$ values were $8.4 \mu \mathrm{g} / \mathrm{mL}$ for harmaline (pure compound) and $10.9 \mu \mathrm{g} / \mathrm{mL}$ for harmine (pure compound), $41.2 \mu \mathrm{g} / \mathrm{mL}$ for the methanolic extract, $95.5 \mu \mathrm{g} / \mathrm{mL}$ for the dichloromethane extract [41]. The two tested alkaloids were the major AChE-inhibitory compounds in Peganum harmala; this plant deserves further studies to test the biological activity in vivo.

Jazayeri et al. (2014) [40] evaluated the acetylcholinesterase-inhibitory activity of eighteen aqueous-methanolic extracts $(1: 1 \mathrm{v} / \mathrm{v})$ obtained by plants commonly used in Iranian traditional medicine collected in Tehran. The inhibitory activity was tested using the in vitro Ellman spectrophotometric method. According to the results, five plants evidenced interesting properties. The inhibitory activity values, expressed as $\mathrm{IC}_{50} \mu \mathrm{g} / \mathrm{mL}$, in fact were $5.96 \mu \mathrm{g} / \mathrm{mL}$ for Camellia sinensis (leaves), $19.57 \mu \mathrm{g} / \mathrm{mL}$ for Citrus aurantifolia (fruits), $24.37 \mu \mathrm{g} / \mathrm{mL}$ for Zizyphus vulgaris (fruits), $84.30 \mu \mathrm{g} / \mathrm{mL}$ for Brassica nigra (seeds), and $93.1 \mu \mathrm{g} / \mathrm{mL}$ for Rosa damascena (flowers) [40]. Further investigations regarding the identification of active components in the extracts are needed.

\subsubsection{Antihyperlipidemic and Antihypertensive Activities}

Asgary et al. (2000) [43] studied the antihyperlipidemic and antihypertensive effects of Achillea wilhelmsii C. Koch drops, with a double-blind placebo-controlled clinical trial. The aerial parts of the plant were collected in Chatrood village in the province of Kerman, Southeast Iran. Moderate hyperlipidemic and primary hypertensive subjects were treated with a hydro-alcoholic extract twice daily for more than six months. The results showed a significant decrease in triglycerides after two months of treatment. Significant decreases in triglycerides, total cholesterol, and low-density lipoproteins (LDL)-cholesterol were observed after four months of treatment. Levels of high-density lipoproteins (HDL)-cholesterol were significantly increased after six months. A significant decrease in diastolic and systolic blood pressure was observed after two and six months, respectively [43]. 


\subsubsection{Gastric Antiulcerogenic Activity}

Karimi et al. (2004) [44] studied the gastric antiulcerogenic activity of aqueous and ethanolic extracts obtained from the plant Portulaca oleracea L. collected in the village of Khaje-rabi, Khorasan province, Iran. Both leaves extracts, tested in vivo in mice, showed remarkable dose-dependent inhibition of gastric lesions induced by absolute ethanol or $\mathrm{HCl}$ [44]. This gastroprotective activity resulted in line with Iranian traditional medicine knowledge, and it deserves further studies to determine the involved mechanisms.

\subsubsection{Anti-Dyspepsia Activity}

Khonche et al. (2017) [45] tested the efficacy of Mentha pulegium L., collected in the Alborz province of Iran, against functional dyspepsia in a randomized double-blind placebo-controlled clinical trial. Leaves of this plant are used in Iranian traditional medicine practices to treat dyspeptic symptoms. The hydro-alcoholic leaf extract taken daily for two months was shown to be effective in the reduction of dyspeptic symptoms, improving quality of life, and contributing to eradicate Helicobacter pylori in patients affected by functional dyspepsia [45].

\subsubsection{Inhibitory Effect on Gastric Acid Output}

Niazmand et al. (2010) [46] studied the effects of the aqueous-ethanolic extract obtained by aerial parts of the plant Achillea wilhelmsii on rat's gastric acid output in basal, vagotomized, and vagal-stimulated conditions. The plant samples were collected from South Khorasan province, Iran. Achillea wilhelmsii is a plant frequently used in Iranian traditional medicine against gastrointestinal disorders. The results of the in vivo study showed that the aqueous-ethanol extract of $A$. wilhelmsii exhibited an inhibitory effect on gastric acid output in basal conditions via the gastric parasympathetic nerve. The extract had no effect on vagal-stimulated conditions [46]. Further studies are needed to identify the compounds and mechanisms responsible for this activity.

\subsubsection{Anti-Colitic Activity}

Minaiyan et al. (2011) [47] tested the anti-colitic activity of hydro-alcoholic extract and the essential oil obtained by Rosmarinus officinalis leaves. The plant material was collected in the city of Isfahan, Iran. The study was performed in vivo on a model of experimental colitis induced by trinitrobenzene sulfonic acid in rats.

Both the extracts at all the tested doses demonstrated to be effective in the reduction of colon tissue lesions and of colitis indices; the higher doses tested were considerably effective in diminishing histopathologic parameters. These data supported the traditional medicine knowledge and suggested that both hydro-alcoholic extract and the essential oil obtained by Rosmarinus officinalis leaves possess consistent anti-colitic activity [47].

\section{Conclusions}

The Iranian territory possesses a great abundance of plants suitable for medicinal use and remarkable heritage of knowledge handed down from generation to generation concerning natural remedies against a wide range of diseases and disorders. Nowadays, the study of this heritage is at an early stage.

As reported in Sections 3 and 4, the bibliographic research evidenced ethnobotanical studies conducted in the Iranian territory, carrying out questionnaires and interviews with traditional healers or local people, and scientific studies inspired by traditional medicinal practices conducted on plants collected in Iran. Comparing ethnobotanical studies and traditional medicine-inspired scientific studies, it is evident that most of the Iranian traditional herbal remedies have not been considered from a scientific point of view yet. Only 34 plants are cited in both Sections 3 and 4 among the 245 of Section 3. Table 3 provides a comparison between traditional uses and tested biological activities of the plants cited both in Sections 3 and 4. 
Table 3. Comparison between traditional uses and tested biological activities of Iranian plants. (N.r. = not reported).

\begin{tabular}{|c|c|c|}
\hline $\begin{array}{l}\text { Plant Name } \\
\text { Family }\end{array}$ & $\begin{array}{c}\text { Traditional Uses } \\
\text { Part of the Plant (When Reported) } \\
\text { Type of Extract (When Reported) } \\
\text { Authors }\end{array}$ & $\begin{array}{l}\text { Biological Activities } \\
\text { Part of the Plant } \\
\text { Type of Extract } \\
\text { Authors }\end{array}$ \\
\hline $\begin{array}{c}\text { Achillea millefolium } \mathrm{L} \text {. } \\
\text { Asteraceae }\end{array}$ & $\begin{array}{c}\text { Antidiabetic } \\
\text { Inflorescence } \\
\text { Boiled, Steamed } \\
\text { [7] Bahmani et al. 2014 } \\
\text { Antiparasitic } \\
\text { Aerial parts } \\
\text { Herbal tea/decoction } \\
\text { [6] Bahmani et al. 2016 }\end{array}$ & $\begin{array}{l}\text { Antibacterial activity } \\
\text { Aerial parts } \\
\text { Methanolic extract } \\
\text { [10] Lotfipour et al. } 2008\end{array}$ \\
\hline $\begin{array}{c}\text { Alhagi maurorum } \\
\text { Fabaceae }\end{array}$ & $\begin{array}{c}\text { Appetite suppressant, Diuretic, Jaundice, Febrifuge } \\
\text { Aerial parts, Manna } \\
\text { [5] Amiri and Joharchi } 2013\end{array}$ & $\begin{array}{c}\text { Antibacterial activity } \\
\text { Leaves } \\
\text { Methanolic extract (Lyophilized) } \\
\text { [11] Bonjar et al. } 2004\end{array}$ \\
\hline $\begin{array}{l}\text { Brassica nigra }(\mathrm{L} .) \\
\text { Brassicaceae }\end{array}$ & $\begin{array}{c}\text { Laxative } \\
\text { Seeds } \\
\text { [5] Amiri and Joharchi } 2013\end{array}$ & $\begin{array}{c}\text { Acetylcholinesterase-inhibitory activity } \\
\text { Seeds } \\
\text { Aqueous-methanolic extract } \\
\text { [40] Jazayeri et al. } 2014\end{array}$ \\
\hline $\begin{array}{c}\text { Camellia sinensis }(\mathrm{L} .) \\
\text { Theaceae }\end{array}$ & $\begin{array}{c}\text { Obesity, Anticancer, Antihypertensive, Hepatitis, } \\
\text { Antihyperlipidemia } \\
\text { Leaves } \\
\text { [5] Amiri and Joharchi } 2013\end{array}$ & $\begin{array}{c}\text { Acetylcholinesterase-inhibitory activity } \\
\text { Leaves } \\
\text { Aqueous-methanolic extract } \\
\text { [40] Jazayeri et al. } 2014\end{array}$ \\
\hline $\begin{array}{l}\text { Citrullus colocynthis (L.) } \\
\text { Cucurbitaceae }\end{array}$ & $\begin{array}{c}\text { Antidiabetic } \\
\text { Fruit } \\
\text { Boiled } \\
\text { [7] Bahmani et al. } 2014 \\
\text { Purgative, Anodyne, Hypoglycemic } \\
\text { Fruit- Seed } \\
\text { [5] Amiri and Joharchi } 2013\end{array}$ & $\begin{array}{l}\text { Antimalarial activity } \\
\text { Fruits } \\
\text { Methanolic extract } \\
\text { [21] Feiz Haddad et al. } 2017\end{array}$ \\
\hline $\begin{array}{c}\text { Citrus aurantiifolia } \\
\text { Rutaceae }\end{array}$ & $\begin{array}{c}\text { Antihypertensive, Calmative } \\
\text { Fruit } \\
\text { [5] Amiri and Joharchi } 2013\end{array}$ & $\begin{array}{c}\text { Acetylcholinesterase-inhibitory activity } \\
\text { Fruits } \\
\text { Aqueous-methanolic extract } \\
\text { [40] Jazayeri et al. } 2014\end{array}$ \\
\hline
\end{tabular}


Table 3. Cont.

\begin{tabular}{|c|c|c|}
\hline $\begin{array}{l}\text { Plant Name } \\
\text { Family }\end{array}$ & $\begin{array}{c}\text { Traditional Uses } \\
\text { Part of the Plant (When Reported) } \\
\text { Type of Extract (When Reported) } \\
\text { Authors }\end{array}$ & $\begin{array}{l}\text { Biological Activities } \\
\text { Part of the Plant } \\
\text { Type of Extract } \\
\text { Authors }\end{array}$ \\
\hline $\begin{array}{c}\text { Cuminum cyminum } \mathrm{L} . \\
\text { Apiaceae }\end{array}$ & $\begin{array}{l}\text { Treatment of colic, Galactogogue, Obesity, Digestive, Flavoring, } \\
\text { Antiseptic } \\
\text { Fruit } \\
\text { [5] Amiri and Joharchi } 2013\end{array}$ & $\begin{array}{l}\text { Antibacterial activity } \\
\text { Leaves } \\
\text { Methanolic extract (Lyophilized) } \\
\text { [11] Bonjar et al. } 2004\end{array}$ \\
\hline $\begin{array}{c}\text { Dorema ammoniacum } \\
\text { Apiaceae }\end{array}$ & $\begin{array}{c}\text { Cystitis, Digestive, Treatment of colic, Treatment of furuncles, } \\
\text { Expectorant, Anthelmintic, Emmenagogue, Anticovulsion } \\
\text { Gum- Root } \\
\text { [5] Amiri and Joharchi } 2013\end{array}$ & $\begin{array}{l}\text { Antibacterial activity } \\
\text { Seeds } \\
\text { Methanolic extract } \\
\text { [13] Abedini et al. } 2014\end{array}$ \\
\hline $\begin{array}{c}\text { Ferula assa-foetida } L \\
\text { Umbelliferae }\end{array}$ & $\begin{array}{l}\text { Antiparasitic } \\
\text { Leaf } \\
\text { Herbal tea/decoction } \\
\text { [6] Bahmani et al. } 2016\end{array}$ & $\begin{array}{l}\text { Antibacterial activity } \\
\text { Seeds } \\
\text { Methanolic extract } \\
\text { [13] Abedini et al. } 2014\end{array}$ \\
\hline $\begin{array}{l}\text { Ferula foetida } \\
\text { Apiaceae }\end{array}$ & $\begin{array}{l}\text { Anthelmintic, Treatment of colic, Emmenagogue } \\
\text { Gum } \\
\text { [5] Amiri and Joharchi } 2013\end{array}$ & $\begin{array}{c}\text { Antibacterial activity } \\
\text { Roots } \\
\text { Methanolic extract } \\
\text { [15] Chitsazian-Yazdi et al. } 2015 \\
\text { Cytotoxic activity } \\
\text { Roots } \\
\text { Methanolic extract } \\
\text { [15] Chitsazian-Yazdi et al. } 2015\end{array}$ \\
\hline $\begin{array}{c}\text { Ferula gummosa } \\
\text { Apiaceae }\end{array}$ & $\begin{array}{l}\text { Anthelmintic, Anticatarrhal, Anti-allergic, Dyspepsia, Appetizer, } \\
\text { Emmenagogue } \\
\text { Gum- Root } \\
\text { [5] Amiri and Joharchi } 2013\end{array}$ & $\begin{array}{c}\text { Antibacterial activity } \\
\text { Leaves } \\
\text { Aqueous extract } \\
\text { [14] Sepahi et al. } 2014\end{array}$ \\
\hline
\end{tabular}


Table 3. Cont.

\begin{tabular}{|c|c|c|}
\hline $\begin{array}{l}\text { Plant Name } \\
\text { Family }\end{array}$ & $\begin{array}{c}\text { Traditional Uses } \\
\text { Part of the Plant (When Reported) } \\
\text { Type of Extract (When Reported) } \\
\text { Authors }\end{array}$ & $\begin{array}{l}\text { Biological Activities } \\
\text { Part of the Plant } \\
\text { Type of Extract } \\
\text { Authors }\end{array}$ \\
\hline $\begin{array}{l}\text { Heracleum persicum } \\
\text { Apiaceae }\end{array}$ & $\begin{array}{c}\text { Stomach ache } \\
\text { Leaf, Flower } \\
\text { Decoction } \\
\text { [8] Delfan et al. } 2015 \\
\text { Treatment of hiccup, Appetizer, Flavoring, Carminative, } \\
\text { Anthelmintic, Stomach tonic fruit } \\
\text { [5] Amiri and Joharchi } 2013\end{array}$ & $\begin{array}{c}\text { Antioxidant activity } \\
\text { Roots } \\
\text { n-Hexane extract (subsequently fractionated) } \\
\text { [24] Dehghan et al. 2017 } \\
\text { Antidiabetic activity } \\
\text { Aerial parts, Roots } \\
\text { n-hexane extract } \\
\text { Roots } \\
\text { n-Hexane extract (subsequently fractionated) } \\
\text { [23] Dehghan et al.2016 and [24] Dehghan et al. } 2017\end{array}$ \\
\hline $\begin{array}{c}\text { Hypericum scabrum } \mathrm{L} . \\
\text { Hypericaceae }\end{array}$ & $\begin{array}{l}\text { Antimigraine, Gastric ulcer, Anti-hemorrhage, Urinary incontinence, } \\
\text { Treatment of headache } \\
\text { Flower } \\
\text { [5] Amiri and Joharchi } 2013\end{array}$ & $\begin{array}{c}\text { Cytotoxic activity and apoptosis induction activity } \\
\text { Leaves } \\
\text { Methanolic extract (fractionated) } \\
\text { [35] Hamzeloo-Moghadam et al. } 2015\end{array}$ \\
\hline $\begin{array}{c}\text { Lawsonia inermis } \mathrm{L} . \\
\text { Lythraceae }\end{array}$ & $\begin{array}{l}\text { Hair color, Treatment of headache, Hair tonic, Washing, Antifungal, } \\
\text { Antiseptic } \\
\text { Leaves } \\
\text { [5] Amiri and Joharchi } 2013\end{array}$ & $\begin{array}{l}\text { Antibacterial activity } \\
\text { Leaves } \\
\text { Methanolic extract (Lyophilized) } \\
\text { [11] Bonjar et al. } 2004\end{array}$ \\
\hline $\begin{array}{l}\text { Malva sylvestris } \mathrm{L} . \\
\text { Malvaceae }\end{array}$ & $\begin{array}{c}\text { Pharyngitis, Furuncles, Aphthous ulcers, Febrifuge, Antitussive, } \\
\text { Jaundice, Laxative, Gastric ulcer, Treatment of wounds } \\
\text { Flower- Fruit } \\
\text { [5] Amiri and Joharchi } 2013\end{array}$ & $\begin{array}{c}\text { Antibacterial activity } \\
\text { Flowers } \\
\text { Methanolic extract } \\
\text { [16] Razavi et al. 2011 } \\
\text { Cytotoxic activity } \\
\text { Flowers and leaves } \\
\text { Methanolic extract } \\
\text { [16] Razavi et al. } 2011\end{array}$ \\
\hline $\begin{array}{c}\text { Medicago sativa } \mathrm{L} . \\
\text { Fabaceae }\end{array}$ & $\begin{array}{c}\text { Appetizer, Tonic, Osteomalacia, Anti-hemorrhage } \\
\text { Aerial parts } \\
\text { [5] Amiri and Joharchi } 2013\end{array}$ & $\begin{array}{l}\text { Antiproliferative on DU-145 cell line } \\
\text { Aerial parts } \\
\text { Hydro-alcoholic extract } \\
\text { [33] Asadi-Samani et al. } 2018\end{array}$ \\
\hline
\end{tabular}


Table 3. Cont.

\begin{tabular}{|c|c|c|}
\hline $\begin{array}{l}\text { Plant Name } \\
\text { Family }\end{array}$ & $\begin{array}{c}\text { Traditional Uses } \\
\text { Part of the Plant (When Reported) } \\
\text { Type of Extract (When Reported) } \\
\text { Authors }\end{array}$ & $\begin{array}{l}\text { Biological Activities } \\
\text { Part of the Plant } \\
\text { Type of Extract } \\
\text { Authors }\end{array}$ \\
\hline $\begin{array}{l}\text { Mentha longifolia } \\
\text { Lamiaceae }\end{array}$ & $\begin{array}{c}\text { Herpes, Anthelmintic, Antacid, Carminative, Antidiarrhea, Digestive } \\
\text { Aerial parts } \\
\text { [5] Amiri and Joharchi } 2013\end{array}$ & $\begin{array}{l}\text { Anticancer activity } \\
\text { Aerial parts } \\
\text { Methanolic extract } \\
\text { [36] Esmaeilbeig et al. } 2015\end{array}$ \\
\hline $\begin{array}{l}\text { Nymphaea alba L. } \\
\text { Nymphaeaceae }\end{array}$ & $\begin{array}{l}\text { Expectorant, Hypnotic, Antitussive, Calmative Flower } \\
\text { [5] Amiri and Joharchi } 2013\end{array}$ & $\begin{array}{l}\text { Antibacterial activity } \\
\text { Leaves } \\
\text { Methanolic extract (Lyophilized) } \\
\text { [11] Bonjar et al. } 2004\end{array}$ \\
\hline $\begin{array}{l}\text { Peganum harmala } \mathrm{L} . \\
\quad \text { Nitrariaceae }\end{array}$ & $\begin{array}{c}\text { Diabetes, Antiseptic, Hypnotic, Treatment of rheumatism and } \\
\text { sciatica disorders, Anthelmintic, Emmenagogue } \\
\text { Seed } \\
\text { [5] Amiri and Joharchi } 2013\end{array}$ & $\begin{array}{l}\text { Acetylcholinesterase-inhibitory activity } \\
\text { Seeds } \\
\text { Methanolic extract and } \\
\text { dichloromethane extract } \\
\text { [41] Adhami et al. } 2011\end{array}$ \\
\hline $\begin{array}{l}\text { Perovskia abrotanoides Kar. } \\
\text { Lamiaceae }\end{array}$ & $\begin{array}{c}\text { Treatment of sinusitis, Treatment of toothache, Antitussive, Nerve } \\
\text { tonic, Carminative, Sedative, Antiseptic, Anthelmintic, Treatment of } \\
\text { colic } \\
\text { Aerial parts } \\
\text { [5] Amiri and Joharchi } 2013\end{array}$ & $\begin{array}{l}\text { Antibacterial activity } \\
\text { Aerial parts } \\
\text { Methanolic extract } \\
\text { [13] Abedini et al. } 2014\end{array}$ \\
\hline $\begin{array}{l}\text { Physalis alkekengi } \mathrm{L} . \\
\text { Solanaceae }\end{array}$ & $\begin{array}{c}\text { Emmenagogue, Treatment of kidney stones, Blood cleansing } \\
\text { Fruit } \\
\text { [5] Amiri and Joharchi } 2013\end{array}$ & $\begin{array}{l}\text { Antimalarial activity } \\
\text { Leaves and fruits } \\
\text { Methanolic extract } \\
\text { [21] Feiz Haddad et al.2017 }\end{array}$ \\
\hline $\begin{array}{l}\text { Portulaca oleracea L. } \\
\quad \text { Portulacaceae }\end{array}$ & $\begin{array}{c}\text { Antitussive, Febrifuge, Anti-thirst, Food digestion, Depurative, } \\
\text { Diuretic, Anti-hemorrhoids } \\
\text { Seed- Leaves } \\
\text { [5] Amiri and Joharchi } 2013\end{array}$ & $\begin{array}{l}\text { Gastric antiulcerogenic activity } \\
\text { Leaves } \\
\text { Aqueous extract and } \\
\text { Ethanolic extract } \\
\text { [44] Karimi et al. } 2004\end{array}$ \\
\hline
\end{tabular}


Table 3. Cont.

\begin{tabular}{|c|c|c|}
\hline $\begin{array}{l}\text { Plant Name } \\
\text { Family }\end{array}$ & $\begin{array}{c}\text { Traditional Uses } \\
\text { Part of the Plant (When Reported) } \\
\text { Type of Extract (When Reported) } \\
\text { Authors }\end{array}$ & $\begin{array}{l}\text { Biological Activities } \\
\text { Part of the Plant } \\
\text { Type of Extract } \\
\text { Authors }\end{array}$ \\
\hline $\begin{array}{l}\text { Quercus infectoria Oliv. } \\
\text { Fagaceae }\end{array}$ & $\begin{array}{l}\text { Nosebleed, Anti-hemorrhage, Uterus ailments, Mouth wounds, } \\
\text { Anti-hemorrhoids } \\
\text { Insect gull } \\
\text { [5] Amiri and Joharchi } 2013\end{array}$ & $\begin{array}{c}\text { Radical scavenging activity } \\
\text { Inhibition of mushroom tyrosinase } \\
\text { Galls } \\
\text { Methanolic extract } \\
\text { [28] Khazaeli et al. } 2009\end{array}$ \\
\hline $\begin{array}{l}\text { Rheum ribes } \mathrm{L} . \\
\text { Polygonaceae }\end{array}$ & $\begin{array}{l}\text { Jaundice, Urinary antiseptic, Diuretic, Depurative, Liver tonic, } \\
\text { Antiseptic, Hair tonic } \\
\text { Fruit- Petiole } \\
\text { [5] Amiri and Joharchi } 2013\end{array}$ & $\begin{array}{c}\text { Antibacterial activity } \\
\text { Leaves } \\
\text { Methanolic extract (Lyophilized) } \\
\text { [11] Bonjar et al. } 2004\end{array}$ \\
\hline $\begin{array}{l}\text { Rhus coriaria L. } \\
\text { Anacardiaceae }\end{array}$ & $\begin{array}{l}\text { Jaundice, Cholesterol-lowering, Diabetes, Antihypertensive, } \\
\text { Antidiarrhea, Anti-hemorrhage, Flavoring } \\
\text { Fruit } \\
\text { [5] Amiri and Joharchi } 2013 \\
\text { Blood refining } \\
\text { Fruit, Leaf, Resin } \\
\text { Boiled } \\
\text { [7] Bahmani et al. } 2014\end{array}$ & $\begin{array}{l}\text { Antibacterial activity } \\
\text { Leaves } \\
\text { Methanolic extract (Lyophilized) } \\
\text { [11] Bonjar et al. } 2004\end{array}$ \\
\hline $\begin{array}{c}\text { Rosa damascena Mill. } \\
\text { Rosaceae }\end{array}$ & $\begin{array}{l}\text { Anti-hemorrhoid, Laxative, Calmative } \\
\text { Flower } \\
\text { [5] Amiri and Joharchi } 2013\end{array}$ & $\begin{array}{l}\text { Acetylcholinesterase-inhibitory activity } \\
\text { Flowers } \\
\text { Aqueous extract and methanolic extract } \\
\text { [40] Jazayeri et al. } 2014\end{array}$ \\
\hline $\begin{array}{l}\text { Salix aegyptiaca L. } \\
\text { Salicaceae }\end{array}$ & $\begin{array}{c}\text { Calmative, Cardiac tonic, Painful menstruation } \\
\text { Flower } \\
\text { [5] Amiri and Joharchi } 2013\end{array}$ & $\begin{array}{l}\text { Antioxidant activity } \\
\text { Male inflorescences } \\
\text { Methanolic extract } \\
\text { [29] Sonboli et al. } 2010\end{array}$ \\
\hline $\begin{array}{c}\text { Satureja hortensis L. } \\
\text { Lamiaceae }\end{array}$ & $\begin{array}{c}\text { Indigestion, Anthelmintic, Appetizer, Antacid, Antidiarrhea } \\
\text { Aerial parts } \\
\text { [5] Amiri and Joharchi } 2013\end{array}$ & $\begin{array}{c}\text { Anticancer activity } \\
\text { Aerial parts } \\
\text { Methanolic extract } \\
\text { [36] Esmaeilbeig et al. } 2015\end{array}$ \\
\hline $\begin{array}{l}\text { Scrophularia striata } \\
\text { Scrophulariaceae }\end{array}$ & $\begin{array}{c}\text { Kidney troubles, Antidiarrhea, Treatment of colic, Carminative, } \\
\text { Treatment of joints pain } \\
\text { Aerial parts } \\
\text { [5] Amiri and Joharchi } 2013\end{array}$ & $\begin{array}{l}\text { Anti-Candida activity } \\
\text { Leaves and stems } \\
\text { Infusion } \\
\text { [19] Pirbalouti et al. } 2009\end{array}$ \\
\hline
\end{tabular}


Table 3. Cont.

\begin{tabular}{|c|c|c|}
\hline $\begin{array}{l}\text { Plant Name } \\
\text { Family }\end{array}$ & $\begin{array}{c}\text { Traditional Uses } \\
\text { Part of the Plant (When Reported) } \\
\text { Type of Extract (When Reported) } \\
\text { Authors }\end{array}$ & $\begin{array}{l}\text { Biological Activities } \\
\text { Part of the Plant } \\
\text { Type of Extract } \\
\text { Authors }\end{array}$ \\
\hline $\begin{array}{l}\text { Thymus daenensis } \\
\text { Lamiaceae }\end{array}$ & $\begin{array}{l}\text { Stomach ache } \\
\text { Flower, Leaf, Branch } \\
\text { Decoction } \\
\text { [8] Delfan et al. } 2015\end{array}$ & $\begin{array}{c}\text { Antibacterial activity } \\
\text { Leaves and flowers } \\
\text { Hydro-distillation and } \\
\text { ethanolic extract } \\
\text { [17] Pirbalouti et al. } 2010 \\
\text { Anti-Candida activity } \\
\text { Leaves } \\
\text { Hydro-distillation } \\
\text { [19] Pirbalouti et al. } 2009 \\
\text { Anticancer activity } \\
\text { Aerial parts } \\
\text { Methanolic extract } \\
\text { [36] Esmaeilbeig et al. } 2015\end{array}$ \\
\hline $\begin{array}{c}\text { Trachyspermum ammi L. } \\
\text { Apiaceae }\end{array}$ & $\begin{array}{l}\text { Carminative, Anthelmintic, Antidiarrhea, Treatment of colic, } \\
\text { Antacid, Galactogogue } \\
\text { Fruit } \\
\text { [5] Amiri and Joharchi } 2013\end{array}$ & $\begin{array}{c}\text { Antibacterial activity } \\
\text { Leaves } \\
\text { Methanolic extract (Lyophilized) } \\
\text { [11] Bonjar et al. 2004 } \\
\text { Anti-Candida activity } \\
\text { Fruits } \\
\text { Hydro-distillation } \\
\text { [19] Pirbalouti et al. } 2009\end{array}$ \\
\hline
\end{tabular}


Table 3. Cont.

\begin{tabular}{|c|c|c|}
\hline $\begin{array}{l}\text { Plant Name } \\
\text { Family }\end{array}$ & $\begin{array}{c}\text { Traditional Uses } \\
\text { Part of the Plant (When Reported) } \\
\text { Type of Extract (When Reported) } \\
\text { Authors }\end{array}$ & $\begin{array}{l}\text { Biological Activities } \\
\text { Part of the Plant } \\
\text { Type of Extract } \\
\text { Authors }\end{array}$ \\
\hline $\begin{array}{c}\text { Trigonella foenum-graecum } \mathrm{L} . \\
\text { Fabaceae }\end{array}$ & $\begin{array}{c}\text { Diabetes, Bronchitis, Osteomalacia, Antihyperlipidemia, Tonic, } \\
\text { Treatment of anemia } \\
\text { Seed } \\
\text { [5] Amiri and Joharchi } 2013\end{array}$ & $\begin{array}{l}\text { Antibacterial activity } \\
\text { Leaves } \\
\text { Methanolic extract (Lyophilized) } \\
\text { [11] Bonjar et al. } 2004\end{array}$ \\
\hline $\begin{array}{l}\text { Urtica dioica } \mathrm{L} . \\
\text { Urticaceae }\end{array}$ & $\begin{array}{l}\text { Hypoglycemic, Enlarged prostate, Anemia, Anti-inflammatory, } \\
\text { Digestive } \\
\text { Whole plant } \\
\text { [5] Amiri and Joharchi } 2013 \\
\text { Antidiabetic } \\
\text { Seed, Aeration organ } \\
\text { Boiled } \\
\text { [7] Bahmani et al. } 2014\end{array}$ & $\begin{array}{l}\text { Antiproliferative on DU-145 cell line } \\
\text { Aerial parts } \\
\text { Hydro-alcoholic extract } \\
\text { [33] Asadi-Samani et al. } 2018\end{array}$ \\
\hline $\begin{array}{l}\text { Ziziphus spina-christi } \\
\text { Rhamnaceae }\end{array}$ & $\begin{array}{c}\text { Stomach ache } \\
\text { Flower, Leaf } \\
\text { Decoction } \\
\text { [8] Delfan et al. } 2015 \\
\text { Eczema, Hair tonic, Antifungal, Antipruritic, Washing } \\
\text { Leaves } \\
\text { [5] Amiri and Joharchi } 2013\end{array}$ & $\begin{array}{l}\text { Anti-Candida activity } \\
\text { Fruits } \\
\text { Infusion } \\
\text { [19] Pirbalouti et al. } 2009\end{array}$ \\
\hline
\end{tabular}


The identification of a direct correspondence between the traditional uses and biological activities represents a complex issue. Some plant species mentioned in this work have already been studied in other parts of the world with different climatic characteristics and, consequently, different phytocomplexes. In our opinion, it is of interest to study plants that are not interesting from a medicinal point of view in other parts of the world if included in traditional medicinal practices in Iran, as they could be active due to a quite different phytocomplex expressed in the particular climatic characteristics and ecosystems of the Iranian territory. It should be pointed out that, considering the research works found in literature, the process of valorization and study of plant species does not often pay particular attention to the aspect of sustainability of eventual systematic exploitation. This aspect is becoming more and more important these days.

Traditional remedies are often effective due to the synergistic activity of a large number of compounds that are part of the plant phytocomplex; therefore, careful research is needed to identify the active molecules. The research work is further complicated by the fact that in some cases, natural remedies act as palliatives. In any case, the evidence that nature has always inspired medicine, constituting itself as a source of inspiration for the development of pharmacological treatments, makes the study of traditional remedies a very important component of basic research in the medicinal and pharmacological field.

A summary of the information in the scientific literature, related to documented traditional medicinal practices and plants studied from a scientific point of view in the same territory, represents a useful tool to plan new researches in order to avoid repeating work already done and to concentrate on apparently effective but not yet scientifically evaluated plants. In our opinion, there is still a large room for scientific works that could deepen the above-stated aspects, encouraging further research in the field.

Author Contributions: Conceptualization, S.M. and H.R.A.-A.; methodology, S.V.; validation, S.V., A.B.; investigation, P.B., R.B., S.S.; resources, S.M.; data curation, P.B.; writing-original draft preparation, P.B.; writing-review and editing, P.B.; supervision, S.M., H.R.A.-A.; project administration, S.V.; funding acquisition, S.M. All authors have read and agreed to the published version of the manuscript.

Funding: The present work has been financially supported by the Ministry of Education and Research (MIUR) of Italy (PRIN: 2017E84AA4_002).

Acknowledgments: The technical support of Elisa Durini is gratefully acknowledged.

Conflicts of Interest: The authors state no conflict of interest.

\section{References}

1. Minaiyan, M.; Ghannadi, A.R.; Afsharipour, M.; Mahzouni, P. Effects of extract and essential oil of Rosmarinus officinalis L. on TNBS-induced colitis in rats. Res. Pharm. Sci. 2011, 6, 13-21.

2. WHO Traditional Medicine Strategy 2014-2023. Available online: https://www.who.int/medicines/ publications/traditional/trm_strategy14_23/en/ (accessed on 1 October 2019).

3. Available online: http://www.who.int/medicines/areas/traditional/denitions/en/ (accessed on 1 October 2019).

4. Rezaeizadeh, H.; Alizadeh, M.; Naseri, M.; Shams Ardakani, M.R. The Traditional Iranian Medicine Point of View on Health and Disease. Iran. J. Public Health 2009, 38 (Suppl. 1), 169-172.

5. Mojahedi, M.; Naseri, M.; Majdzadeh, R.; Keshavarz, M.; Ebadini, M.; Nazem, E.; Isfeedvajani, M.S. Reliability and Validity Assessment of Mizaj Questionnaire: A Novel Self-report Scale in Iranian Traditional Medicine. Iran. Red Crescent Med. J. 2014, 16, e15924. [CrossRef] [PubMed]

6. Amiri, M.S.; Joharchi, M.R. Ethnobotanical investigation of traditional medicinal plants commercialized in the markets of Mashhad, Iran. Avicenna J. Phytomed. 2013, 3, 254-271. [PubMed]

7. Bahmani, M.; Tajeddini, P.; Ezatpour, B.; Rafieian-Kopaei, M.; Naghdi, N.; Asadi-Samani, M. Ethenobothanical study of medicinal plants against parasites detected in Shiraz, southern part of Iran. Der. Pharm. Lett. 2016, 8, 153-160. 
8. Bahmani, M.; Zargaran, A.; Rafieian-Kopaei, M.; Saki, K. Ethnobotanical study of medicinal plants used in the management of diabetes mellitus in the Urmia, Northwest Iran. Asian. Pac. J. Trop. Med. 2014, 7 (Suppl. 1), S348-S354. [CrossRef]

9. Delfan, B.; Bahmani, M.; Hassanzadazar, H.; Saki, K.; Rafieian-Kopaei, M.; Rashidipour, M.; Bagheri, F.; Sharifi, A. Ethnobotany study of effective medicinal plants on gastric problems in Lorestan province, West of Iran. J. Chem. Pharm. Res. 2015, 7, 483-492.

10. Koochak, H.; Seyyednejad, S.M.; Motamedi, H. Preliminary study on the antibacterial activity of some medicinal plants of Khuzestan (Iran). Asian Pac. J. Trop. Med. 2010, 3, 180-184. [CrossRef]

11. Abedini, A.; Roumy, V.; Mahieux, S.; Gohari, A.; Farimani, M.M.; Rivie, C.; Samaillie, J.; Sahpaz, S.; Bailleul, F.; Neut, C.; et al. Antimicrobial activity of selected Iranian medicinal plants against a broad spectrum of pathogenic and drug multiresistant micro-organisms. Lett. Appl. Microbiol. 2014, 59, 412-421. [CrossRef]

12. Chitsazian-Yazdi, M.; Agnolet, S.; Lorenz, S.; Schneider, B.; Es'haghi, Z.; Kasaian, J.; Khameneh, B.; Iranshahi, M. Foetithiophenes C-F thiophene derivatives from the roots of Ferula foetida. Pharm. Biol. 2015, 53, 710-714. [CrossRef]

13. Baharvand-Ahmadi, B.; Bahmani, M.; Naghdi, N.; Saki, K.; Baharvand-Ahmadi, S.; Rafieian-Kopaei, M. Medicinal plants used to treat infectious and non-infectious diseases of skin and skin appendages in city of Urmia, northwest Iran. Der. Pharm. Lett. 2015, 7, 189-196.

14. Pirbalouti, A.G.; Malekpoor, F.; Enteshari, S.; Yousefi, M.; Momtaz, H.; Hamedi, B. Antibacterial Activity of Some Folklore Medicinal Plants Used by Bakhtiari Tribal in Southwest Iran. Int. J. Biol. 2010, 2, 2. [CrossRef]

15. Shahidi, B. Evaluation of antibacterial properties of some medicinal plants used in Iran. J. Ethnopharmacol. 2004, 94, 301-305. [CrossRef]

16. Lotfipour, F.; Nazemiyeh, H.; Fathi-Azad, F.; Garaei, N.; Arami, S.; Talat, S.; Sadegpour, F.; Hasanpour, R. Evaluation of Antibacterial Activities of Some Medicinal Plants from North-West Iran. Iran. J. Basic Med. Sci. 2008, 11, 80-85.

17. Nariman, F.; Eftekhar, F.; Habibi, Z.; Falsafi, T. Anti-Helicobacter pylori Activities of Six Iranian Plants. Helicobacter 2004, 9, 146-151. [CrossRef]

18. Razavi, S.M.; Zarrini, G.; Molavi, G.; Ghasemi, G. Bioactivity of Malva Sylvestris L., a Medicinal Plant from Iran. Iran. J. Basic Med. Sci. 2011, 14, 574-579.

19. Imani, Z.; Asgarpanah, J.; Hashemi, F.; Hashemi Hezaveh, J. Composition and antifungal activity of Zhumeria majdae essential oil. Curr. Med. Mycol. 2015, 1, 13-19. [CrossRef]

20. Sepahi, S.; Ghorani-Azam, A.; Sepahi, S.; Asoodeh, A.; Rostami, S. In Vitro Study to Evaluate Antibacterial and Non-haemolytic Activities of Four Iranian Medicinal Plants. West Indian Med. J. 2014, 63, 289-293.

21. Afshar, F.H.; Delazar, A.; Asnaashari, S.; Vaez, H.; Zolali, E.; Asgharian, P. Screening of Anti-Malarial Activity of Different Extracts Obtained from Three Species of Scrophularia Growing in Iran. Iran. J. Pharm. Res. 2018, 17, 668-676.

22. Pirbalouti, A.G.; Bahmani, M.; Avijgan, M. Anti-Candida Activity of Some of the Iranian Medicinal Plants. Electron. J. Biol. 2009, 5, 85-88.

23. Alinezhad, H.; Baharfar, R.; Zare, M.; Azimi, R.; Nabavi, S.F.; Nabavi, S.M. Biological activities of ethyl acetate extract of different parts of Hyssopus angustifolius. Pharm. Biol. 2012, 50, 1062-1066. [CrossRef] [PubMed]

24. Dehghan, H.; Sarrafi, Y.; Salehi, P. Antioxidant and antidiabetic activities of 11 herbal plants from Hyrcania region, Iran. J. Food Drug Anal. 2016, 24, 179-188. [CrossRef]

25. Haddad, F.M.H.; Mahbodfar, H.R.; Zamani, Z.; Ramazani, A. Antimalarial evaluation of selected medicinal plant extracts used in Iranian traditional medicine. Iran. J. Basic Med. Sci. 2017, 20, 415-422. [PubMed]

26. Ebrahimabadi, A.H.; Ebrahimabadi, E.H.; Djafari-Bidgoli, Z.; Kashi, F.J.; Mazoochi, A.; Batooli, H. Composition and antioxidant and antimicrobial activity of the essential oil and extracts of Stachys inflata Benth from Iran. Food Chem. 2010, 119, 452-458. [CrossRef]

27. Dehshiri, M.M.; Aghamollaei, H.; Zarini, M.; Nabavi, S.M.; Mirzaei, M.; Loizzo, M.R.; Nabavi, S.F. Antioxidant activity of different parts of Tetrataenium lasiopetalum. Pharm. Biol. 2013, 51, 1081-1085. [CrossRef]

28. Fathiazad, F.; Mazandarani, M.; Hamedeyazdan, S. Phytochemical analysis and antioxidant activity of Hyssopus officinalis L. from Iran. Adv. Pharm. Bull. 2011, 1, 63-67.

29. Pourmorad, F.; Hosseinimehr, S.J.; Shahabimajd, N. Antioxidant activity, phenol and flavonoid contents of some selected Iranian medicinal plants. Afr. J. Biotechnol. 2006, 5, 1142-1145. 
30. Dehghan, H.; Sarrafi, Y.; Salehi, P.; Ebrahimi, S.N. $\alpha$-Glucosidase inhibitory and antioxidant activity of furanocoumarins from Heracleum persicum. Med. Chem. Res. 2017, 26, 849-855. [CrossRef]

31. Khazaeli, P.; Goldoozian, R.; Sharififar, F. An evaluation of extracts of five traditional medicinal plants from Iran on the inhibition of mushroom tyrosinase activity and scavenging of free radicals. Int. J. Cosmet. Sci. 2009, 31, 375-381. [CrossRef]

32. Hamzeloo-Moghadam, M.; Khalaj, A.; Malekmohammadi, M. Cytotoxic Activity and Apoptosis Induction of Hypericum scabrum L. Iran. Red Crescent Med. J. 2015, 17, e19453. [CrossRef]

33. Sonboli, A.; Mojarrad, M.; Ebrahimi, S.N.; Enayat, S. Free Radical Scavenging Activity and Total Phenolic Content of Methanolic Extracts from Male Inflorescence of Salix aegyptiaca Grown in Iran. Iran. J. Pharm. Res. 2010, 9, 293-296. [PubMed]

34. Jassbi, A.R.; Firuzi, O.; Miri, R.; Salhei, S.; Zare, S.; Zare, M.; Masroorbabanari, M.; Chandran, J.N.; Schneider, B.; Baldwin, I.T. Cytotoxic activity and chemical constituents of Anthemis mirheydari. Pharm. Biol. 2016, 54, 2044-2049. [CrossRef] [PubMed]

35. Esmaeilbeig, M.; Kouhpayeh, S.A.; Amirghofran, Z. An Investigation of the Growth Inhibitory Capacity of Several Medicinal Plants from Iran on Tumor Cell Lines. Iran. J. Cancer Prev. 2015, 8, e4032. [CrossRef] [PubMed]

36. Asadi-Samani, M.; Rafieian-Kopaei, M.; Lorigooini, Z.; Shirzad, H. A screening of growth inhibitory activity of Iranian medicinal plants on prostate cancer cell lines. BioMedicine 2018, 8, 16-21. [CrossRef] [PubMed]

37. Sahranavard, S.; Naghibi, F.; Mosaddegh, M.; Esmaeili, S.; Sarkhail, P.; Taghvaei, M.; Ghafari, S. Cytotoxic activities of selected medicinal plants from Iran and phytochemical evaluation of the most potent extract. Res. Pharm. Sci. 2010, 4, 133-137.

38. Hasanein, P.; Felehgari, Z.; Emamjomeh, A. Preventive effects of Salvia officinalis L. against learning and memory deficit induced by diabetes in rats: Possible hypoglycaemic and antioxidant mechanisms. Neurosci. Lett. 2016, 622, 72-77. [CrossRef]

39. Ebrahimzadeh, M.A.; Pourmorad, F.; Bekhradnia, A.R. Iron chelating activity, phenol and flavonoid content of some medicinal plants from Iran. Afr. J. Biotechnol. 2008, 7, 3188-3192.

40. Adhami, H.R.; Farsam, H.; Krenn, L. Screening of Medicinal Plants from Iranian Traditional Medicine for Acetylcholinesterase Inhibition. Phytother. Res. 2011, 25, 1148-1152. [CrossRef]

41. Abbas-Mohammadi, M.; Farimani, M.M.; Salehi, P.; Ebrahimi, S.N.; Sonboli, A.; Kelso, C.; Skropeta, D. Acetylcholinesterase-inhibitory activity of Iranian plants: Combined HPLC/bioassay-guided fractionation, molecular networking and docking strategies for the dereplication of active compounds. J. Pharm. Biomed. Anal. 2018, 158, 471-479. [CrossRef]

42. Lorigooini, Z.; Kobarfard, F.; Ayatollahi, A. Anti-platelet aggregation assay and chemical composition of essential oil from Allium atroviolaceum Boiss growing in Iran. Int. J. Biosci. 2014, 5, 151-156.

43. Jazayeri, S.B.; Amanlou, A.; Ghanadian, N.; Pasalar, P.; Amanlou, M. A preliminary investigation of anticholinesterase activity of some Iranian medicinal plants commonly used in traditional medicine. DARU J. Pharm. Sci. 2014, 22, 17. [CrossRef] [PubMed]

44. Asgary, S.; Nader, I.G.H.; Sarrafzadegan, N.; Mohammadifard, N.; Mostafavi, S.; Vakili, R. Antihypertensive and Antihyperlipidemic Effects of Achillea Wilhelmsii. Drugs Exp. Clin. Res. 2000, 26, 89-93. [PubMed]

45. Karimi, G.; Hosseinzadeh, H.; Ettehad, N. Evaluation of the Gastric Antiulcerogenic Effects of Portulaca oleracea L. Extracts in Mice. Phytother. Res. 2004, 18, 484-487. [CrossRef] [PubMed]

46. Khonche, A.; Huseini, H.F.; Abdi, H.; Mohtashami, R.; Nabati, F.; Kianbakht, S. Efficacy of Mentha pulegium extract in the treatment of functional dyspepsia: A randomized double-blind placebo-controlled clinical trial. J. Ethnopharmacol. 2017, 206, 267-273. [CrossRef] [PubMed]

47. Niazmand, S.; Khooshnood, E.; Derakhshan, M. Effects of Achillea wilhelmsii on rat's gastric acid output at basal, vagotomized, and vagal-stimulated conditions. Pharmacogn. Mag. 2010, 6, 282-285. [CrossRef] [PubMed]

(C) 2020 by the authors. Licensee MDPI, Basel, Switzerland. This article is an open access article distributed under the terms and conditions of the Creative Commons Attribution (CC BY) license (http://creativecommons.org/licenses/by/4.0/). 